\title{
Light Water Reactor Sustainability Program Plant Modernization Technical Program Plan for FY 2019
}

\author{
Nancy J Lybeck, Ken Thomas
}

September 2018

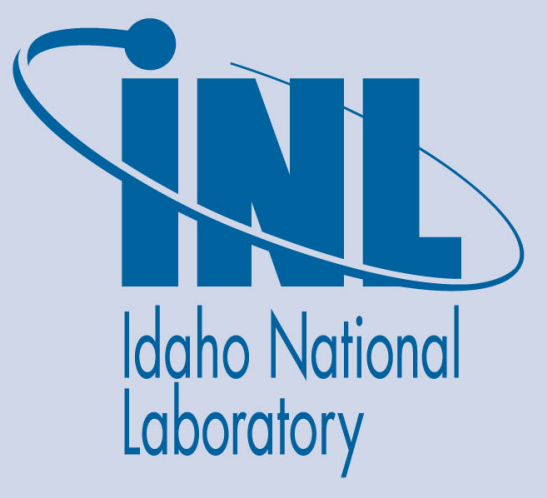

The INL is a U.S. Department of Energy National Laboratory operated by Battelle Energy Alliance 


\section{Light Water Reactor Sustainability Program Plant Modernization Technical Program Plan for FY 2019}

Nancy J Lybeck, Ken Thomas

September 2018

Idaho National Laboratory Idaho Falls, Idaho 83415

http://www.inl.gov

Prepared for the

U.S. Department of Energy

Under DOE Idaho Operations Office

Contract DE-AC07-05ID14517 


\section{Light Water Reactor Sustainability Program}

\section{Plant Modernization \\ Technical Program Plan for FY 2019}

September 2018

U.S. Department of Energy

Office of Nuclear Energy 


\section{DISCLAIMER}

This information was prepared as an account of work sponsored by an agency of the U.S. Government. Neither the U.S. Government nor any agency thereof, nor any of their employees, makes any warranty, expressed or implied, or assumes any legal liability or responsibility for the accuracy, completeness, or usefulness, of any information, apparatus, product, or process disclosed, or represents that its use would not infringe privately owned rights. References herein to any specific commercial product, process, or service by trade name, trade mark, manufacturer, or otherwise, does not necessarily constitute or imply its endorsement, recommendation, or favoring by the U.S. Government or any agency thereof. The views and opinions of authors expressed herein do not necessarily state or reflect those of the U.S. Government or any agency thereof. 
INL/EXT-13-28055

Revision 8

\section{Plant Modernization Technical Program Plan for FY 2019}

Nancy Lybeck

Ken Thomas

September 2018

Idaho National Laboratory

Light Water Reactor Sustainability Program

Idaho Falls, Idaho 83415

http://www.inl.gov

Prepared for the

U.S. Department of Energy

Office of Nuclear Energy

Under DOE Idaho Operations Office

Contract DE-AC07-05ID14517 



\begin{abstract}
This report presents the Technical Program Plan for FY 2019 for the U.S. Department of Energy (DOE) Light Water Reactor Sustainability (LWRS)

Program - Plant Modernization research pathway. A summary of the vision and strategy is provided to explain how this program addresses key issues and barriers for modernizing instrumentation and control technologies and infrastructure in domestic nuclear power plants. The report describes the pilot projects that have been formulated to develop and validate enabling technologies over the next several years that will result in digital alternatives to the legacy analog instrumentation and controls systems in place today. This will allow much needed modernization of these systems to address reliability and obsolescence problems, as well as serve as a platform for substantial operational improvement. The report further describes key project resources and cooperative relationships, including the Electric Power Research Institute, the Nuclear Energy Institute (NEI), the Institute of Nuclear Power Operations (INPO), the IFE Halden Reactor Project, the Nuclear Regulatory Commission, and industry suppliers, that are instrumental to the success of the program. The report also lists the schedule for all program products, including the titles and report numbers for all published reports under this program.
\end{abstract}




\section{CONTENTS}

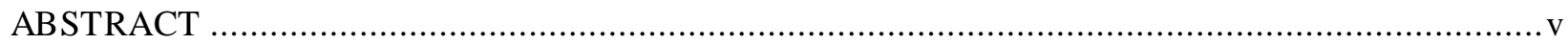

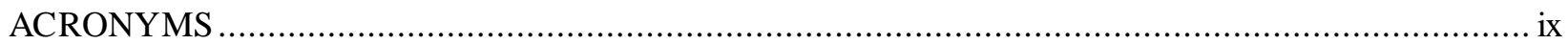

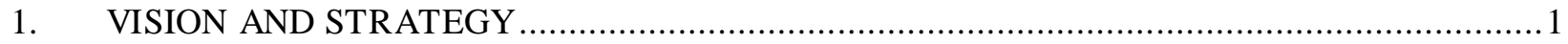

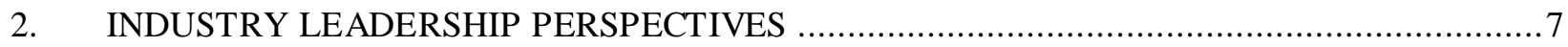

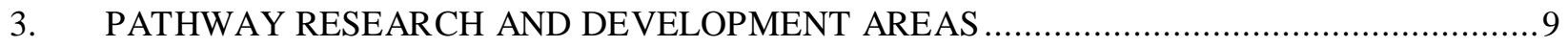

3.1 Stages of Transformation ................................................................................... 9

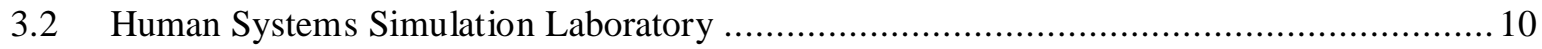

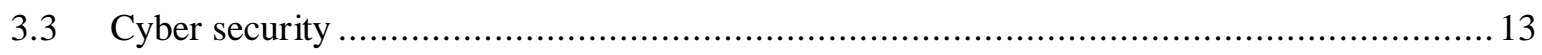

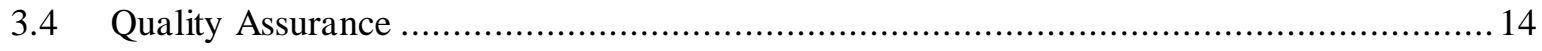

3.5 Digital Technology Business Case Methodology …........................................... 14

4. RESEARCH AND DEVELOPMENT COOPERATION ................................................... 16

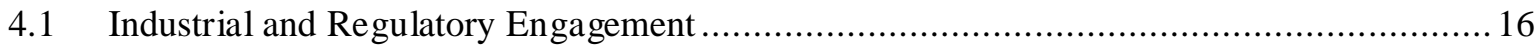

4.2 Electric Power Research Institute ........................................................................ 18

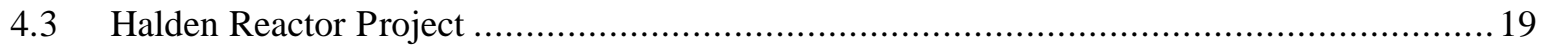

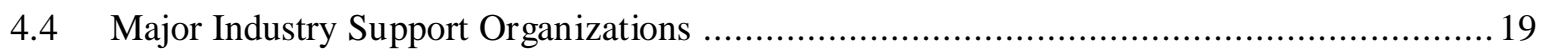

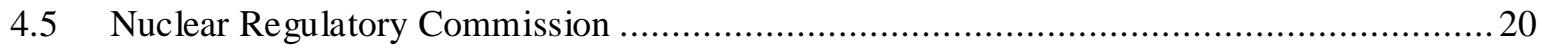

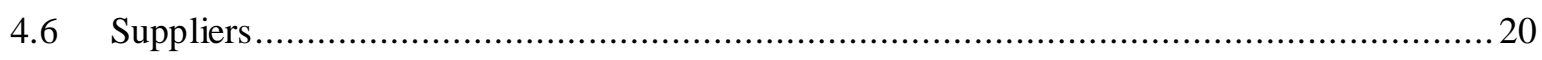

4.7 Department of Energy - Nuclear Energy Enabling Technologies Program ...................... 21

5. RESEARCH AND DEVELOPMENT PRODUCTS AND SCHEDULES ..........................22

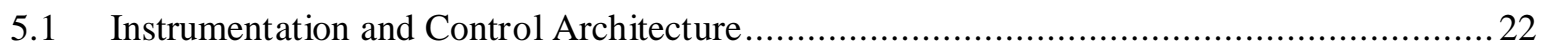

5.1.1 Control Room Modernization ................................................................. 24

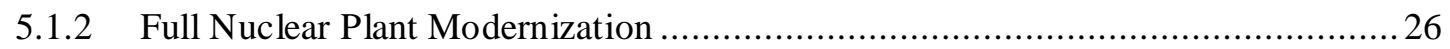

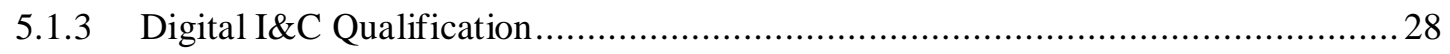

5.1.4 Instrumentation and Control Infrastructure Modernization ...............................29

5.1.5 Computerized Operator Support Systems ..................................................... 30

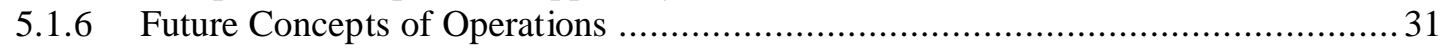

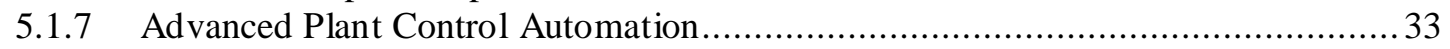

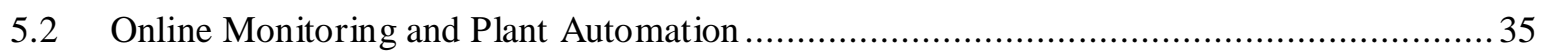

5.2.1 Online Monitoring of Active Components ...................................................... 37

5.2.2 Online Monitoring of Concrete Structures in Nuclear Power Plants ...................... 38

5.2.3 Online Monitoring of Secondary System Piping in Nuclear Power Plants .............. 41

5.2.4 Digital Architecture for an Automated Plant ................................................... 43

5.2.5 Advanced Remote Monitoring for Operations Readiness .................................... 44

5.2.6 Technology-Enabled Risk-Informed Maintenance Strategy .............................. 45

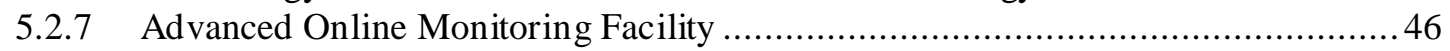

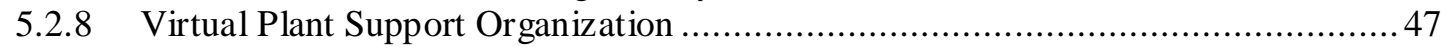

5.2.9 Management Decision Support Center ...................................................... 49

5.3 Advanced Applications and Process Automation ................................................ 51

5.3.1 Mobile Technologies for Nuclear Power Plant Field Workers ...............................53 
5.3.2 Computer-Based Procedures for Nuclear Power Plant Field Workers ................... 54

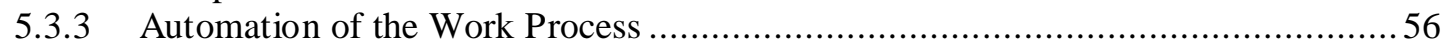

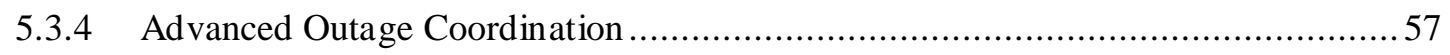

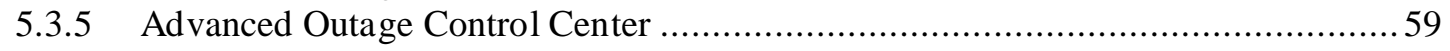

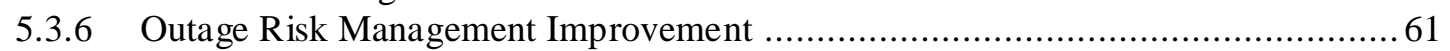

5.3.7 Augmented Reality for Nuclear Power Plant Field Workers .............................62 62

5.3.8 Automating Manually Performed Plant Activities .......................................... 63

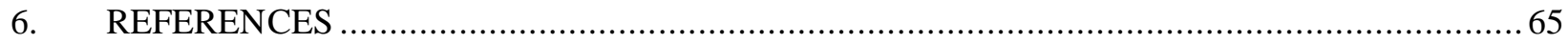

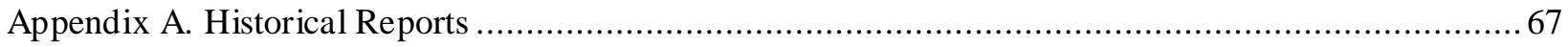

\section{FIGURES}

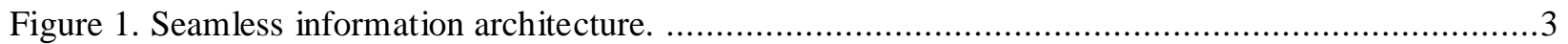

Figure 2. Pilot projects grouped in three areas of enabling capabilities.........................................

Figure 3. Stages of transformation in the Plant Modernization Pathway Vision and Strategy.................9

Figure 4. Human Systems Simulation Laboratory-Reconfigurable Hybrid Control Room

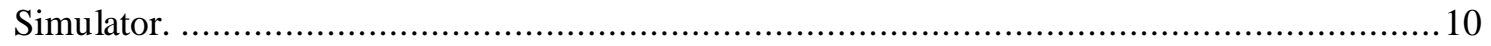

Figure 5. HSSL used to evaluate digital upgrades in a hybrid control room ................................... 11

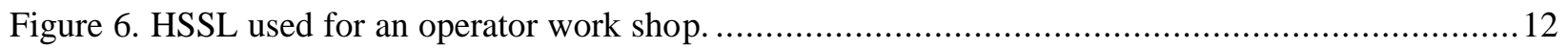

Figure 7. HSSL being used for eye tracking of operators using an advanced display.......................... 12

Figure 8. Advanced hybrid control room studies in the HSSL. ...............................................25

Figure 9. PHM framework for concrete structure health monitoring. ........................................... 39

Figure 10. Conceptual representation of the online monitoring system's output..............................42

Figure 11. Operator at Catawba Nuclear Station using hand-held technology for component

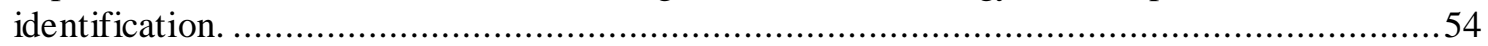

Figure 12. A field worker at Palo Verde Nuclear Generating Station uses the CBP to execute a task. 55

Figure 13. A control room operator and a field operator at Diablo Canyon Power Plant discuss a procedure using the CBP system on the hand-held device.

Figure 14. Remote collaboration technology in use at the spring 2011 Byron Nuclear Station refueling.

Figure 15. Advanced Outage Control Center concept design. .60

Figure 16. Advanced Outage Control Center at Palo Verde 


\section{ACRONYMS}

AOCC Advanced Outage Control Center

APR advanced pattern recognition

AWPs automated work packages

EWPs electronic work packages

BEA Battelle Energy Alliance

BOP balance of plant

CBP computer-based procedure

CCF common cause failure

CDA critical digital asset

CNO Chief Nuclear Officer

CSAT Cyber Security Assessment Team

DOE Department of Energy

DOE-NE DOE-Office of Nuclear Energy

EPRI Electric Power Research Institute

FW-PHM Fleet Wide Prognostic and Health Management

FY fiscal year

GW guided wave

HSI human-system interface

HSSL Human Systems Simulation Laboratory

I\&A Infrastructure and Application

I\&C instrumentation and control

I\&RE Industrial and Regulatory Engagement

IFE Institute of Energy Technology

INL Idaho National Laboratory

INPO Institute for Nuclear Power Operations

IT Information Technology

LWR light water reactor

LWRS Light Water Reactor Sustainability

MOOSE Multi-physics Object Oriented Simulation Environment

NEI Nuclear Energy Institute

NITSL Nuclear Information Technology Strategic Leadership

NPP nuclear power plant

NRC Nuclear Regulatory Commission 


$\begin{array}{ll}\text { O\&M } & \text { operating and maintenance } \\ \text { OCC } & \text { outage control center } \\ \text { OLM } & \text { online monitoring } \\ \text { PM } & \text { preventive maintenance } \\ \text { R\&D } & \text { research and development } \\ \text { RUL } & \text { remaining useful life } \\ \text { SHMs } & \text { structural health monitoring } \\ \text { SOER } & \text { Significant Operating Experience Report } \\ \text { SOER } & \text { Significant Operating Experience Report } \\ \text { SwRI } & \text { Southwest Research Institute } \\ \text { UGW } & \text { ultrasonic guided wave } \\ \text { UWG } & \text { Utility Working Group }\end{array}$




\section{Plant Modernization Technical Program Plan for FY 2019}

\section{VISION AND STRATEGY}

The Plant Modernization Pathway conducts targeted research and development (R\&D) to address nuclear power plant (NPP) economic viability in current and future energy markets through innovation, efficiency gains, and business model transformation through digital technologies. [1] This work involves two strategic goals:

1. To develop transformative digital technologies for nuclear plant modernization that renew the technology base for extended operating life beyond 60 years.

2. To enable implementation of these technologies in a manner that results in broad innovation and business improvement in the nuclear plant operating model, thereby lowering operating costs.

The R\&D products will enable modernization of plant systems and processes while building a technology-centric business model platform that supports improved performance at lower cost, contributing to the long-term sustainability of the light water reactor (LWR) fleet, which is vital to the nation's energy and environmental security.

The focus of these research activities is on near-term opportunities to introduce new digital technologies into costly plant work activities, eliminating some labor-intensive activities altogether while making remaining work activities far more efficient. Likewise, through the development and application of smart technologies, there is a focus on reducing human error that often results in production losses, nuclear safety challenges, and regulatory impacts. Finally, the research addresses inefficiencies in the operation and support of nuclear plants due to antiquated communication, collaboration, and analytical methods that have largely been replaced in other business sectors with modern digital capabilities.

A key tenet of the Plant Modernization Pathway is to continuously engage the nuclear power industry to ensure responsiveness to the challenges and opportunities in the present and future operating environment, a correct understanding of the plant modernization technology development issues and requirements as currently experienced in the operating NPPs, and to develop approaches to address aging instrumentation and control (I\&C) systems and demonstrate these systems in individual pilot projects with operating NPPs. This provides validation of the developed technologies as fully meeting utility requirements. The results can be used by other owners/operators to address similar aging issues and to achieve new efficiencies. This approach is unique to this pathway and is essential because future planned $\mathrm{R} \& \mathrm{D}$ efforts are built on the concepts and successes from prior projects. This creates a stepwise approach to long-term modernization and refurbishment of I\&C technologies across the LWR fleet. The engagement strategy with nuclear utilities serves to identify priorities for modernization and safety enhancement, timeframes for action, a means of coordinating resources and research partnerships, and a forum to communicate the results of research efforts to the broader nuclear industry and vendor community.

$$
\begin{aligned}
& \text { Instrumentation and Control }(I \& C) \text { Systems are a } \\
& \text { vital part of plant safety and provisions for their } \\
& \text { refurbishment must be included in long-term } \\
& \text { planning. }
\end{aligned}
$$


Reliable I\&C systems technologies are essential to ensuring safe and efficient operation of the U.S. LWR fleet. These technologies affect every aspect of NPP safety, production, and balance-of-plant operations. They are varied and dispersed, encompassing systems from the main control room to primary systems and throughout the balance of the plant. They interact with every active component in the plant and serve as a kind of central nervous system.

Current instrumentation and human-machine interfaces in the nuclear power sector employ analog technologies. In other power generation sectors, analog technologies have largely been replaced with digital technologies. This is in part due to the manufacturing and product support base transitioning to these newer technologies. It also accompanies the transition of education curricula for $\mathrm{I} \& \mathrm{C}$ engineers to digital technologies. Consequently, product manufacturers refer to analog I\&C as having reached the end of its useful service life. Although considered obsolete by other industries, analog I\&C continues to function reliably, though spare and replacement parts are becoming increasingly scarce as is the workforce that is familiar with and able to maintain it. In 1997, the National Research Council conducted a study concerning the challenges involved in modernizing existing analog-based I\&C systems with digital I\&C systems in NPPs. [2] Their findings identified the need for new I\&C technology integration; 20 years, later this still has not yet been achieved.

Replacing existing analog with digital technologies is broadly perceived as involving significant technical and regulatory uncertainty. This translates into delays and substantially higher costs for these types of refurbishments. Such experiences have slowed the pace of analog I\&C replacement and further contribute to a lack of experience with such initiatives. In the longer run, this may delay progress on the numerous I\&C refurbishment activities needed to establish plants that are cost competitive in future energy markets when plants enter long-term operation. Such delays could lead to an additional dilemma: delays in reinvestment needed to replace existing I\&C systems could create a "bow wave" of needed future reinvestments. Because the return period on such reinvestments becomes shorter the longer they are delayed, they become less viable. This adds to the risk that I\&C may become a limiting or contributing factor that weighs against the decision to operate nuclear power assets for longer periods.

I\&C replacement represents potential high-cost or high-risk activities if they are undertaken without the needed technical bases and experience to facilitate their design and implementation. The I\&C R\&D program addresses critical gaps in technology development and deployment to reduce risk and cost. The objective of these efforts is to develop, demonstrate, and support deployment of new digital I\&C technologies for nuclear process control, enhance worker performance, and provide enhanced monitoring capabilities to ensure the continued safe, reliable, and economic operation of the nation's NPPs.

I\&C systems can deliver new value through integrated long-term planning.

Most digital I\&C implementation projects today result in islands of automation distributed throughout the plant. They are physically and functionally isolated from one another in much the same way as were their analog predecessors. Digital technologies are largely implemented as point solutions to performance concerns with individual I\&C components, such as aging. This approach is characterized by planning horizons that are short and typically only allow for "like-for-like" replacements. [3] It is reactive to incipient failures of analog devices and uses replacement digital devices to perform the same functions as analog devices. Consequently, many features of the replacement digital devices are not used. This results in a fragmented approach to refurbishment that is driven by immediate needs. This approach to I\&C aging 
management minimizes technical and regulatory uncertainty though, ironically, it reinforces the current technology base.

To displace the piecemeal approach to digital technology deployment, a new vision for efficiency, safety, and reliability is needed that leverages the benefits of digital technologies. This includes considering goals for NPP staff numbers and types of specialized resources; targeting operation and management costs and the plant capacity factor to ensure commercial viability of proposed long-term operations; improving methods for achieving plant safety margins and reductions in unnecessary conservatisms; and leveraging expertise from across the nuclear enterprise.

New value from I\&C technologies is possible if they are integrated with work processes, directly support plant staff, and are used to create new efficiencies and ways of achieving safety enhancements. For example, data from digital I\&C in plant systems can be provided directly to work process applications and then, in turn, to plant workers carrying out their work using mobile technologies. This saves time, creates significant work efficiencies, and reduces errors. A goal of these efforts is to motivate the development of a seamless digital environment (Figure 1) for plant operations and support by integrating information from plant systems with plant processes for plant workers through an array of interconnected technologies, which include:

- Plant systems. Beyond centralized monitoring and awareness of plant conditions, deliver plant information to digitally based systems that support plant work and directly to workers performing these work activities.

- Plant processes. Integrate plant information into digital field work devices, automate many manually performed surveillance tasks, and manage risk through real-time centralized oversight and awareness of field work.

- Plant workers. Provide plant workers with immediate, accurate plant information that allows them to conduct work at plant locations using assistive devices that minimize radiation exposure, enhance procedural compliance and accurate work execution, and enable collaborative oversight and support even in remote locations.

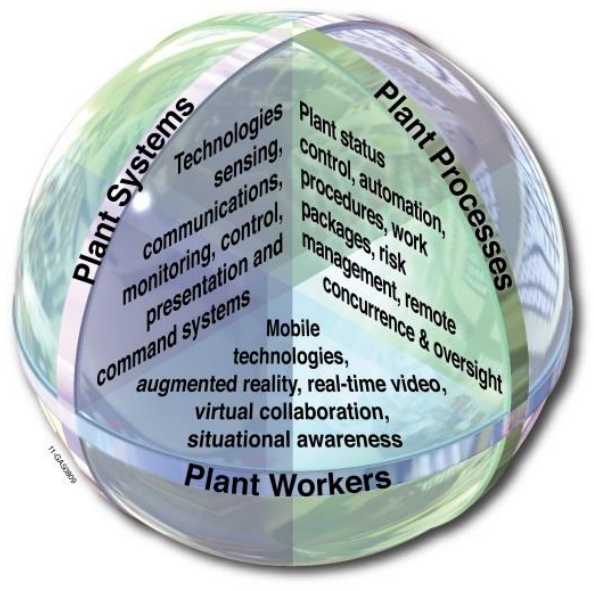

Figure 1. Seamless information architecture.

The path to long-term operability and sustainability of plant I\&C systems will likely be accomplished by measured, stepwise modernization through refurbishments. Through successive refurbishments, the resulting collection of $\mathrm{I} \& \mathrm{C}$ systems will reflect a hybrid mixture of analog and digital technologies. 
Operators and maintainers of $\mathrm{I} \& \mathrm{C}$ systems will, for an extended duration, require competencies with both types of technologies. This represents a least-risk and most realistic approach to refurbishment that allows plant personnel to become familiar with newer digital systems as they gradually replace analog devices.

Within this R\&D framework, three areas have been identified that enable capabilities needed for long-term sustainable plant operation: I\&C architecture; online monitoring (OLM) and plant automation; and advanced applications and process automation. These areas provide the hardware needed to address the aging of existing I\&C technologies, the information necessary to provide state awareness, and software that will enable power plant staff to perform their jobs more efficiently. These are shown in Figure 2. In each of these areas, a series of pilot projects are planned that enable plant modernization in existing nuclear plants. Through the U.S. Department of Energy (DOE) Light Water Reactor Sustainability (LWRS) Program, individual utilities and plants are able to participate in these projects or otherwise leverage the results of projects conducted at demonstration plants.

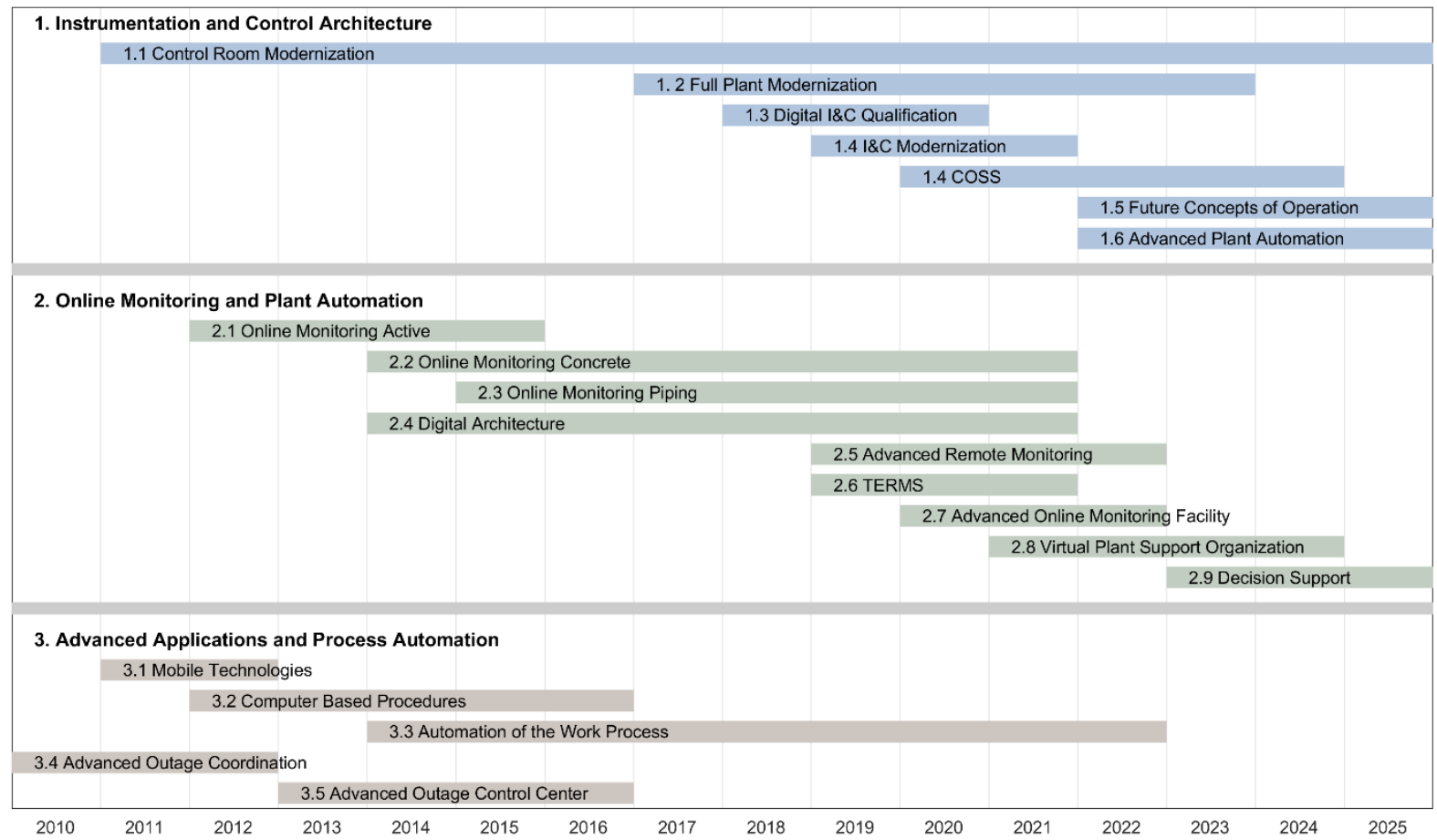

Figure 2. Pilot projects grouped in three areas of enabling capabilities.

Analog I\&C has been the predominant means used for process control in the nuclear power industry for decades. Its use dates back to an era when human labor was more affordable, and maintaining an $\mathrm{I} \& \mathrm{C}$ technology base through a larger workforce conducting frequent rounds for surveillances, inspections, and tests was accepted in the nuclear power generation business model. Today's power generation business climate is much different than the preceding decades and $\mathrm{I} \& \mathrm{C}$ technologies are needed in the long run that are more highly automated and require less cost to operate and maintain, are as highly reliable as those used today, and will be familiar to a future work force. They should also enable performance gains for nuclear utilities so that they are not merely a sunken cost, as this would weigh heavily on the balance sheet at a time of particularly high-cost competitiveness in electricity markets. The growing presence of gas generation is resulting in substantial cost pressure on nuclear generation, particularly in non-regulated markets. The closings of several nuclear plants due to electricity market 
price are such examples of immediate impact. For other nuclear plants, long-term cost implications will bear on life extension options.

Improvement in the competitive position of the nuclear plants can come from either higher capacity factors or lowered costs. There remains some upside in capacity factors, but the industry has been quite successful in maximizing this opportunity. Now the larger opportunity is in cost reduction. For a typical plant, around $70 \%$ of non-fuel operating and maintenance (O\&M) costs are labor. Therefore, work efficiency and work elimination are the most promising means of appreciable reductions. In non-nuclear power generation sectors, this has taken the form of a shift in the business model from one that is labor-centric to one that is technology-centric. Granted, for current nuclear plants, many labor requirements are embedded in and reflect elements of plant design. However, there is an ever-expanding opportunity to reduce labor dependence with the development and application of advanced technologies.

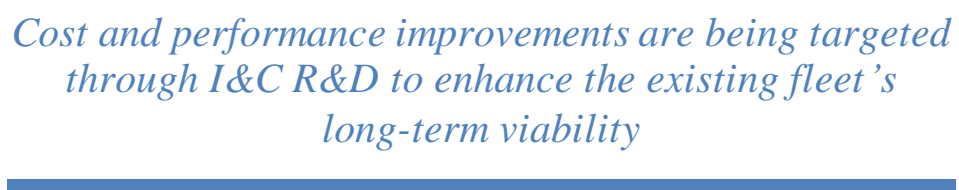

Digital technology has long been an enabler of business models in power generation that seek to lower production costs. Significant efficiencies can be gained in process improvement through applications of this technology. For example, for a typical plant support activity, no more than $35 \%$ of the labor effort is applied directly to the task (wrench time); the bulk of the labor effort is associated with various pre- and post-job activities, or resolving issues that arise during the course of work execution. Real-time process-related information access as well as collaboration with remotely situated support staff can greatly improve the efficiency of in-plant activities. In some cases, activities can be eliminated altogether, such as through online monitoring (OLM) of active components in lieu of periodic or condition-based testing.

Another opportunity for reducing cost and enhancing safety is by reducing human error and its consequences. There are substantial direct and indirect costs that result from human error. This includes the immediate consequences of the error (i.e., lost production, delayed outages, etc.), as well as indirect activities such as event investigations, remedial training, apparent and root causes, analysis of extent of condition/cause, management reviews, corrective actions, regulatory actions, operating experience reports, and so forth. When reactor trips are involved, there are even further costs in reactor trip reports, plant safety committee reviews, and recovery and restart activities. An appreciable percentage of plant staff time is consumed in these types of activities when they occur.

In 2010, the Institute for Nuclear Power Operations (INPO) issued Significant Operating Experience Report (SOER) 10-02 Engaged, Thinking Organization [4], which described a number of safety lapses that had recently occurred in the industry and highlighted a number of human performance concerns associated with these events.

The SOER recommended reinforcing desired operator behaviors as the means of resolving these human performance issues. While this is certainly appropriate, technology remains underutilized in the nuclear industry as a means to improve human performance, as well as to correct performance deficiencies. Other power generation and process control industries have demonstrated that technologies, such as operator advisory systems, can significantly enhance operator performance without supplanting their licensed role as ultimate decision-makers.

Similar human performance problems occur in nuclear plant field activities. This includes problems such as incorrect component identification, procedure use, and procedure adherence. The current approach to address this problem frequently employs human performance improvement techniques that 
add additional time and labor to the task. Current human performance improvement techniques may asymptote in their potential to reduce human error and its consequences since there is a practical limit to how far human performance issues can be dealt with through additional human performance.

This research program investigates a variety of ways that technology may enhance human performance. It has already demonstrated that digital technology is well-suited to help workers maintain situational awareness of plant conditions, and is effective in verifying that field work activities are appropriately conducted on the correct components. Technology can also alleviate the need for independent verifications in some situations due to the highly reliable confirmations that can be obtained with advanced digital capabilities (i.e., knowledge of plant mode and configuration, bar code readers, etc.).

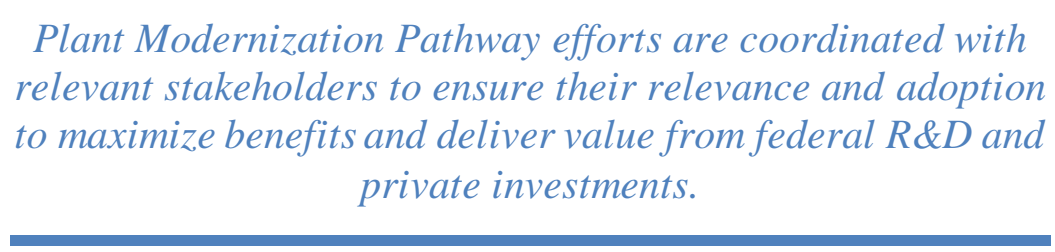

This $R \& D$ initiative engages relevant stakeholders to plan and execute the appropriate $R \& D$ activities needed to create a sustainable and efficient plant technology base for operating organizations. It is a public-private partnership with each party making in-kind contributions through $R \& D$, engineering, infrastructure, investments, and finances to address common issues and needs.

A Utility Working Group (UWG), currently comprised of 14 nuclear operating companies, provides a forum for utility input regarding issues and priorities related to $I \& C$ technologies. It also serves as a means for utilities to participate in the pilot projects when there is a match between their own performance improvement needs and the objectives of the research program.

The Electric Power Research Institute (EPRI) participates in the research program in a jointly coordinated and collaborative research role. EPRI technical experts directly participate in the formulation of the project technical plans and in the review of the pilot project results, bringing to bear the accumulated knowledge from their own research projects and collaborations with nuclear utilities.

This program coordinates with other major industry support groups such as INPO, the Nuclear Energy Institute (NEI), and the Nuclear Information Technology Strategic Leadership (NITSL). These organizations have active efforts in the I\&C area related to operational standards of excellence, regulatory initiatives, information technology (IT) infrastructure, and cyber security.

Periodic meetings are held with both DOE and the U.S. Nuclear Regulatory Commission (NRC) to exchange information regarding the research plans and activities of each of the respective organizations. Industry conference, workshops, and technical meetings also serve as important vehicles for information exchange and communication of the research program developments to the industry at large. Likewise, direct discussions with major nuclear industry suppliers ensure that there will be a viable technology transfer path from research results to solid commercial product offerings.

Altogether, these partnerships and collaborations ensure that the I\&C R\&D program focuses on those capabilities that are needed to position nuclear power assets to remain a safe and viable source of long-term electricity. By coordinating with relevant stakeholders who play vital roles in the nuclear power industry, the investments in $\mathrm{R} \& \mathrm{D}$ are targeting issues and priorities incrementally. This improves the chances that individual utilities can apply the results of individual pilot projects - technologies and methods for their successful introduction - to address challenges of aging I\&C technologies at their own sites. 


\section{INDUSTRY LEADERSHIP PERSPECTIVES}

It is important to understand the perspectives of nuclear industry leaders in regard to the needs and requirements for technology in addressing long-term sustainability issues facing the nuclear plants. Efforts were initiated and will continue to obtain senior leadership perspectives and input on pathway planning and strategy, as well as to learn how activities and initiatives can most benefit the fleet of LWR operators. The following summarizes some of these initial efforts.

An interview was conducted with the Chief Nuclear Officer (CNO) of one of the participating utilities in the I\&C Utility Working Group (UWG). The discussions confirmed many of the working assumptions of the research program. The key points made include:

- There is a high probability of pursuing NPP life extension beyond 60 years, and the plants are being maintained in a manner to minimize the effects of aging to the degree practical.

- Digital upgrades for I\&C systems are necessary, but must be done in a deliberate manner. They are not pursued for the sake of modernizing $I \& C$, but are undertaken when replacement is needed.

- Some analog systems will be retained if there is no reason to change them out, so staff must be trained to maintain it on an ongoing basis.

- The control and information systems must be contained within the plant "protected area" due to cyber security concerns. This may limit wireless applications for certain functions for some time.

- Many digital-based process improvements are potentially advantageous, including electronic work packages, robotics, and remote dose monitoring. The challenge is to get the maximum efficiency out of these applications.

- New condition-monitoring technologies will be important, especially in the areas of metallurgy, concrete, and cabling.

- The business case for these projects must be based on "quality, safety, and dollars." While cost savings are always desired, quality and safety benefits are also recognized in the decisions to undertake these types of projects.

This CNO noted that his company valued their relationship with the LWRS Program in pursuing joint development projects under this research program. He stated that his company was a good partner in this arrangement because "we are big and we like our people to learn." He elaborated on this to say that they have the need and resources to participate effectively in this type of arrangement. He noted that the mission of his organization is not research, but he sees the value of a relationship with an organization that is research-based.

Another CNO recently addressed an industry technology conference and commented on the need for greater operational efficiencies. He noted that cost is measured in dollars per megawatt-hour, of which the "denominator" is hard to change (apart from uprates and outage length reduction). Therefore, improvement must come from the "numerator" or cost-side and that technology can play a key role. He further indicated that costs are rising due to a variety of factors, so it is even more important to pursue applications in the areas of electronic work orders, paperless processes, and "hardhat cameras" to stream video to engineers for improved understanding, etc. He stressed that the industry can use these technologies to create new efficiencies in our work activities, which would improve cost performance.

Meetings were held with INPO senior management. The emphasis of these meetings were on several of the individual pilot projects from the I\&C R\&D pathway, namely those associated with the hybrid control room, advanced outage control center (AOCC), computer-based procedures (CBPs) for field workers, and OLM of active and passive components. After individual briefings on these projects, a number of points were made: 
- The approach to development and implementation of digital technologies in existing analog control rooms emphasizes systematic interactions with licensed operations personnel as a key stakeholder in the process that is based upon best practices and regulatory guidance. This was viewed as a strong point of the I\&C research pathway and an area where an opportunity to jointly pursue this further as a beneficial industry practice.

- Advanced outage control technologies are being deployed today, and the partnership of the LWRS Program with several industry organizations that are recognized for their performance in this area could create an opportunity for an industry community of practice. Informal methods of best-practice dissemination facilitated and supported by INPO may be appropriate.

- Hand-held electronic field procedures may be a key to overcoming some of the challenges in human performance that are regularly observed in operating events and industry experience. In addition, this technology may be able to address some of the recent concerns identified regarding the cumulative impact of industry corrective action programs.

- Online monitoring may alleviate some of the burden of time-consuming work that can be better accomplished through remote monitoring. It may provide some advantages over manual surveillances, but has to be balanced with the need to have plant workers in the field maintaining their proficiencies.

A discussion with the CNO of a large southern nuclear utility at the 2014 American Nuclear Society Utility Working Conference confirmed an interest in new technologies to improve nuclear plant work efficiency. He mentioned that the "cumulative effect" of more process requirements does not mean that the industry is safer and that these measures are becoming less effective due to the burden imposed on workers. In hearing more details about the ongoing pilot projects, he expressed interest in the work of the LWRS Program and the potential for benefit within his company.

The additional emphasis that has been placed on obtaining industry leadership perspectives is made possible, in part, by the maturation and deployment of LWRS technologies at operating plants. As technologies and partnerships with the industry continue and broaden, efforts will continue to obtain input from senior industry leadership. These will be used to verify that pathway research priorities address long-term industry needs. Future meetings with the CNOs of the operating commercial nuclear plants are already being planned and will provide a major opportunity to acquire this level of feedback on program objectives and activities. 


\section{PATHWAY RESEARCH AND DEVELOPMENT AREAS 3.1 Stages of Transformation}

The transformation of the nuclear plant operating model to that which is described as the future vision will take more than a decade to fully assimilate pilot project technologies into plant operations and business processes. The rate of transformation is a function of how pilot projects are defined and sequenced, such that later combinations of these technologies create new capabilities that address the requirements of more complex nuclear plant work activities. The transformation stages are depicted in Figure 3.

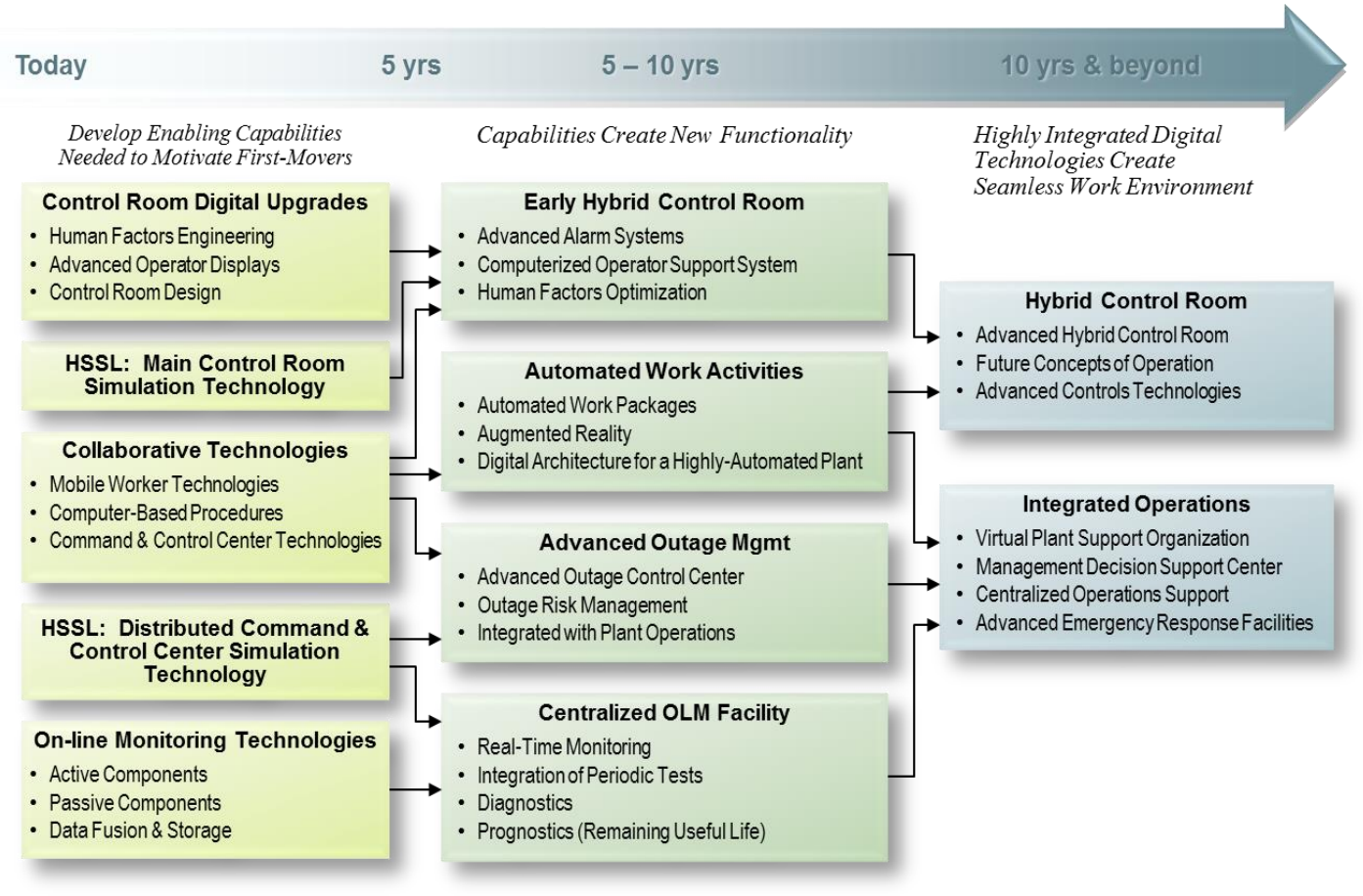

Figure 3. Stages of transformation in the Plant Modernization Pathway Vision and Strategy.

The first stage involves the development of enabling capabilities that are needed to motivate the first movers in the industry to adopt new digital technologies. The pilot projects serve to introduce new technologies to the nuclear plant work activities and validate them as meeting the special requirements of the nuclear operating environment. They must be demonstrated to not only perform the intended functions with the required quality and productivity improvements, but they must also fit seamlessly into the established cultural norms and practices that define the safety culture of nuclear power industry. This stage is characterized as new digital technologies improving the quality and productivity of work functions as they are now defined.

The outcomes of the first stage are Control Room Digital Upgrades, Collaborative Technologies, and Online Monitoring Technologies. The Human Systems Simulation Laboratory (HSSL) is a key development focus of this stage to enable studies and validations of main control room simulation as well as distributed command and control center (e.g., outage control center) simulation. (Refer to Section 3.2, "Human Systems Simulation Laboratory").

The second stage occurs when the enabling capabilities are combined and integrated to create new functionality. This is something of an aggregation stage; however, it includes the introduction of even 
more enabling capabilities as further advancements are made. The pilot project technologies have been formulated in anticipation of this integration stage such that they will work in cooperation with each other to support large organizational functions. This stage is characterized as the reformulation of major organizational functions based on an array of integrated technologies.

The outcomes of the second stage are the Early Hybrid Control Room, Automated Work Activities, Advanced Outage Management, and Centralized Online Monitoring Facilities.

The third stage occurs when there is substantial transformation of how the nuclear plant is operated and supported based on all major plant functions being embedded in a seamless digital environment. Again, this transformation is enabled by both newly developed technologies and the continued creation of new capabilities based on previously developed technologies. This stage is characterized as a transformation of the nuclear plant organization and plant operating model based on advanced digital technologies that redefine and focus the roles of plant workers and support organizations on value-added tasks, rather than organizational and informational interfaces.

The outcomes of the third stage are the Hybrid Control Room and Integrated Operations.

\subsection{Human Systems Simulation Laboratory}

The HSSL at Idaho National Laboratory (INL) is used to conduct research in the design and evaluation of hybrid control rooms, integration of control room systems, development and piloting of human-centered design activities with operating crews, and visualizations of different end-state operational concepts. [5] This advanced facility supports human factors research for operating nuclear plant control rooms, including human-in-the-loop performance and human-system interfaces (HSIs), and can incorporate mixtures of analog and digital hybrid displays and controls. It is applicable to the development and evaluation of control systems and displays of NPP control rooms, and other command and control systems.

The HSSL consists of a full-scope, full-scale reconfigurable control room simulator that provides a high-fidelity representation of a LWR analog-based control room (Figure 4).

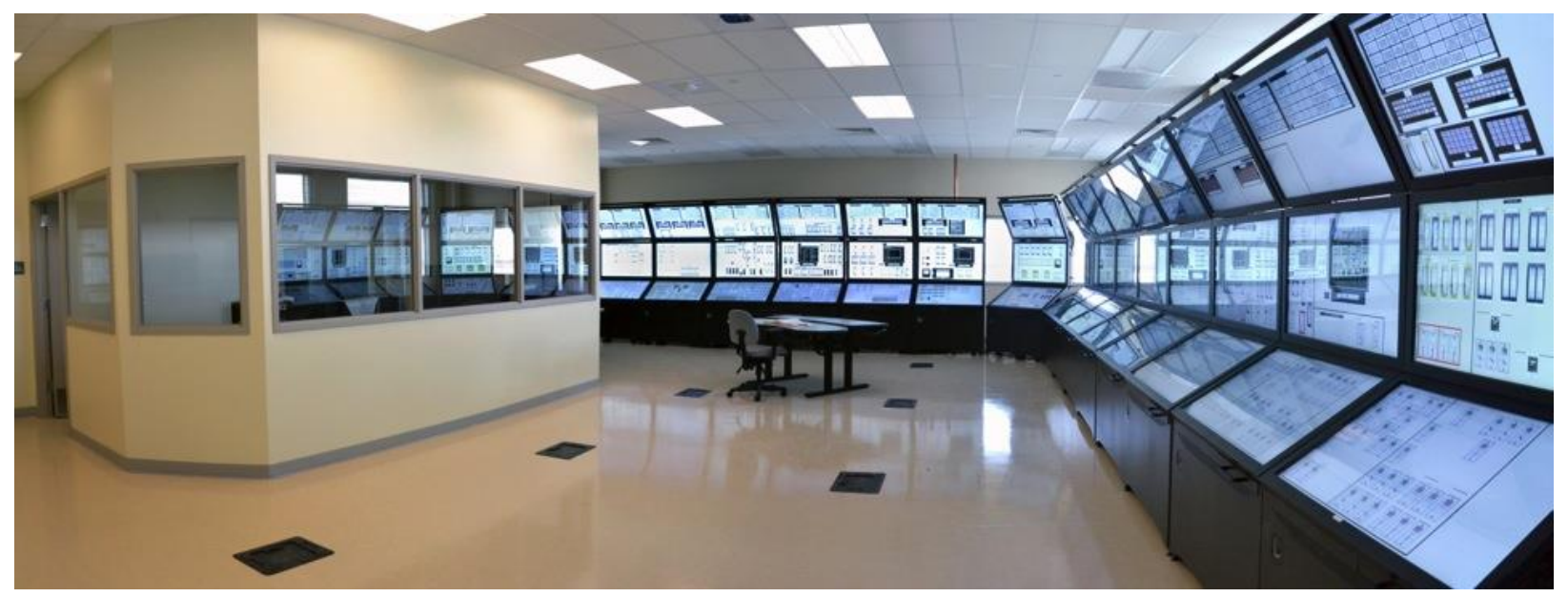

Figure 4. Human Systems Simulation Laboratory-Reconfigurable Hybrid Control Room Simulator.

The simulator consists of 15 bench board-style touch panels that respond to touch gestures similar to the control devices in an actual control room. The simulator is able to run actual LWR plant simulation software used for operator training and other purposes. It is reconfigurable in the sense that the simulator can be easily switched to the software and control board images of different LWR plants, thus making it a universal test bed for the LWR fleet. 
For this research program, the HSSL will be mostly used to study human performance in a realistic operational context for hybrid control room designs. New digital systems and operator interfaces will be developed in software and depicted in the context of the current state control room, enabling comparative studies of the effects of proposed upgrade systems on operator performance (Figure 5). Prior to full-scale deployment of technologies (such as control room upgrades), it is essential to test and evaluate the performance of the system and the human operators' use of the system in a realistic setting. In control room research simulators, upgraded systems can be integrated into a realistic representation of the actual system and validated against defined performance criteria.

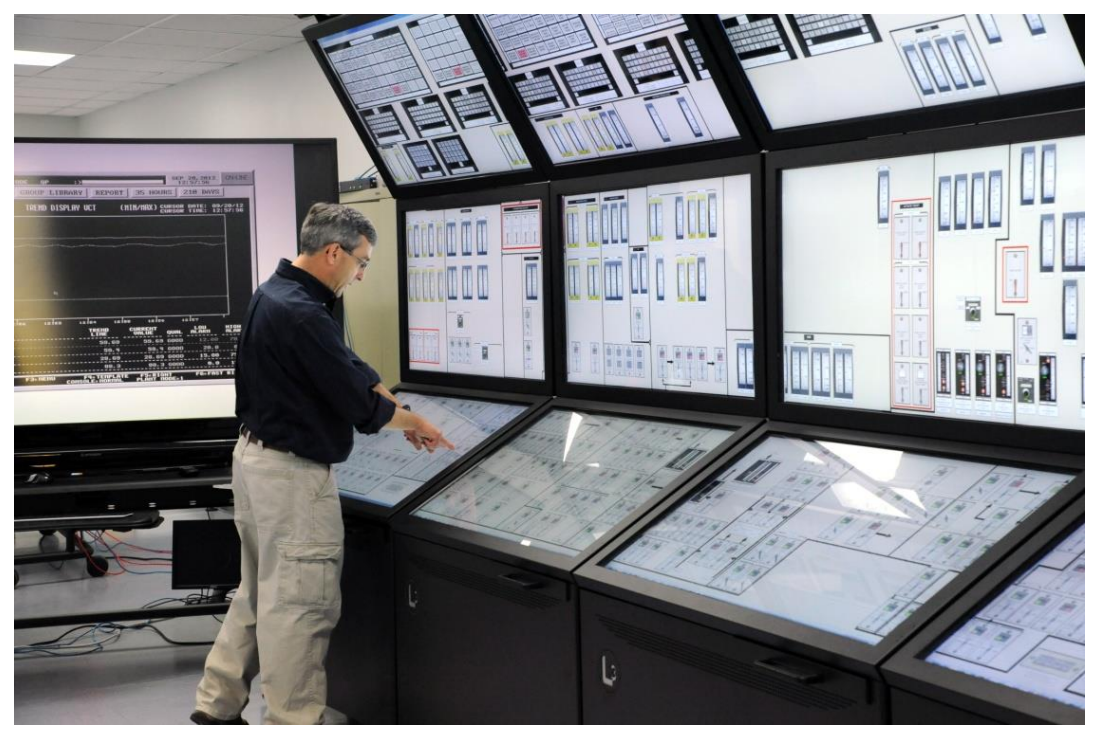

Figure 5. HSSL used to evaluate digital upgrades in a hybrid control room

The facility is equally suitable for human performance measurement in other NPP control centers, such as an outage control center (OCC), a centralized OLM center, and emergency response facilities. An assessment of human performance in a naturalistic setting includes studies in a range of the following focus areas:

3. Human-system performance relationships between the reliability of the operator, the time available to perform an action, performance success criteria, and the influence of the performance characteristics of the plant or system on task performance and outcome(s).

4. Usability of the human systems interface, which includes the effectiveness, efficiency, safety, and reliability with which an operator can perform specific tasks in a specific operational context (e.g., normal or emergency). This includes the effect on human performance with different technologies and different HSI configurations.

5. Human performance expressed as physical and cognitive workload under different operational conditions, including the following:

a. Monitoring of plant status and system performance

b. Human error, human reliability, and human error mechanisms

c. Task completion (e.g., accuracy, speed, tolerance, variability).

d. Procedure following

e. Problem diagnosis: (1) decision making and (2) response times.

6. Situational awareness with a given HSI and control configuration under different operational conditions. 
7. Crew communication effectiveness with given technologies under different operational conditions.

8. Human performance with different staffing configurations and a given control room configuration.

The HSSL provides the simulation, visualization, and evaluation capabilities needed for pilot projects involving the development and evaluation of new technologies for the main control room and other control centers. As such, the new technologies will first be staged in the HSSL for proof-of-concept prior to demonstration at host utility NPPs. This will enable research on function allocation, task analysis, staffing, situational awareness, and workload in hybrid control rooms (Figure 6).

The HSSL also employs physiological measurement devices to support human factors evaluations, such as eye tracking (Figure 7), which enables researchers to determine where an operator's attention is focused. It is envisioned that the HSSL will be used to validate new operational concepts, human-centered design methods, and many first-of-a-kind technologies for the LWR fleet, thereby ensuring that NPP modernization of I\&C systems is based on demonstrated and validated scientific principles.

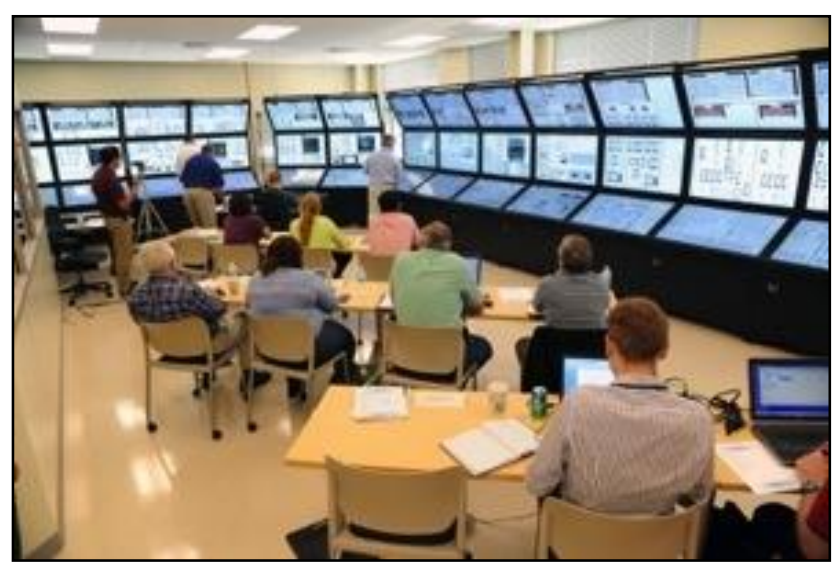

Figure 6. HSSL used for an operator work shop.

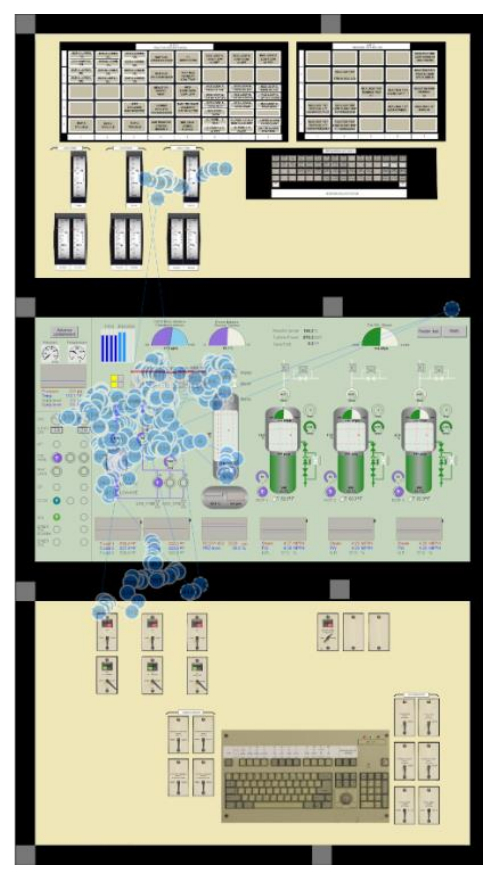

Figure 7. HSSL being used for eye tracking of operators using an advanced display. 


\subsection{Cyber security}

Cyber security is recognized as a major concern in implementing advanced digital I\&C technologies in NPPs in view of the considerable security requirements necessary to protect these facilities from potential adversaries, as well as to protect company-proprietary information. The members of the UWG have expressed the need to ensure that cyber security vulnerabilities are not introduced through the adoption of these advanced digital technologies. Furthermore, these utilities have internal cyber security policies and regulatory obligations for which compliance is required in implementing the project technologies. Responsibility for cyber security ultimately lies with the utilities that implement the technologies from this research program. They must ensure that their own policies and regulatory commitments are adequately addressed.

DOE has significant cyber security expertise and resources that have been developed to address the security concerns of INL as well as those of many security-critical U.S. government facilities. DOE's experience in identifying, characterizing, and mitigating cyber security threats is highly applicable to the type of concerns that potentially would be created in technology areas of the pilot projects.

To this end, a project task was created to address cyber security issues arising from the technology developments in the pilot projects, with DOE cyber security experts at INL reviewing the pilot project technologies and providing a report on appropriate practices to minimize cyber security risk. The report is entitled Cyber Security Considerations in Support of the Light Water Reactor Sustainability Program, Revision 2 (INL/LTD-12-27315), with the latest revision having been published in July 2013. [6]

To help nuclear utilities better understand the cyber security implications for the digital technologies being developed under this research program, an assessment was conducted in FY 2014 of the pilot project technologies against the requirements of 10 CFR 73.54, "Protection of Digital Computer and Communication Systems and Networks," and the associated regulatory guidance of NEI 08-09, "Cyber Security Plan for Nuclear Power Reactors."

A nuclear industry consulting firm that routinely conducts these types of assessments for utilities was contracted to perform this assessment. It consisted of a table-top exercise to evaluate developed technologies against the requirements of a typical nuclear utility cyber security program to determine what controls would be needed to support production usage. A mock Cyber Security Assessment Team (CSAT) was set up by the consulting firm with cyber security, information technology, and engineering expertise represented. The principal investigators of each of the pilot projects presented relevant computer and communication aspects of their respective pilot project technologies to the CSAT, which systematically analyzed them according to the NEI 08-09 assessment criteria.

The results of the assessment were documented in project report Cyber Security Evaluation of I\&C Technologies (INL/EXT-14-33609) [7]. The major findings of the report included:

- Most I\&C technologies will reside the cyber security business layer and will probably be treated as workplace tools, like measurement and test equipment. This is particularly true of the mobile work technologies (including field work CBPs and automated work packages [AWPs]). This is also true of the AOCC technologies.

- Online monitoring (OLM) technologies will also reside in the business layer, except for the special case where they might be used for real-time configuration status, such as wireless valve position status. In this case, they would be critical digital assets (CDAs) if used for automated tech specification surveillances. CDAs require full application of prescribed cyber security controls, or acceptable alternates, if they are applicable to the particular component.

- The hybrid control room technologies will mostly be CDAs in that they provide real-time information to plant operators during transients and accidents. 
- Three currently prohibited situations were identified: (1) wireless connection to safety-related and important-to-safety equipment; (2) wireless control in the main control room (e.g., use of CBPs with soft controls [Type 3] on a tablet); and (3) control functions from outside the plant protected area (fence), which only applies to a future pilot project on "Advanced Concepts of Operations" with possible fleet-central control certain balance of plant (BOP) systems or remote digital control rooms for use during severe accidents.

As a measure of confirmation of the results of this assessment, cyber security experts from two large nuclear utilities reviewed the report and stated that the assessment conclusions appeared to be accurate based on their experience and that their respective utilities would likely draw similar conclusions regarding the pilot project technologies.

It is recognized that these technologies represent a "proof-of-concept" state; therefore, these technologies are not as prescriptive in terms of underlying technologies as might normally be required in an actual cyber security evaluation for a nuclear plant. For example, a technology might refer to the use of wireless transmission of information to mobile field workers, without specifying the type of wireless protocol. Therefore, in future utility evaluations of actual implementations of the pilot project technologies, assessment outcomes might be different according to implementation options.

The research pathway will continue to apply the cyber security resources, expertise, and experience of DOE, as well as the nuclear industry, to provide a sound information basis for utilities in prudent technology implementation practices and mitigation measures.

\subsection{Quality Assurance}

Quality assurance requirements for this research program are defined in INL/EXT-10-19844, Light Water Reactor Sustainability Program Quality Assurance Program Document. [8] This Quality Assurance Program is based on the requirements in American Society of Mechanical Engineers NQA-1-2008, 1a-2009, "Quality Assurance Requirements for Nuclear Facility Applications." [9] It covers all of the R\&D activities of the program, including any quality assurance requirements applicable to the technologies and related concepts developed and implemented under the pilot projects.

A specific quality assurance plan is developed for the work package associated with each pilot project, employing an assessment matrix that examines each task in the project to classify it according to the type of research it represents: basic, applied, or development. These research types correspond to a graded approach to the quality assurance requirements, in which the quality assurance requirements appropriate to each type are applied.

An audit of the Quality Assurance requirements was conducted in FY 2017 with no findings.

\subsection{Digital Technology Business Case Methodology}

The lack of a business case is often cited by utilities as a significant barrier in pursuing wide-scale application of digital technologies to their nuclear plant work activities. While the performance advantages of these new capabilities are widely acknowledged, it has proven to be difficult for utilities to derive business cases resulting in actual cost offsets that can be credited in budget allocations for site organizations, and thereby truly reduce O\&M costs. This is because the technologies are typically applied in a manner that simply enhances existing work methods rather than eliminates work or makes it significantly more efficient, such that it changes overall staffing and material cost requirements. For technologies that have this offset potential, a methodology is needed to capture this impact in a credible manner. 
To address this need, the research program developed INL/EXT-14-33129, Digital Technology Business Case Methodology [10] working with ScottMadden Management Consultants, a firm that has years of experience in preparing performance improvement business cases for senior leadership in the nuclear power industry. The purpose of the business case methodology is to provide a structure for building the business case for adopting pilot project technologies in a manner that captures the total organizational benefits that can be derived from improved work methods. This includes direct benefits in targeted work processes, efficiencies gained in related work processes, and avoided costs through improvement in work quality and reduction in human error.

The business case methodology consists of a business case methodology workbook (spreadsheet) that is customized and populated with standard nuclear plant work activities and typical plant staffing totals for each plant organization. It calculates the aggregate benefit of a technology across all the work activities it impacts, including being able to credit reduction in recovery costs for rework and performance errors, based on the historical rate of their occurrence in the targeted activities.

Specifically, the business case methodology also serves as a user guide, presenting a structured approach to developing a sound business case, as well as identifying where in the process to employ the business case methodology workbook for benefits/cost savings identification. The approach enables collaboration between the Plant Modernization Pathway and utility partners in applying new technologies across multiple NPP organizations and their respective work activities, wherever there is opportunity to derive benefit. In this manner, the business case methodology drives an "economy of scale" that maximizes the value of the technologies relative to the implementation cost.

The business case methodology leverages the fact that, in spite of what seems to be a wide and disparate array of work activities among a NPP's operational and support organizations, the work activities themselves are largely composed of common tasks. For example, whether the work activities are in operations, chemistry, radiation protection, or even security, they have in common such tasks as pre-job briefs, use of procedures, correct component identification, emergent conditions requiring work package alteration, etc. It is at this task level that the technologies are applied; therefore, the benefits of the technologies can be realized across as many plant activities as can be identified to employ these tasks. In this manner, a much more comprehensive business case can be derived that greatly increases the benefit/cost ratio. This has the added benefit of driving consistency across the NPP organizations, which is a fundamental principle of successful NPP operational and safety management.

In FY 2015, a business case study was conducted with a large operating nuclear plant to determine the cost and performance benefits that could be obtained with wide-scale implementation of mobile worker technologies. ScottMadden Management Consultants were again contracted to conduct another study using the business case methodology workbook. In addition to determining the benefits of the technology, the study was used to confirm the adequacy and accuracy of the features of the business case methodology workbook. The study resulted in the identification of approximately $\$ 6.5 \mathrm{M}$ in annual savings for the plant with full implementation of mobile work packages, including CBPs. This represents a net present value of over $\$ 21 \mathrm{M}$ through the expected 15-year life of the technology. This value is considered to be on the low end of the range of expected of benefits due to conservative assumptions that were made in the analysis. In addition to cost savings, considerable benefits were identified in reduced human error, with positive impacts on a number of important plant key performance indicators. The study is documented in report INL/EXT-15-35327, Pilot Project Technology Business Case: Mobile Work Packages. [11]

Two new business case studies applying the business case methodology were conducted in FY 2016: Advanced Outage Management and Control Room Modernization. 
A Business Case for Advanced Outage Management (INL/EXT-16-38265) [12] documents the quantitative and qualitative performance improvement potential of advanced outage management technologies. The analysis presented is built upon and is incremental to the business case for mobile work packages. The Advanced Outage Management business case demonstrates that new communication, networking, and analytical technologies will allow nuclear utilities to conduct outages with fewer people in management roles and the remaining outage staff can be more effective and more productive. The benefits are quantified by a rough order of magnitude providing directional guidance to nuclear utilities interested in developing similar business cases. The following improved capabilities are described in this report:

- Automated status updates

- Advanced bulk work and schedule analysis

- Networked meetings (remote access)

- Networked emergent work teams

- Coordination of dispatchable resources

- Outage configuration management

- Remote job oversight

- Paperless outage coordination.

The business case analysis resulted in a cost savings present value of $\$ 27.23 \mathrm{M}$ and when combined with the full benefit of mobile work packages, it is $\$ 48.96 \mathrm{M}$. The analysis assumes a discount rate (internal rate of return) of $10 \%$ and a cost recovery period of 15 years. These figures are not net of the application investment, which would have to be determined on a specific utility basis. However, because these figures are calculated based on a discount rate, the investment could be up to these amounts and still have a positive return.

A Business Case for Nuclear Plant Control Room Modernization (INL/EXT-16-39098) [13] documents the cost savings enabled by seven elements of performance improvement in the form of eliminated work, work efficiencies, and other direct cost savings (e.g., reduced paper cost, reduced power replacement cost due to shorter refueling outages), with a present value over 15 years of $\$ 10.46 \mathrm{M}$. This figure does not count some labor savings deemed not to enable staffing reductions, but still represents opportunities to use the labor in higher-value ways. The report also documents improvements expected in key performance indicators that are over and above the estimated cost savings.

\section{RESEARCH AND DEVELOPMENT COOPERATION}

A systematic engagement activity is underway with NPP owner/operators, suppliers, industry support organizations, and the NRC. Together, these engagement activities are intended to ensure that R\&D activities focus on issues of challenge and uncertainty for NPP owners and regulators alike, the products of research can be commercialized, and roadblocks to deployment are systematically addressed.

\subsection{Industrial and Regulatory Engagement}

The Plant Modernization Pathway of the LWRS Program conducts a vigorous engagement strategy with the U.S. nuclear power industry, including the nuclear operating companies, major support organizations, the RC, and suppliers; this is a support function of the Pathway known as Industrial and Regulatory Engagement (I\&RE). The goal of this engagement strategy is to develop a shared vision and common understanding across the nuclear industry of the need for nuclear plant modernization, the performance improvement that can be attained, and the opportunities for partnering to enact this vision. 
To ensure that the research activities of the Pathway are relevant and of the maximum impact for sustainability of the LWR fleet, the industry stakeholders are specifically engaged on identifying:

- The key issues and challenges in operating aging systems and managing obsolescence.

- The priorities for mitigating aging and obsolescence through a common set of priorities suitable for federal research.

- The issues that impact ability to implement technical solutions, needed research to enable needed regulation, and other areas for joint research.

The I\&RE function conducts a set of ongoing activities with the nuclear industry stakeholders, including:

- Meetings and conference calls with nuclear utilities to communicate Plant Modernization Pathway developments and to develop partnerships in project activities.

- Communications to the nuclear industry through presentations in technical meetings and through the publication of articles and technical papers.

- Regular communications to major industry support organizations such as EPRI, INPO, and the NEI.

- Communications with the Nuclear Regulatory Commission staff as needed.

- Meetings with nuclear industry technology suppliers to promote commercial development of new technologies developed under the Plant Modernization research program.

For FY 2019, a specific engagement will be conducted with "first-mover" utilities who have expressed interest in pursuing nuclear plant modernization. The Pathway intends to hold engage these utilities to develop a suitable action plan to develop a comprehensive nuclear plant modernization strategy, including such components of the strategy as an end-state architecture, business case, regulatory approach, and implementation plan. The action plan will be coordinated with interested industry stakeholder organizations such as EPRI and NEI. The intent and activities of the action plan will be appropriately communicated to the NRC.

To achieve the broader purposes of the Pathway, the I\&RE function engages nuclear utilities in what is referred to as the UWG, which is the set of nuclear utilities that the Pathway has worked with over the life of the LWRS Program. At present, the UWG consists of 14 leading U.S. nuclear utilities. Additional membership for the UWG is constantly pursued with the intent to involve every U.S. nuclear operating fleet in the program. Utilities that are currently or have been engaged in the work of the Pathway include:

- Arizona Public Service

- Dominion Energy

- Duke Energy

- Entergy

- Exelon Nuclear

- First Energy Nuclear Operating Company

- Luminant

- Nebraska Public Power

- NextEra Energy

- Pacific Gas \& Electric 
- Public Service Electric and Gas

- Southern Nuclear

- South Texas Project

- Tennessee Valley Authority

- Utilities Service Alliance (USA)

- Xcel Energy

Engagement activities with the UWG include periodic meetings, conference calls, and direct communications to provide status updates on the pilot project activities and to publicize opportunities to participate in the development activities. There are other special purpose meetings and conference calls focusing on particular sets of technologies, and they are attended by the utility members that have near-term interests in those technologies.

Either individually or in focused groups with common research interests, the UWG that serves several important functions in partnering with the Pathway.

- Provides direct input on the needs and requirements of nuclear utilities for technology.

- Provides direct input on the operating environments and safety culture aspects for which the technologies must conform.

- Provides input on the scope and priority of pilot projects.

- Serves as utility hosts for demonstration projects and studies to prove the effectiveness of new technologies in actual nuclear plant settings.

- Provides a means of developing industry consensus on the requirements for technologies so that they are widely suitable across the range of individual utility work practices. This also enables a robust supplier market for these technologies due to common requirements.

Serving as host utilities for pilot project development and study activities is perhaps the most important way that utilities participate in the work of the pathway. This occurs when utilities have their own business process and performance improvement objectives that match up with pilot project development plans. In this way, the utilities become "first movers" for the industry and have the opportunity to help set the requirements for the industry. The utilities serving as hosts benefit from both the process and technology expertise that the pathway brings to the projects, as well as the cost benefit of a cooperative development effort in proving the effectiveness of the technologies.

In turn, to benefit the nuclear power industry in general, the pilot project hosts will make the results of the R\&D available and accessible to other commercial nuclear utilities and participate in efforts to support deployment of systems, technologies, and lessons learned by other NPP owners. Host utilities regularly make presentations in key industry technical meetings to describe their motivations and efforts in the pilot projects and to communicate important findings to the industry.

\subsection{Electric Power Research Institute}

The EPRI is a member of the UWG and serves in a direct role in collaborative research with the Plant Modernization Pathway. EPRI has conducted numerous R\&D activities over the past several decades in support of NPP digital implementation and related issues, and has made relevant reports and guidelines available to this research pathway. EPRI technical experts directly participate in the formulation of the project technical plans and in the review of pilot project results, bringing to bear the accumulated knowledge from their own research projects and collaborations with nuclear utilities. EPRI will assist in 
the transfer of technology to the nuclear utilities by publishing formal guidelines documents for each of the major areas of development.

Regular meetings and conference calls are conducted with EPRI to coordinate R\&D plans, share insights on technology requirements for nuclear utilities, and coordinate plans for publicizing and disseminating the information produced through the projects. In addition, each organization participates in industry meetings of the other, thereby maximizing the understanding of the utilities of the developments of the coordinated research. This has proven to be an effective means of ensuring the capabilities and benefits of the new technologies are known to the entire commercial nuclear power industry.

\subsection{Halden Reactor Project}

The R\&D programs of the Halden Reactor Project, sponsored by the Noreweigan Institute for Energy Technology (IFE), address many aspects of NPP operations; however, the main area of interest to the Plant Modernization Pathway is the man-machine-technology research program that conducts research in the areas of computerized surveillance systems, human factors, and man-machine interaction in support of control room modernization. Halden has been on the cutting edge of new NPP technologies for several decades. Their research is directly applicable to the capabilities being pursued under the pilot projects. In particular, Halden has assisted a number of European NPPs in implementing I\&C modernization projects, including control room upgrades.

The Plant Modernization Pathway will work closely with Halden to evaluate their advanced I\&C technologies to take advantage of applicable developments. In addition to the technologies, the validation and human factors studies conducted during development of the technologies will be carefully evaluated to ensure similar considerations are incorporated into the pilot projects. Specific Halden developments of interest to the pilot projects include:

- Advanced control room layout

- Computer-based procedures

- Advanced, state-based alarm systems

- Integrated operations

- Plant worker mobile technologies.

In addition, DOE will enter into a bilateral agreement in areas of research where collaborative efforts with Halden will accelerate development of the technologies associated with the pilot projects.

\subsection{Major Industry Support Organizations}

The LWR fleet is actively supported by major industry support groups, namely EPRI, the NEI, the INPO, and the NITSL. These organizations have active efforts in the I\&C area, including technical developments, regulatory issues, and standards of excellence in conducting related activities. It is important that these organizations be informed of the purpose and scope of this research program and activities be coordinated to the degree possible. In the case of EPRI, even though they are a partner in development activities, there are opportunities to collaborate with other major programs they sponsor, such as the I\&C Program and the Nuclear Maintenance Application Center.

It is a task of this research program to engage these organizations to enable a shared vision of the future operating model based on an integrated digital environment and to cooperate in complementary activities to achieve this vision across the industry with maximum efficiency and effectiveness.

Collaborations with EPRI have been previously presented in Section 4.2. Regarding NEI, a new level of collaboration was established in FY 2015 with a representative of the Plant Modernization Pathway participating in the NEI Digital I\&C Working Group, which has been tasked by the CNOs of the nuclear 
utilities to work with the NRC to find resolutions to certain long-standing barriers to implementing digital technologies. The Working Group is now actively engaged with the NRC with their work schedule to continue in FY 2019. The technologies, facilities, and expertise of the Plant Modernization Pathway will likely be of use in working through these regulatory barriers.

Engagement with INPO continued in FY 2017 through discussions with INPO senior leadership on how new technologies can improve performance and reduce burden on NPP workers and managers. Similar to EPRI, both organizations have participated in the other's industry meetings to increase awareness of these development activities and to share insights and requirements. Of particular note, areas for specific collaboration have been identified in the areas of nuclear work process improvement and control room operator performance enhancement. INPO has been a participant in several development activities with utility project hosts, thus helping to ensure that the technologies are in concert with the broad principles of nuclear operational excellence.

There is considerable ongoing collaboration with NITSL in the area of mobile worker technologies and digital architecture. The Plant Modernization Pathway has partnered with the NITSL Infrastructure and Application (I\&A) Committee to define the requirements for mobile worker technologies for NPPs. In addition, the I\&A Committee is also a development partner in the Digital Architecture Pilot Project (see Section 5.2.4). NITSL and the Plant Modernization Pathway conduct regular conference calls on these topics, which provide needed utility input on these development topics and provides access to utility experts in the implementation aspects of these technologies.

\subsection{Nuclear Regulatory Commission}

Periodic informational meetings are held between DOE Headquarters personnel and members of NRC management to communicate about aims and activities of individual LWRS Program pathways. Briefings and informal meetings will continue to be provided to inform staff from the NRC's Office of Nuclear Regulatory Research about technical scope and objectives of the LWRS Program.

Also, as described in Section 4.4, there is ongoing engagement with the NRC through participation in the NEI Digital I\&C Working Group on certain regulatory topics that have become some degree of impediment to digital implementation in NPPs. These topics include digital implementation without prior NRC approval under 10 CFR 50.59, improvements to the digital licensing process, methods of addressing software common cause failure, and treatment of NPP components with embedded digital devices. The Plant Modernization Pathway will assist in the resolution of these issues both in direct communications with the NRC and through the efforts led by NEI.

\subsection{Suppliers}

Ultimately, it will be the role of the nuclear industry I\&C suppliers to provide commercial products based on technologies developed under this research program. In the absence of an industry-wide I\&C modernization strategy, products currently offered by these suppliers reflect the more limited approach of fragmented, like-for-like digital implementations as driven by the market. As a collective vision for an improved operating model based on an integrated digital environment takes hold within the LWR fleet, leading suppliers will seize the market opportunity to provide products that enact this vision.

An engagement strategy for nuclear industry I\&C suppliers will be conducted with the following tasks:

- Communicate to suppliers the objectives of the research program and the specific technologies and operational concepts that are being developed and validated through the pilot projects.

- Obtain input from suppliers on how they are developing their products with respect to this market.

- Set up a mechanism for ongoing communications. 
- Facilitate a long-term commercialization strategy for the program's developed technologies.

\subsection{Department of Energy - Nuclear Energy Enabling Technologies Program}

The DOE-Office of Nuclear Energy (DOE-NE) sponsors a crosscutting technology R\&D program addressing common I\&C needs in all DOE-NE-sponsored programs. This program, the Advanced Sensors and Instrumentation crosscut, is conducting research intended to address gaps and needed capabilities for I\&C technologies in all DOE-NE -sponsored R\&D programs.

I\&C-related technologies are or will be needed to meet some of the long-term sustainability goals that are beyond the scope of LWRS Program research activities today. This includes improved technologies to support fuels and materials research capable of providing higher quality data during in-pile irradiations (planned to be coordinated in other LWRS R\&D pathways). It also includes technologies that will enable some of the vision elements of the I\&C research pathway. Examples of these include digital technologies that can reduce the highly labor-intensive aspects of plant maintenance (such as inspections, tests, and surveillances of sensors and controllers). In addition, digital technology introduction still presents a challenge for most plants because of the considerable regulatory uncertainties - both real and perceivedto obtain approvals, creating significantly higher costs and schedule uncertainty.

The current fleet of LWRs still employs many of the same technologies and algorithms in balance of plant control as when the systems were originally commissioned. Because of the amount of system noise and measurement uncertainty, set point regulation imposes a high burden on plant margins and creates a control structure that is inflexible. Consequently, control system behavior is deterministic and cannot easily or rapidly account for small system disturbances or significant external transients without quickly reaching protection system set points. This results in more "unavoidable" shutdowns and runbacks than would be necessary if installed control systems could be made more resilient and better able to cope with anticipated transients. Advances in control systems technologies would enable a range of operational improvements that would support higher rates of plant availability and reduced thermal cycling on major plant components caused by rapid plant shutdowns.

Two significant issues confront the massive communications architectures required to transmit signal and control data from and between the more than 100,000 individual plant components. The first relates to the material aging of copper cables for medium and low-voltage cables, especially the performance of insulating material. Although research is underway to understand and propose mitigations to counter the effects of material aging and degradation, a diversification of communication approaches may reduce the amount of amelioration that is eventually necessary once a solution is found. In addition, many plant components are not physically "wired" to the control system and exist outside the awareness of the control system and the operational staff. This introduces significant challenges in maintaining a desired plant configuration and requires substantial manual efforts to periodically assess and verify configuration status. In both cases, wireless communications technologies may one day be substituted for many physical cabling. In concert, power-harvesting technologies would help realize the goal to have all components physically coupled to plant control systems without imposing additional requirements for power cabling.

Finally, the reactor accidents at Fukushima Daiichi have raised a number of issues regarding the ability of current $\mathrm{I} \& \mathrm{C}$ technologies to withstand the environmental and accident conditions of severe accidents. Currently, emergency operating procedures and severe accident management guidelines in U.S. NPPs require access to reliable information from sensors and controls to manage anticipated transients. However, the severe accidents at Fukushima Daiichi highlight the potential for loss of all instrumentation and the ensuing difficulties in implementing emergency actions as a consequence. Further research is needed to understand the root causes of instrument failure, to determine alternative approaches to estimate plant conditions, and to determine alternatives to accident management and recovery. 


\section{RESEARCH AND DEVELOPMENT PRODUCTS AND SCHEDULES}

DOE and partner utilities will conduct broad collaboration in R\&D activities for nuclear plant modernization. The objective is to provide the technical bases for technical and process transformations that ensure and enable sustainable operating life beyond 60 years. This will have four key focus areas; (1) I\&C and Control Room Modernization, (2) Online Monitoring and Plant Automation, (3) Advanced Applications and Process Automation, and (4) Informed Decision Making.

For each of the areas of enabling capability, the current performance issues and needs are described, followed by a description of how technology developments can improve performance. Each of the pilot projects is then described in terms of activities and deliverables, including a concise summary of each project. A list of previously completed deliverables for all projects can be found in Appendix A.

\subsection{Instrumentation and Control Architecture}

The U.S. operating nuclear fleet is an important national asset providing approximately $20 \%$ of the nation's electric supply, as well as providing critical grid stability, carbon-free energy, and generation fuel-diversity. However, the economic viability of the fleet is challenged by the abundance of low-cost shale gas generation and heavily subsidized renewable generation. Electricity capacity markets today do not compensate nuclear plants for distinct operational contributions they make in addition to baseload generation. As a result, there have been nuclear plant closings due to unprofitable operations, continued economic challenges for many plants in the operating fleet, and an overarching need to address improvements to the underlying efficiencies for production.

Nuclear plants have a significant opportunity to lower their operating costs while actually improving operational performance through plant modernization. Most sectors of the industrial economy renew and modernize their infrastructure on a periodic basis, adjusting to new market conditions and applying new technologies, particularly digitally-based. The operating nuclear fleet, by contrast, is largely based on a state of technology and related operating model that is over 40 years old. It is characterized by analog technology and large operating staffs performing manual activities for most plant functions. Over the lives of these operating plants, nuclear utilities acted on a number of non-discretionary capital investments to address safety and regulatory issues. This has resulted in the deferral of much-needed reinvestment in the plants to address their aging systems and improve their operational efficiency. This reinvestment is now vital to their long term sustainability. It is therefore critical that proven solutions be identified and become available to nuclear utilities for wide-scale plant modernization that provide nearterm cost reductions while resulting in a future state that is operationally and financially sound for decades to come.

Currently the LWR fleet has a mixture of traditional analog I\&C technology and newer digital technology. Virtually all U.S. nuclear plants have undertaken some amount of digital upgrades over the lifetime of the stations. In some cases, digital systems were the only practical replacement option for legacy analog components. In other cases, digital systems were the preferred technology in that they could provide more precise control and greater reliability. The cumulative effect for the LWR fleet has been an ever-increasing presence of digital systems in the LWR control rooms.

Developing and demonstrating an effective and efficient path forward for licensing and deployment of modernizing the LWR fleet through digital I\&C has been elusive thus far. This has resulted in digital I\&C upgrade projects at commercial NPPs costing substantially more than expected, taking longer to perform, and has had a chilling effect on modernization and investments of this type in commercial NPPs.

Several challenging issues remain unresolved and require significant $R \& D$ for nuclear utilities to move forward with modernization. These key issues include defining the end-state digital architecture, developing the business case for implementation, addressing licensing process burden, technical and developing implementation schedules compatible with short refueling outages. 
In addition to addressing the challenges associate with a modern I\&C infrastructure, there have been no large-scale changes to the layout or function of LWR control rooms. Nuclear utilities have understandably been reluctant to undertake significant control room upgrades or modernization projects in consideration of cost, regulatory risk, and impact on the large investment in procedures, training programs, and other support functions accompanying large upgrades. Also, there is a general desire to retain the high degree of operator familiarity with current control room arrangements, and thereby avoid potential human performance issues associated with control board configuration changes.

Nuclear utilities constantly strive to improve operator performance, and in particular address performance weaknesses identified as contributors to plant safety challenges. This usually takes the form of enhancements to operator performance protocols and expected behaviors. The difficulty with this approach lies in trying to correct human performance deficiencies with additional expectations, which can never entirely eliminate the effects of human variability. There is no question that technology is underutilized in control rooms as a means of enhancing operator performance. Many other safety-critical industries, notably aviation, have made effective use of advanced digital technologies to improve operations and safety, without supplanting the role of the operator (or pilot) as the ultimate authority and decision-maker.

Introducing digital systems into control rooms creates opportunities for improvements in control room functions that are not possible with analog technology. These can be undertaken in measured ways such that the proven features of the control room configuration and functions are preserved, while addressing gaps in human performance that have been difficult to eliminate. By applying human-centered design principles in these enhancements, recognized human error traps can be eliminated and the introduction of new human error traps can be avoided.

Digital technology introduction provides an opportunity to enhance human performance in the control room. The process of designing and implementing digital control room technologies to replace analog systems serves as an opportunity to implement human-centered design activities throughout the various stages of design, acquisition, and implementation. These design activities and their technical bases (human factors design standards and cognitive science research) were not available at the time of the original design of main control rooms. Considerable progress has been made in these fields since the completion of the industry's response to the Three Mile Island-2 Action Plan, which requires a human factors approach to control room changes. Replacement digital technologies having more powerful and flexible graphical and informatics capabilities, together with a substantially improved understanding of how to leverage these capabilities to support effective human performance, afford the opportunity to realize a more human-centered main control room. This does not require a full-scope approach to control room modernization, such as refurbishing or replacing an entire main control room as a single engineering project. Rather, it can be accomplished through gradual and step-wise-related projects that are carried out when digital I\&C systems are implemented to replace analog I\&C systems to address near-term reliability and operational needs. These types of enhancements can be performed anytime in the life cycle of the main control room and can add to the business case for implementing digital I\&C.

Pilot projects have been defined to develop the needed technologies and methodologies to achieve performance improvement through incremental control room enhancements as nuclear plant I\&C systems are replaced with digital upgrades. These pilot projects are targeted at realistic opportunities to improve control room performance with the types of digital technologies most commonly being implemented, notably distributed control systems and plant computer upgrades. 
This work employs HSSL as a test bed providing a realistic hybrid control room simulation (refer to Section 3.2) for development and validation studies as part of the pilot projects. In addition, the Plant Modernization research program has an agreement in place for access to control room upgrade technologies developed by the Halden Reactor Project, which has played a key role in several of the European control room upgrades. The Plant Modernization research program is well-positioned to provide enabling science for U.S. hybrid control rooms control room enhancements.

\subsubsection{Control Room Modernization}

More and more digital conversions of analog I\&C systems will be undertaken by U.S. nuclear utilities as concerns over reliability and component aging continue to accrue. These new systems typically come with advanced operator interfaces that are quite different than the analog control devices of the legacy systems. This raises the questions of how to incorporate the new technology into the existing control room and what the impact on operator performance and regulatory requirements will be. One strategy has been to preserve the same operator interfaces of the old analog controls with the same or similar board-mounted discrete control and indication devices in lieu of modern HSIs. While this has minimized the cost of changes to the conduct of operations (e.g., procedures and training), it has diminished the value and potential benefits of the digital technology.

In other cases, dedicated HSI have been incorporated into the control boards in the general area where the former analog controls were located. However, this has sometimes introduced different types of operator interfaces, such as integrated flat-panel displays, large-screen overview displays, touch panels, track balls, a standard computer mouse, and multiple keyboards. Obviously, this impacts control room human factors and can result in undesirable or unanticipated changes to operator and team performance if not properly implemented. Further, nuclear utilities plan to implement these modifications over an extended period of time, which will result in a progression of interim hybrid control room states mixing analog and digital HSIs in different proportions. Each of these interim states must be evaluated from a human factors perspective to ensure that operator performance is not diminished.

Therefore, the prospect of multiple, disparate digital interfaces in a hybrid control room will drive the need to readdress control room layouts in a more holistic manner to provide operators with a consistent, uniform interface for various digital systems. Such upgrades will involve significant human factors research and development to be performed to provide the needed technical bases for regulatory submittals.

It is imperative that control room upgrades reflect the correct application of human factors principles. Expertise in human factors has been substantially lost in nuclear utility staffs since the days of completing the Three Mile Island-2 Action Plan in the late 1980s. Furthermore, the understanding of human-factors has substantially improved since that time and regulatory requirements and guidance have continued to evolve. DOE maintains considerable expertise in human factors research and application and has the capabilities of the HSSL to develop and validate design methods and technologies for control room modernization, including requirements for safety-related systems (Figure 8). DOE collaborates with leading international efforts such as those conducted by the Halden Reactor Project to leverage the expertise in modernizing control rooms that has been developed in other countries and, in particular, those that have been undertaken in Europe. 


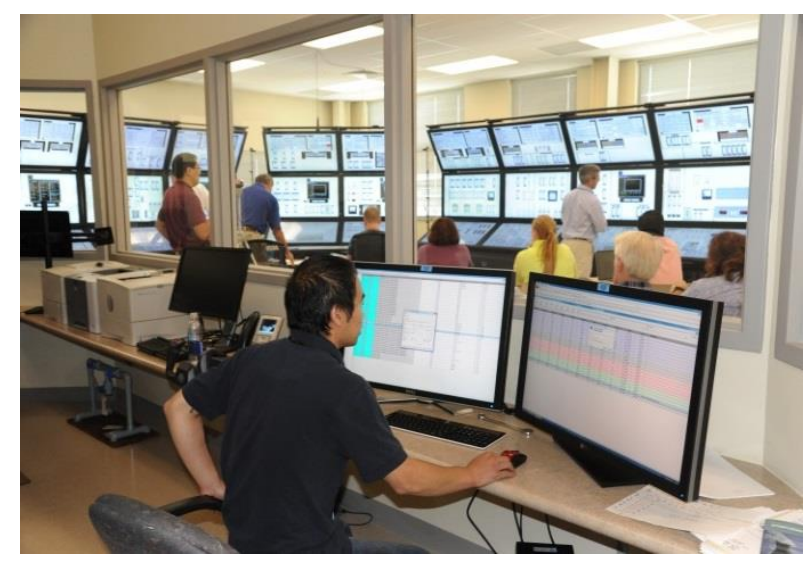

Figure 8. Advanced hybrid control room studies in the HSSL.

This pilot project will develop principles that can be used in guidelines for design and layout of a modernized analog control room and standardized operator interfaces, according to human factors' engineering principles. It will develop standardized operator interface displays and control board layout guidelines based on human factors engineering principles and regulatory guidance.

A reference human factors engineering plan will be developed for control room modernization for use by industry based on the practical knowledge gained in this pilot project. It will involve workshops conducted in the HSSL with utility-licensed operators to address human factors issues such as workload, situation awareness, and changes to the conduct of operations through changes in humans system interface and the re-allocation of functions between operators and systems. These activities will lead to the ability to conduct integrated system validation, which looks at the total effect of hardware, software, and human factors changes to ensure that desired outcomes are indeed obtained without introducing undesirable factors.

Work in this demonstration project is being conducted with a major focus on collaboration with Duke Energy in applying human factors to control room upgrades for the Brunswick, Harris, and Robinson Nuclear Stations. This work involves developing new techniques and methodologies for applying human factors to control room upgrades in the Planning and Analysis Phase, Design Phase, and Verification and Validation Phase of NUREG-0711. [18] These methods employ the HSSL to measure human factors aspects of new I\&C systems and associated HSIs through direct observation of operators performing plant evolutions on realistic simulations of proposed control room changes. Certain portions of this project will result in proprietary documentation for Duke Energy, which will be accomplished through cost-recovery contractual arrangements as associated work with the pilot project. However, the general information gained from these efforts will be published for industry use as a part of the pilot project milestone reports. It is anticipated that similar collaboration of this nature will be conducted with other nuclear utilities where there are additional aspects of control room human factors to be developed or where it is advantageous to assist the industry with control room modernization.

This research will develop new display and information technologies for control room operator use to improve control room operator response. The transition from analog to digital systems through control room modernization efforts enables the development of new technologies and information that can be used to guide control room operator performance by integrating new data sources and providing decision support and operator aids. Digital technology also provides the opportunity to reduce costs cost by automating or streamlining manual processes. Alarm management and procedure use and adherence have been two of the key human and technology challenges identified in existing analog-technology based main control rooms. They have been a source of human performance challenges since the accident at Three Mile Island Unit 2, and current technologies result in a large number of control room staff required to safely operate a NPP control room. 
Schedule: FY 2011 to FY 2025

Remaining Project Milestones:

- (2019) Develop and demonstrate advanced operator interfaces for advanced alarms and taskbased overviews in the HSSL.

- (2019) Evaluate advanced operator interfaces for advanced alarms and task-based overview in Operator workshops with the partnering utility.

- (2019) Develop the decision making criteria and process for assessing options between sustaining obsolete I\&C vs incremental or integrated I\&C upgrade.

- (2020) Develop a strategy to introduce computer based procedures into the control room.

- (2021) Demonstrate the strategy to introduce computer based procedures into the control room.

- (2022) Develop a compact operator console to support seated operation.

- (2023) Demonstrate a compact operator console to support seated operation.

- (2024) Develop a conceptual plant interface for operators to interact with support processes.

- (2025) Demonstrate the conceptual plant interface for operators to interact with support processes.

\subsubsection{Full Nuclear Plant Modernization}

Digital upgrades are needed because analog systems, although still reliable, have reached the end of their useful service life. Projects are being conducted with nuclear utilities to evaluate the impact of these upgrades. Utilities operate in substantially different market settings that in turn, affects the business case and decision-making for conducting these types of capital investment projects. The research is working with first-movers in the nuclear sector to address legacy analog technology issues of reliability, obsolescence, as well as to enable improved operator and plant performance. This will demonstrate the feasibility and benefits of control room modernization to other commercial nuclear operators, suppliers, and industry support community. Together, these pilot projects will provide data and results that are representative for the majority of the U.S. operators who face I\&C aging and pending obsolescence concerns, and who can benefit from a longer-term, staged analog replacement approach to obsolescence management that is planned and strategic - with an end state in mind - rather than piecemeal approaches, necessitated by immediate replacement needs of aging systems.

These projects will also help resolve some of the legacy I\&C technology issues that may impact the long-term operation of the LWR fleet. LWRS program researchers apply state-of-the-art standards, guidance, and principles to evaluate planned digital upgrades. This research also uses the Human Systems Simulation Laboratory and employs a variety of data collection methods to form a technical basis for decisions to reduce risk and regulatory uncertainty. This research and its findings will be used to address the human factors aspects of LWRS control room modernization. The objective of this research is to enable large scale control room modernization efforts. U.S. owner-operators face unique challenges that heavily influence plans to modernize. The Plant Modernization pathway is partnering with nuclear utilities in several separate large-scale, long-term control room modernization projects and will leverage these various collaboration opportunities to conduct research on a spectrum of technical and regulatory issues key to control room and plant modernization. Information will be captured and this knowledge and technology will continue accruing to the benefit of the entire operating nuclear fleet as more and more plants undertake needed analog I\&C technology replacement.

To mitigate the substantial technical, financial, and regulatory risks for modernizing the control rooms for a fleet of plants, the LWRS Plant Modernization Pathway will seek to partner with a nuclear 
utility in a deregulated market to perform a Fleet-Based Control Room Modernization Design Project. The purpose is to assist a utility that owns a large fleet of plants in addressing legacy analog technology issues of reliability, and obsolescence, as well as to enable improved operator and plant performance. An additional goal is to consider the differences that must be addressed for fleets operating in merchant markets where different decision factors weigh on investment decisions, and to demonstrate methods and techniques for modernization and investment in NPPs in these settings. This will demonstrate the feasibility and benefits of control room modernization to the commercial nuclear operators, suppliers, and industry support community. This project will be a major step in resolving legacy I\&C issues that potentially impact long-term sustainability of the LWR fleet.

The Plant Modernization project commitment will be a significant cost contribution over several years, with similar utility, nuclear steam supply system supplier, distributed control system vendor cost-share. In addition, the Plant Modernization Pathway will commit facilities, such as the HSSL and expert staff, to participate in this project. The Plant Modernization Pathway, with participating collaborators, will work with the utility to develop one or more end-state control room concepts. International and domestic experience would be leveraged in developing the concepts though current associations (e.g., Halden, EPRI, and domestic new builds). DOE facilities at INL will be used to develop and validate the design concepts, including the reconfigurable control room HSSL simulator, the virtual reality laboratory, and three-dimensional design and ergonomics software.

Future end-state concepts will be developed for conceptual design to determine a cost estimate and work scope for implementing the modernized control room. INL and the utility partner will collaborate to determine what modifications will need to be made to the existing I\&C and control room. This design will be scoped to take advantage of the capabilities of the digital upgrades for current and future I\&C systems to enhance the business case for the modernization effort. Implementation planning will also be conducted to determine the various transition states for the control room, as well as human factors considerations for these intermediate states. Finally, a business case will be developed that captures the cost and operator performance improvements resulting from the modernized control room.

DOE and partner utilities will conduct broad collaboration in research, development, and demonstration activities for nuclear plant modernization that addresses critical I\&C infrastructure modernization issues.

\section{Schedule: FY 2017 to FY 2023}

Remaining Project Milestones:

- (2019): Develop the strategy for full nuclear plant modernization with a participating utility based upon digital technologies that demonstrates a sustainable plan and approach for efficient long term plant operation and risk informed asset management.

- (2019): Develop a digital I\&C architecture design and approach for managing the transition of legacy analog I\&C to new advanced digital I\&C that effectively addresses human factors concerns, cost and regulatory considerations.

- (2019) Develop the human factors engineering technical bases that support approaches to plant modernization of main control room and plant systems.

- (2019): Results of Human Factors Engineering Planning and Analysis Activities to Support Full Nuclear Plant Modernization.

- (2020) Development of a Requirements Document Describing the Integration of Multiple I\&C Domains.

- (2020) Development of a Prototype I\&C Infrastructure on a Simulator Platform to demonstrate completeness of identified requirements. 
- (2021) Perform Cost-Benefit Analysis for Full Plant Modernization to support LWR fleet modernization efforts.

- (2021) Perform Analyses to Identify Technical Input Required for Regulatory Licensing Changes.

- (2022) Based on the research, complete developing a prototype I\&C infrastructure that improves operational performance, reduces human error, and potentially enables reductions in operations shift staffing. The operations training simulator software load will be installed on the reconfigurable simulator in the DOE HSSL to develop a prototype that will support further research in operator human factors studies in order to optimize the control room concept and realtime diagnostic and prognostic functions for decision-support in addressing safety and operational threats.

- (2023) Develop a concept for integrating the I\&C architecture into a seamless digital environment that enables wide-spread automation and process efficiencies across the plant support functions. This integration strategy will be consistent with all design and regulatory bases (including cyber security). It is envisioned that many collateral plant support duties of operators will be significantly streamlined if not entirely automated.

\subsubsection{Digital I\&C Qualification}

A significant barrier to nuclear plant modernization is the qualification of digital $\mathrm{I} \& \mathrm{C}$ systems for safety-significant applications. Qualification refers both to the technical and regulatory acceptability of the use of digital technology, in view of such issues as software quality and software common cause failure (CCF). Nuclear utilities have expressed reluctance to pursue these system upgrades until qualification methods are established that reduce the current level of financial and regulatory risk of license amendments that would permit their usage.

Research will be conducted into methods for developing the technical basis for qualifying safety related I\&C intended to be used in regulatory-approved applications. This research will utilize representative near-term technologies as well as propose future technologies and develop the means to demonstrate their licensing and qualification for safety-related applications (i.e., Class $1 \mathrm{E}$ systems) in commercial nuclear power systems. The initial candidate qualification method is exhaustive (100\%) testing of a simple digital component, such as a digital transmitter. The NRC considers exhaustive testing (or "testability" as the NRC terms it) to be one of two design attributes sufficient to eliminate consideration of software-based or software logic-based CCF (the other one being diversity).

Technical qualification of safety-related $I \& C$ systems is one aspect of a complex and interrelated set of issues that must be addressed for nuclear utilities to move forward with implementation. Other issues include the business case, licensing process burden, technical and human change management, cyber security, and implementation sequences compatible with short refueling outages. A number of nuclear industry organizations are now engaged in developing a viable path for implementing safety-related I\&C systems. These include the nuclear utilities, the NEI, the EPRI, the INPO, and the nuclear supplier community. In addition, the NRC has developed an Integrated Action Plan to modernize the digital I\&C regulatory infrastructure as a means of addressing regulatory barriers (and associated costs) for digital upgrades. Based on this collective industry focus, some nuclear utilities are now expressing interest in moving forward with safety-related digital I\&C implementations under the assumption that these barriers can be resolved within a reasonable time frame.

To enable an industry approach to plant modernization, a strategy is being developed for implementation of safety-related digital I\&C systems. This strategy is defined in terms of end-state architecture, operations and maintenance cost benefits, regulatory approach, and optimum implementation sequence. The strategy will identify research and development priorities for new methods in qualifying these systems, with the testability qualification method being the first such new method, if proven to be successful. 
The major activities of this project will be to:

- Conduct research and development activities on one or more methods that enable the technical qualification of safety-related digital I\&C systems. These will be selected from a prioritized list reflecting industry input on near-term value to the nuclear utilities.

- Identify future technologies and methods that would reduce burden and improve technical results in the qualification of safety-related digital I\&C systems.

- Conduct a pilot implementation of the developed method with an industry partner for the technical qualification of safety-related digital I\&C systems. Assess the effectiveness of the method and make recommendations for improvements.

- Develop R\&D plans for additional potential qualification methods that nuclear industry review confirms value for safety-related digital I\&C systems.

Schedule: FY 2018 to FY 2020

Remaining Project Milestones:

- (2019) Analyze test results from the a demonstration of digital device testability

- (2020) Conduct a pilot implementation for safety-related digital I\&C systems qualification.

\subsubsection{Instrumentation and Control Infrastructure Modernization}

The nuclear power industry is continuously challenged by an aging and often obsolete I\&C infrastructure. The industry relies heavily on 1980s technologies, which only provide a minimum level of functionality and introduce sustainability challenges. I\&C technologies available and commonly used in other industries introduce capabilities directly reducing the maintenance costs in power plants. Implementation of modern I\&C is hindered by the current I\&C infrastructure. The challenges of I\&C infrastructure modernization are associated with quantifying the value of the upgrade, resolving technical challenges, minimizing the impact on the plant operation, and meeting regulation requirements. This project will focus on the technical challenges of the I\&C infrastructure upgrade. Specifically, these challenges include:

- Obsolescence of components and the path to replace them with modern I\&C

- Compatibility of hybrid digital and analog I\&C infrastructure

- Modern systems interconnectivity and interfacing options

- Interference impact of the plant on the new I\&C technologies

- Use of modern instrumentation such as foundation field bus instruments

- Adequacy of knowledge and documentation and means to address the lack of necessary infrastructure knowledge

- Spare parts stocking strategy

- Migration of minor changes processes

- Digitization of control functions and control decentralization

- Automation of the validation and verification of the upgrade

- Collateral issues that arise during an I\&C infrastructure upgrade. 
The project identifies the current state of the art of I\&C infrastructure upgrade practices and methods in other industries, leverages other industries' experience, identifies nuclear-specific I\&C infrastructure modernization obstacles, and develops solutions to overcome these obstacles.

Schedule: FY 2019 to FY 2021

Remaining Project Milestones:

- (2019) I\&C Hardware Architecture recommendation for NPPs based on evaluation of current I\&C infrastructure modernization practices in other industries.

- (2019) Decision making criteria and process for assessing options between sustaining obsolete $\mathrm{I} \& \mathrm{C}$ and performing incremental or integrated I\&C upgrades.

- (2020) Technology to overcome an obstacle of modernizing I\&C infrastructure of a NPP.

- (2021) Technology to overcome an additional obstacle of modernizing I\&C infrastructure of a NPP.

\subsubsection{Computerized Operator Support Systems}

Situational awareness is critical to the safe operation of NPPs. It requires an accurate understanding of the current plant state and operating configuration, the intricacies of the plant process and control systems, the physics of the plant processes (i.e., nuclear, thermal, fluid, and electrical), and the current operating margins with respect to safety and regulatory limits. Today, this enormous amount of information has to be mentally integrated by the operators to arrive at an accurate understanding of how the plant is operating and where it is headed. This is a daunting task for even the most experienced operators and could become a significant concern in the future as a wave of new operators replaces the aging nuclear workforce.

As more and more plant information becomes available in a digital form, it will be possible to provide operators with advanced information systems that aid in assessing current plant status, safety margins, and deviations from expected operations. Through advanced simulation techniques, it will be possible to predict where the plant is going operationally and how long operators will have to intercede in undesirable plant trends.

A computerized operator support system is a collection of capabilities to assist operators in monitoring overall plant performance and making timely, informed decisions on appropriate control actions for a projected plant condition. It could contain the following features [19]:

- Advanced nuclear, thermal-hydraulic, and electrical models to assess actual plant performance relative to predicted plant performance and report deviations and trends to operators. It could also use directly measured parameters and derived parameters to analyze plant performance. It could distinguish between real plant performance deviations and those due to failed instruments.

- A faster-than-real-time simulator that could predict the effect of operator actions prior to those actions being taken. This would detect interactions that might not be apparent to the operator due to unusual plant configurations and other operating restrictions. It could project the timing of the gradual effect of actions on reactor power, such as boration and dilution. Depending on the fidelity of the simulator, it could be very helpful in off-normal conditions where emergency procedures cannot anticipate every combination of component unavailability.

- Learning systems that become more robust as they experience a wider variety of operational conditions. This would include systems employing advanced algorithms to monitor sensors and other inputs to perform monitoring of plant and subsystem performance. 
- Continual reinforcement of training within the control room by providing direct reference to training material when it would not be a distraction to operational duties. This form of embedded training has been used elsewhere in other industries (notably aviation) with beneficial effect.

This pilot project conducts research to build these aggregate plant models and connect them to current and new advanced sensors to obtain precise measurements of current operating parameters. These models will be validated against actual plant performance at a host utility's NPP. They will be refined until they produced an accurate picture of a plant's operating state and degree of deviation from expected performance.

It should be noted that this project will require a substantial cost-share on the part of the host utility. DOE's responsibility in the project will be to provide the computerized operations support system platform suitable for testing and demonstration. However, the largest portion of the work will be in modeling the host utility NPP to a degree of detail that will provide useful information to the operators. This would be the responsibility of the host utility.

Schedule: FY 2020 to FY 2024

Remaining Project Milestones:

- (2020) Develop concepts for using NPP full-scope simulators as operator advisory systems in hybrid control rooms and complete a technical report on prototype demonstrations in the HSSL.

- (2021) Develop concepts for a real-time plant operational diagnostic and trend advisory system with the ability to detect system and component degradation and complete a technical report on prototype demonstrations in the HSSL.

- (2022) Develop an operator advisory system fully integrated into the HSSL control room simulator that provides plant steady-state performance monitoring, diagnostics and trending of performance degradation, operator alerts for intervention, and recommended actions for problem mitigation, with application of control room design and human factors principles.

- (2023) Develop an operator advisory system that provides plant transient performance monitoring with operator alerts for challenges to nuclear safety goals.

- (2024) Develop an end-state vision and implementation strategy for an advanced computerized operator support system, based on an operator advisory system that provides real-time situational awareness, prediction of the future plant state based on current conditions and trends, and recommended operator interventions to achieve nuclear safety goals.

\subsubsection{Future Concepts of Operations}

Control room staffing and protocols for the current LWR fleet are based on operational concepts that go back to the beginning of the industry. Staffing is generally sized to handle plant emergencies. Operational concepts employ protocols maximizing command and control, rigorous formality, and operator attention-to-detail. They mandate minimum staffing present in the control room due to the need for physical proximity to information displays and controls. These protocols are absolutely essential today because the operator is the point of integration for information about the current operating state of the plant.

While this operating model has been very successful in safe and productive operation of the LWR fleet, it drives a number of inefficiencies in staffing because operators who are monitoring plant systems generally cannot be involved in other activities. Therefore, additional operators are required for work management functions, system tag-out developments, plant rounds and field operations, and monitoring special processes such as reactor refueling or dry cask storage loading. 
In the future, it will be possible to gain significant efficiencies by employing new concepts of operation made possible by the combined technologies for control room upgrades and enhanced operator performance. Specifically, there could be a reduction in the number of operators who are required to be either onsite or in the control room on a continual basis. In addition, operating protocols could be substantially more flexible in allowing operators to conduct auxiliary tasks while maintaining adequate situational awareness of the operating units while being immediately available to take necessary control actions.

These future concepts of operations may alleviate the need for as large a physical presence to effectively control the plant; the new levels of automation may relieve the operators of performing tedious diagnosis and control functions, enhancing their roles to one of oversight of plant protection and control systems and intervening only as needed.

There are strong precedents for this concept in aviation today. For example, with current flight control technology, pilots do not have to actually be in the cockpit to fly an airplane. Unmanned aerial vehicles have systems that can perform real-time flight control functions by responding to broader directions and objectives given by a remote pilot. A similar concept is employed in virtually all modern aircraft cockpits, where the flight controls, throttles, avionics, and navigation systems are coupled under a flight management system that automatically directs the flight according to the flight plan and pre-determined instructions of the pilot, freeing the pilot to stay in an oversight mode of ensuring all systems are operating correctly and the flight is proceeding as planned.

The idea of using technology to reduce control room staffing or to permit plant control from outside the control room using advanced display and communication technologies will be highly controversial, notwithstanding the potential efficiency gains. This concept will run against the grain of deeply held beliefs on the conduct of nuclear operations. However, there is already a provision for some of the control room staff to be out of the control room provided they can return within a set time (e.g., the shift technical advisor). Therefore, with no additional risk imposed, this concept can first be validated by giving these technologies to control room crew members that can already be out of the control room to determine their effectiveness in increasing situational awareness while away. The concept can slowly evolve from there as experience and human factors studies determine whether there are efficiency gains without undue concerns over loss of effectiveness of the control room crew.

These technologies and capabilities would include the following:

- Portable interface devices (e.g., tablets and heads-up displays) providing continual plant status and control capability anywhere in the plant.

- New control capabilities automating large operational sequences such as power maneuvers and putting systems into service. Further, they could diagnose and manage (without manual operator actions) the early portions of transients and accidents for the time required for operators to return to the control room. These capabilities can transform required operator actions from long sequences of individual control actions to broad, high-level objective commands (e.g., "place alternate letdown in service").

- Computerized operations support systems detecting deviations and trends very early and provide much more response time to operators to react to and intervene in the situation.

- Ability of qualified operators to assist with certain tasks from where they are (i.e., at home, in remote parts of the plant facility, or at a sister nuclear unit).

- For operators in the control room, technology would enable them to participate in activities that today would require them to be present in other parts of the facility (e.g., pre--job briefings). This capability would rely on real-time video, collaboration tools, and virtual meeting software to allow participation in these activities from their normal operating station. 
The Halden Reactor Project is already experimenting with high-fidelity control room displays on portable devices (such as digital tablets) to study potential improvement in situational awareness for operators temporarily away from the control room. This effort, and other similar research studies, will provide insight into how these technologies can safely be used by control room crews.

This project will assess the capabilities beneficial to an updated control room and develop concepts for operating the nuclear unit in a more flexible and efficient manner. This will include a minimum presence of staffing in the control room, assessment of the control room workload based on advanced technologies, and flexibility for crew members to conduct activities outside the control room while remaining "in-the-loop" through the technologies. A human factors study of crew dynamics would be conducted and would focus on collective situational awareness.

Other future concepts of operation would be explored, with the objective to enhance how the control room interacts with special-purpose control centers such as the OCC, work execution center, technical support center, operational support center, and the emergency operations facility.

Schedule: FY 2022 to FY 2025

Remaining Project Milestones:

- (2022) Complete a technical report on operator attention demands and limitations on operator activities based on current conduct of operations protocols. This report will identify opportunities to maximize operator efficiency and effectiveness with advanced digital technologies.

- (2023) Develop and demonstrate prototype mobile technologies for operator situational awareness and limited plant control capabilities for NPP support systems in the HSSL (e.g., plant auxiliary systems operations and remote panel operations).

- (2024) Develop and demonstrate new concepts for remote operator assistance in high activity periods (e.g., refueling outages) and accident/security events in the HSSL, allowing offsite operators to remotely perform low safety-significant operational activities, freeing the control room operators to concentrate on safety functions.

- (2025) Develop validated future concepts of operations for improvements in control room protocols, staffing, operator proximity, and control room management, enabled by new technologies providing mobile information and control capabilities and the ability to interact with other control centers (e.g., emergency response facilities for severe accident management guidelines implementation).

\subsubsection{Advanced Plant Control Automation}

Because of the pervasive analog I\&C technology in NPPs today, much of plant control is conducted by operators manually manipulating a large array of discrete control devices. The exceptions to this include the process control system for the reactor coolant system, heat transfer (steam generators for pressurized water reactors), and turbine-generator controls for power production. Also, the emergency core cooling system is typically auto-started on certain emergency signals, but has to be manually adjusted as the accident mitigation sequence progresses. Other plant systems are largely reliant on manual operator actions for normal and emergency operations.

In converting manual operator actions to plant control automation, nuclear safety and plant production can be enhanced by reducing the opportunity for human error. Further, this results in improved situational awareness for the operator, maintaining more of an oversight role of changing plant conditions and automatic control system performance.

Building on work from the pilot project on automating manually performed plant activities, especially the portion concerning conversion of stand-alone control loops to digital technologies, it is possible to implement a distributed control system in a way that automates large sequences of commands to relieve 
the operators of tedious plant manipulations. This concept also involves converting some manually operated components to automatic functions.

Priorities for advanced plant control automation concepts would be those activities that are frequently performed, time and attention -intensive for the operators, and entail some nuclear safety or production risk. Examples of such activities include:

- Performing plant heat-ups and cool-downs

- Automated managing of plant transients

- Swapping operating trains where there are redundant systems

- Aligning systems to their test configuration

- Placing systems into service

- Conducting in-service maintenance activities such as backwashes of strainers.

Human factors evaluations would be a key element of this project because there are significant concerns on how this level of automation will affect operator skills and knowledge. Operator performance studies would be run in the HSSL to address the following issues:

- Would an over-reliance on the automation technology be created so operators would not maintain the skills necessary for performing the actions manually if the technology failed?

- Would operators have a sufficient understanding of what the automated systems were doing throughout any automated plant evolution?

- Would operators lose focus in monitoring the plant during long sequences of automated control?

- Would operators immediately recognize a control system failure even when there was no significant plant excursion?

Working with a host utility NPP, this project would use the HSSL to develop a prototype of plant control automation to conduct human factors studies to answer these questions. The project would develop a prioritized list of plant control functions to be included in an advanced plant control implementation for a first-mover NPP. Also, the project would develop a technical report for applying advanced plant controls in a manner consistent with human factors principles as validated in project studies.

\section{Schedule: FY 2022 to FY 2025}

\section{Remaining Project Milestones:}

- (2022) Develop concepts for advanced control automation for control room operators based on human technology function allocation developed in the pilot project for automating manually performed plant activities. Publish a technical report on candidate applications for automation reflecting design and human factors principles.

- (2023) Develop and demonstrate prototype plant control automation strategies in the HSSL for representative normal operations evolutions (e.g., plant start-ups and shut-downs, equipment rotation alignments, test alignments).

- (2024) Develop and demonstrate prototype plant control automation strategies in the HSSL for representative plant transients (e.g., loss of primary letdown flow or loss of condensate pump).

- (2025) Develop the strategy and priorities and publish a technical report for automating operator control actions for important plant state changes, transients, and power maneuvers, resulting in 
nuclear safety and human performance improvements founded on engineering and human factors principles.

\subsection{Online Monitoring and Plant Automation}

As NPP systems begin to be operated during periods longer than originally anticipated, the need arises for more and better types of monitoring of material and component performance. This includes the need to move from periodic, manual assessments and surveillances of physical components and structures to centralized online condition monitoring. This is an important transformational step in the management of NPPs. It enables real-time assessment and monitoring of physical systems and better management of active components based on their performance. It also provides the ability to gather substantially more data through automated means and to analyze and trend performance using new methods to make more informed decisions regarding maintenance strategies. Of particular importance will be the capability to determine the remaining useful life (RUL) of a component to justify its continued operation over an extended plant life.

The current technology base for monitoring in the U.S. nuclear industry consists of signal processing techniques and advanced pattern recognition (APR) programs that are technically mature and commercially supported. The application of advanced analytics is in the early stages of implementation by leading nuclear utilities. The implementation rate has been slow due to the required funding and infrastructure development for integrating monitoring programs within the operating and business environment.

APR provides highly sensitive anomaly detection of current condition or behavior for targeted components. Much of the value of OLM comes from early warning of imminent component failures. Commercial APR products rely on the continuous input of well correlated- plant data to provide this early warning. (These products typically have been applied only to active plant components). After the initial warning, the plant support staff conducts an investigative review to identify the actual failure mode and cause, and then suggests appropriate corrective actions. The review can involve many onsite operations and technical staff, consultants, and field experts in achieving a maintenance strategy. In these cases, the diagnostic process is manually intensive, consuming available warning time and potentially extending damaging operating conditions. While APR systems are effective at identifying equipment operating im conditions that may shorten the equipment's RUL, they are limited to identifying operating data values that are "not normal" in comparison to a historical baseline. Commercially available APR products cannot perform the next essential step of diagnosing the underlying cause for the abnormal data values. This diagnosis step relies entirely on a staff of highly trained specialists to troubleshoot and diagnose the underlying problem and to recommend a corrective action response. Furthermore, the RUL of the monitored asset cannot be determined by APR technology. In addition, there are long term failure modes that are not detectable with APR technology, and APR systems cannot incorporate or influence business analytics. Hence, current APR products are not suitable for long term- monitoring and management of nuclear assets and, in particular, for passive assets evaluated on an intermittent basis using nondestructive evaluation measurement techniques.

The development and advancement in diagnostic and prognostic capabilities is required to achieve an automated ability to directly identify equipment condition from initial warning signatures. This will support analysis of long term-component behavior, related risk, and RUL. It will further provide verification of asset condition as evidence of design qualification and economic viability.

Advanced and digital monitoring technologies will enable early detection of degradation conditions that can be addressed before they significantly contribute to life-limiting damage. The early detection of degradation is one of the more significant factors in extending a component's lifetime. A more timely response to the causes of degradation also can significantly improve nuclear safety and prevent collateral damage to other nearby components and structures. Finally, these new capabilities will reduce the cost of manual diagnostic work. 
Therefore, a gap exists between the current state of technology development and the effective application of diagnostics and prognostics to nuclear plant assets. To address this gap, the following research tasks have been defined:

1. Develop a monitoring infrastructure at the operating and management levels of the nuclear power industry.

2. Develop an organizational structure that defines the contributing research organizations, their roles, resource availability, and utility hosts. This includes EPRI, national laboratories, universities, utilities, and technology developers.

3. Continue R\&D of the diagnostics and prognostics technology for adaption to the nuclear power industry.

4. Develop the structure-specific models, component-specific models, analytical methods, and the supporting data requirements needed to enable diagnostics and prognostics analysis.

5. Obtain access to the real physical assets in service in an NPP and determine the critical measurements needed to support the analysis.

6. Develop additional monitoring methods (such as transient analysis) to support RUL analysis.

7. Identify environmental conditions detrimental to aging mechanisms, including fatigue monitoring and assessment.

8. Identify component-specific failure and aging mechanisms/precursors.

9. Identify measurement and sensor requirements to support analytical methods.

10. Develop an end-to-end digital data architecture to enable effective use of heterogeneous data to streamline advanced analytics and visualization of information

11. Research and develop information visualization capabilities to ensure the right information is available to the right personnel in the right format at the right time to support informed decision making.

An effective means to accomplish portions of the above research tasks is through the conduct of pilot projects. These projects will be structured around a narrowly defined set of objectives to accomplish specific tasks requiring access to real-time plant assets and operational data. There are significant limitations to benchtop modeling and scaled-down component behavior analysis in the progression of technologies from proof-of-concept to real-world- component applications. The utilization of real physical components and operational data is required to develop technologies beyond the laboratory. The process of applications engineering and research is not within the capabilities of the utilities or the engineering staff at NPPs. Host utilities are required to support the needed research to provide access to major components in actual service.

EPRI provided a lead role in establishing OLM capabilities through their continued development and support of the Fleet-Wide Prognostic and Health Management (FW-PHM) Suite software, in addition to their other OLM research activities. The Plant Modernization Pathway has supported EPRI by conducting pilot projects to develop the diagnostic and prognostic analytical framework for representative active assets.

It is expected that utilities will find that a central monitoring function will be the most efficient way to implement this technology in the nuclear fleet. Indeed, this has been the practice of some of the early movers for OLM using the APR technology. This concept work for centralized monitoring will be accomplished through the pilot project on the advanced OLM center (as described in Section 5.2.7). The Plant Modernization Pathway will also serve the role of integrating the OLM information into the overall digital information architecture such that it will provide needed information to other plant activities. 
Within the theme of centralized monitoring, many industries have taken advantage of new digital technologies to consolidate operational and support functions for multiple production facilities to improve efficiency and quality. This concept is sometimes referred to as integrated operations. Mainly, it uses technology to overcome the need for onsite support, thereby allowing the organization to centralize certain functions and concentrate a company's expertise in fewer workers. These workers, in turn, develop higher levels of expertise because they are exposed to a larger variety of challenges and issues than if they supported just a single facility. It allows them to outsource functions, where beneficial, while maintaining immediate access to the services even if the services are provided remotely. The concept also enables standardized operations and economy of scale in maintaining a single organization instead of duplicate capabilities at each location.

One of the examples is the Halden Reactor Project, which has been quite active in this concept for Norwegian off-shore oil platforms. The oil companies have developed integrated operations to move large parts of their platform operations and support functions to centralized on-shore locations. This has resulted in dramatic improvement in the efficiency, economy of operations and the quality of life for participating workers. While there remains a need for sufficient staff on the platforms to conduct the hands-on work, virtually any activity that can be controlled or monitored through a digital system is a candidate for integrated operations.

Likewise, for years, airlines have maintained centralized flight monitoring centers, recognizing the impracticality of providing this as an onboard service. Data links are used to stream in-flight performance data to the centers, where they are monitored by systems experts. The experts can then confer directly with the pilots on any immediate operational concerns. Otherwise, minor issues can be documented and addressed at the next convenient opportunity.

NPPs have a similar opportunity to improve support functions by developing an integrated operations concept. Indeed, some steps in this direction have already been taken by utilities that have implemented a centralized OLM center for plant components equipped with remote monitoring capability. However, there are many more opportunities to consolidate support services across the fleets using digital technologies that enable work to be performed just as effectively as if it were onsite. Furthermore, the concept can extend beyond the utility organization to create seamless interfaces with suppliers, consultants, and original equipment manufacturers. In this way, an operating company could build a virtual organization of trusted partners rather than providing all services in-house.

\subsubsection{Online Monitoring of Active Components}

A pilot project will be conducted involving three active components representative of those for which extended life is highly important to LWR sustainability. The components are emergency diesel generators and large power transformers and induction motors.

The objective will be to develop the diagnostic and prognostic analysis framework for these components, including the ability to predict RUL. These capabilities will enable industry to implement OLM for these components and will establish the methodology for industry to extend the concept to other active plant components where aging and degradation mechanisms must be managed for extended life.

Using EPRI;s FW-PHM suite software, the pilot project will develop the databases and analytical models needed to process sensor signals to identify specific component degradation and fault conditions. The databases include the asset fault signature database and the RUL database. The analytical models will be those needed for the diagnostic and RUL advisors. The project also will include identification of additional sensor development and monitoring capabilities needed to enhance the monitoring capabilities for these components.

For each of these component types, a technical report will be published that describes the technical basis and analysis framework to enable OLM for these components. These technical reports, along with the results and experience from the pilot projects, will be used to develop guidelines for utilities to 
implement centralized OLM and information integration for the components/structures important to plant life extension.

This pilot project currently is underway with two host utilities: Exelon Nuclear (Braidwood Nuclear Station) for emergency diesel generator monitoring and Progress Energy (Harris Nuclear Station) for large power transformer monitoring. For the induction motor project, Idaho State University will develop an experimental test bed that will include two 40-horsepower induction motors instrumented with current, temperature, and vibration sensors. The experimental test bed will support development of diagnostic models for loss of bearing lubrication, contamination of bearing lubrication, misalignment, and loss of cooling degradation.

Schedule: FY 2012 to FY 2015

Remaining Project Milestones:

None

\subsubsection{Online Monitoring of Concrete Structures in Nuclear Power Plants}

The pilot project focuses on concrete structures. Concrete structures are present in all NPPs and are grouped into four categories: (1) primary containment, (2) containment internal structures, (3) secondary containment/reactor buildings, and (4) other structures such as used fuel pools, dry storage casks, and cooling towers. The age-related deterioration of concrete needs to be measured, monitored, and analyzed to support long-term operation and maintenance decisions.

This project will be a combined effort between the Plant Modernization Pathway, the Materials Aging and Degradation pathway, Vanderbilt University, University of Alabama, and University of NebraskaLincoln, University of Tennessee - Knoxville, and EPRI. It will develop a framework for health diagnosis and prognosis of aging concrete structures in NPPs that are subject to physical, chemical, and mechanical degradation, by integrating modeling, monitoring, data analytics, and uncertainty quantification techniques. Current knowledge and ongoing national/international research efforts in individual directions will be leveraged and synthesized to advance the state of the art in full field, multi--physics- assessment of concrete structures.

The framework (shown in Error! Reference source not found.) for the health monitoring of NPP concrete structures will include four technical elements: (1) damage modeling, (2) monitoring, (3) data analytics, and (4) uncertainty quantification [14]. The framework will enable plant operators to make risk informed decisions on the structural integrity, RUL, and performance of concrete structures. The framework will be generalizable to a variety of aging passive components in NPPs. The four tasks corresponding to the four technical elements are outlined below.-informed decisions on the structural integrity, RUL, and performance of concrete structures. The framework will be generalizable to a variety of aging passive components in NPPs. The four tasks corresponding to the four technical elements are outlined below. 


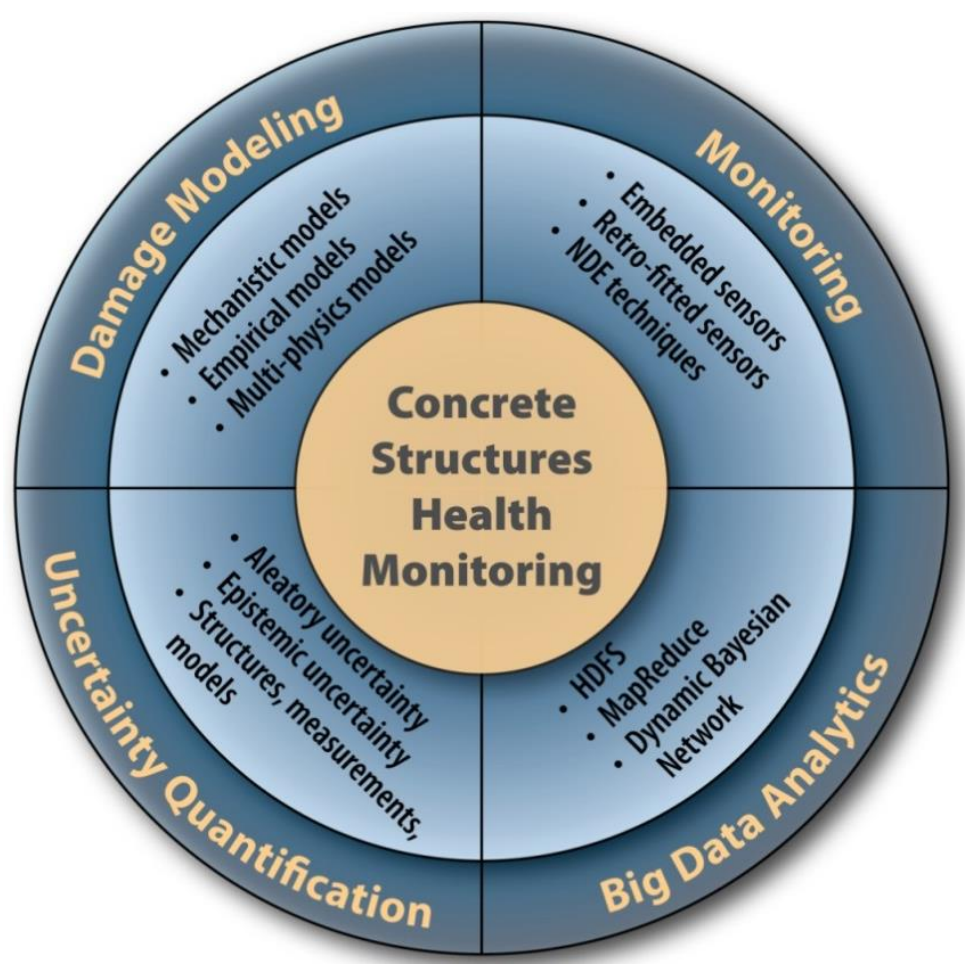

Figure 9. PHM framework for concrete structure health monitoring.

Damage Modeling. This task will leverage the modeling of chemical, physical and mechanical degradation mechanisms (such as alkali-silica- reaction, chloride penetration, sulfate attack, carbonation, freeze/thaw cycles, shrinkage, and radiation damage) to assist monitoring and risk management decisions. alkali-silica- reaction is currently receiving prominent attention and will be used for initial development; other damage mechanisms will be included in subsequent years. The interactions of multiple mechanisms will receive significant consideration. The task requires modeling and computational advances and combined-physics experiments (including multi-scale and micromechanics effects), and the integration of multiple models through an appropriate simulation framework. The computational models developed by Oak Ridge National Laboratory and in the Grizzly software of the Multi-physics Object Oriented Simulation Environment (MOOSE) at INL will be leveraged.

Monitoring. This task will explore the effective combination of promising structural health monitoring (SHM) techniques for full field multi- physics monitoring of concrete structures. Optical, thermal, acoustic, and radiation- based techniques will be investigated for full-field imaging. Examples of these techniques include digital image correlation (optical), infrared imaging (thermal), velocimetry and ultra sonics (acoustic), and X--ray- tomography. Within the acoustic monitoring, vibro-acoustic technique will be evaluated as part of active acoustic technique and the research would benefit from passive acoustic technique performed at The University of Tennessee Knoxville on large concrete specimens. Particular considerations include interaction effects in SHM measurements under operational environments, and the linkage of chemical degradation to the observed mechanical degradation, which requires synergy between damage modeling and monitoring. Efforts will be directed towards cross-verification of acoustic techniques using measurements from embedded strain and $\mathrm{pH}$ sensors. 
Data Analytics. The information gathered from multiple health monitoring techniques results in high volume, rate, and variety (heterogeneity) of data. This task will incorporate big data techniques for storage, access and analysis of heterogeneous data (numerical, text, and image), and effective inference of concrete degradation. The data analytics framework will also integrate information from model prediction, laboratory experiments, plant experience and inspections, and expert opinion. Data mining, classification and clustering, feature extraction and selection, and fault signature analyses with heterogeneous data will be orchestrated through a Bayesian network for effective inference.

Uncertainty Quantification. This task will quantify the uncertainty in health diagnosis and prognosis in a manner that facilitates risk management decisions. Sources of natural variability, data uncertainty, and model uncertainty arising in both modeling and monitoring activities will be considered and their effects quantified. In addition to measurement and processing errors, data uncertainty due to sparse and imprecise data for some quantities, and due to large data on other quantities (i.e., data quality, relevance, and scrubbing), will be considered. Model uncertainty in multi--physics degradation modeling due to model form, model parameters, and solution approximations will be included. The various uncertainty sources do not combine in a simple manner; therefore, a systematic Bayesian network approach will be developed for comprehensive uncertainty quantification that facilitates risk- informed operations, maintenance, inspection, and other risk- management- activities.

A second pilot project will be conducted involving passive components and structures representative of those for which extended life is highly important to LWR sustainability. The passive components or structures will target large and economically important plant assets for which the science of managing long-term- material degradation is yet unsolved. In this effort, the Plant Modernization research program and EPRI will work with the LWRS Program's Materials Aging and Degradation Pathway to select suitable components or structures based on importance to utility decision-making in pursuing additional life extension (beyond 60 years) and the prospects for research success within the timeframe of this project.

The Materials Aging and Degradation Pathway will be responsible for developing the scientific basis for modeling the degradation mechanisms and determining the types of information needed to monitor the degradation. It is possible that new types of sensors will have to be fabricated for this purpose. The Plant Modernization research program will devise the material interrogation techniques on conjunction with the Materials Aging and Degradation Pathway and EPRI, signal processing capabilities to convey the sensed parameters to the monitoring system, data analytics, and trending used for analyzing and visualizing the results of materials interrogation, and uncertainty quantification of the results. Also, the LWRS Program will develop the technologies needed to enable utilities to retrieve, store, process, and integrate the large volumes of information collected through the OLM systems installed on these passive plant components.

LWRS Program's Plant Modernization and Materials Aging and Degradation Pathways are working with EPRI in developing a Concrete NDE Roadmap. The team has identified three areas that needs attention going forward. These include (1) advancement in NDE techniques; (2) structural health monitoring; and (3) approaches to understand different degradation mechanisms. Short-term (1 to 3 years) research needs and long-term (> 3 years) research needs will be discussed and finalized in FY 2019.

Schedule: FY 2014 to FY 2021

Remaining Project Milestones:

- (2019) Develop a methodology that would support the implementation of the vibro-acoustic modulation technique to detect mechanisms of material degradation due to Alkali-Silica Reaction on large reinforced concrete specimen for structural health monitoring.

- (2019) Development of enhanced structural health monitoring framework for reinforced concrete structures based on VAM technique. 
- (2019) Perform experimental analysis, data collection and analysis, development of diagnostic and prognostic models along with uncertainty bounds.

- (2020) Conduct a pilot demonstration of multi-modal online diagnostic monitoring system on reinforced concrete.

- (2021) Develop a risk model with structural integrity information to enable risk-informed decision-making.

\subsubsection{Online Monitoring of Secondary System Piping in Nuclear Power Plants}

Based on INL/EPRI joint workshops and feedback from utilities, the OLM of structural health of secondary pipes was selected for the second pilot project on passive component sustainability. This purpose of this work is to reduce the cost of preventive maintenance of secondary structures in NPPs using state-of-the art sensor modalities, data fusion, and advanced data analytics. Specifically, this pilot project aims to develop and validate an integrated multi-sensor OLM system capable of inspecting large piping components in secondary systems and providing a pathway to move from inspection based- maintenance to condition-based maintenance. The OLM system is expected to provide a current estimate of pipe wall thickness along with the RUL estimate. Such a system could provide the following benefits:

- Improved capacity factor by reducing unplanned and planned outages

- Improved safety through fewer unexpected failures and repairs

- Optimized equipment operation and maintenance through early identification of faults

- Improved fault diagnostics through increased availability of data relating to faults and shared knowledge of fault behavior based on case studies and expertise

- Lifetime extension of existing NPPs by having an increased understanding of the current health of the plant components and RUL estimation

- Minimizing human factors effects on non-destructive testing.

The OLM system will have a larger area of coverage than the current NDE techniques and will aim to answer the question which current Aging Management Programs are facing (such as, where to inspect or identification of inspection locations). There is no currently available technology that would pinpoint which piping component needs to be inspected. This is the major reason for redundant inspections. The conceptual representation of the OLM system output is shown in Error! Reference source not found.. 


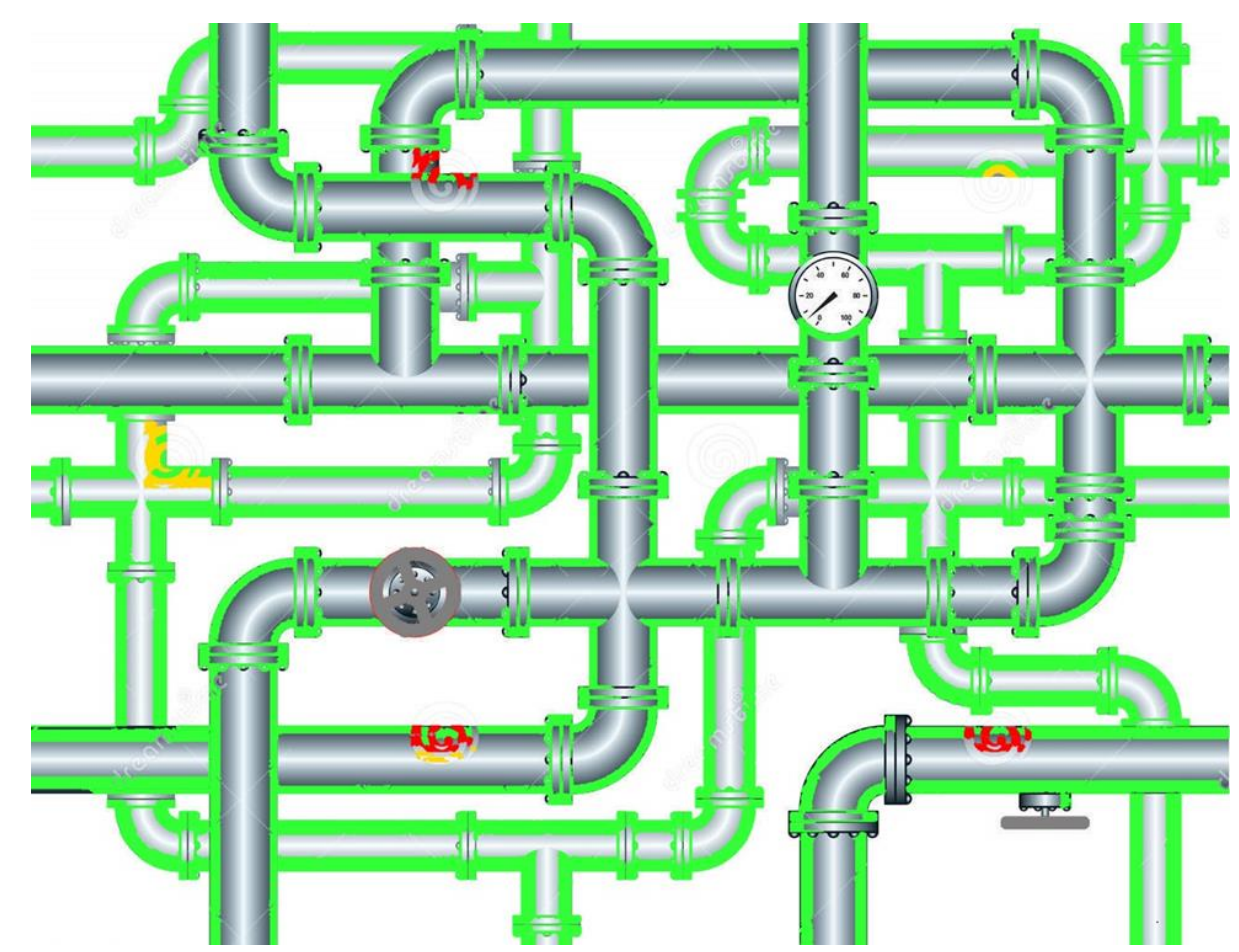

Figure 10. Conceptual representation of the online monitoring system's output.

The wall thickness is color coded with green representing the safe thickness, yellow-borderline thickness, and red representing the wall thickness close to safety threshold, which requires immediate attention.

A technical report and peer reviewed publications will be published that describe the technical basis and analysis framework to enable OLM for selected secondary system components. These technical reports, along with the results and experience from the pilot projects, will provide guidance for utilities to implement centralized monitoring and information integration for the passive components and structures important to plant life extension.

The majority of periodic piping inspections do not discover any degradation, while contributing significantly to operation and maintenance costs. This activity will enable reducing the cost of periodic piping inspections performed at NPPs. INL will collaborate with South West Research Institute (SwRI) on advanced signal processing and pattern recognition of ultrasonic guided wave (UGW) data collected on secondary piping components. The research will focus on processing multi-segment UGW and data fusion of multiple segments to extend the range and improve flaw characterization. In this collaboration effort, SwRI will provide the UGW data and consultations on data collection procedures. INL will perform research on data fusion and data characterization. Extending the range of UGW systems for better characterization of the flaws will also reduce the cost of UGW systems themselves, as fewer sensors will be required to cover long stretches of straight piping. Based on EPRI's information, introduction of a piping monitoring system with predictive capabilities can significantly reduce the number of required inspections.

Schedule: FY 2015 to FY 2021

Remaining Project Milestones:

- (2019) Research and develop high spatial resolution fiber sensors to improve detection of corrosion/erosion-induced defects in complex piping geometries such as elbows, tees, and bends. 
- (2019) Collect piping degradation data using high-resolution fiber optics sensors permanently installed on different piping components, including elbows, bents, and tees. The data will be used to develop data fusion and pattern recognition algorithms for online piping monitoring system.

- (2019) Install equipment and collect piping degradation data using high-resolution fiber optics sensors installed at a participating utility to enable development of advanced data fusion and pattern recognition algorithms for online piping monitoring system.

- (2020) Research and develop permanently installed ultrasonic guided wave system on a stretch of straight piping adjacent to the elbow instrumented with high-resolution fiber optics sensors.

Collect data from both sensor modalities. The data will be used to develop data fusion and pattern recognition algorithms for online piping monitoring system.

- (2021) Research data processing techniques and develop a data fusion software system to provide a holistic picture of piping monitored with two sensor modalities: UGW and fiber optics sensors. The system will provide end state vision and implementation plan for online piping monitoring system.

\subsubsection{Digital Architecture for an Automated Plant}

To automate operating NPPs to their full potential, integration of digital technologies must extend to encompass databases from the different plant processes. A NPP collects data from plant process, work management systems, scheduling, systems engineering, operator logs, condition reporting, etc. These databases have different structures and tools, and are therefore used independently. The integration of data from these databases is performed manually as needed. For example, an LWRS pilot study previously attempted to integrate scheduling activities from one tool with work order steps from another for the purpose of tracking work progress in an outage. Since a scheduled activity can represent one step in a work order or a set of steps, the mapping process had to be performed manually and required tens of hours to map one work order to one schedule. The problem is much broader than this example. The tools used currently and that may be used in the future in NPPs employ different information and data terminologies, and the databases that support these tools have elements that do not represent the same data in other tools. The best mechanism to facilitate the coupling of these tools is a common data or information model. A common information model exists in different forms for various applications and industries, but a comprehensive model does not exist for the nuclear power industry. This project recognizes the need for a common information model, and builds on existing work to create a model and an architecture that is specific to the different types of data that are used by processes and applications in the nuclear industry. This aims to enable and automate the data integration and create a streamlined process to combine the data from all plant data sources in to a common data form. The benefits of this work include reducing the amount of data search activities and therefore increasing work efficiency, enabling the use of machine decision making for streamlined and improved plant activities, revealing information and improving the visual perception of all parts of NPP operations and maintenance, reducing the need for training on various tools for plant staff, and enabling a holistic staff perception of plant activities.

Schedule: FY 2014 to FY 2021

Remaining Project Milestones:

- (2019) Develop a common information model that addresses requirements for NPP databases to support greater work process and plant automation

- (2019) Develop an example of a common information model application that enables efficient, streamlined, and cost-effective data integration.

- (2020) Demonstrate integration of multiple plant data sources into a common data architecture. 
- (2021) Pilot an advanced application that demonstrates automation of plant information and process decision making based on integrated data

\subsubsection{Advanced Remote Monitoring for Operations Readiness}

The nuclear power industry is challenged with high operation costs, specifically operations surveillance activities, which are performed to comply with license requirements. They are currently heavily reliant on manual activities on a periodic basis as mandated in the plant's technical specification. The main objectives of these activities are to ensure plant equipment readiness when needed and to detect process anomalies. This effort will develop an advanced operations approach that automatically ensures plant readiness and identifies plant anomalies along with the root cause as issues progress. This will reduce the number of plant workers gathering data, allowing the operations team to focus on ensuring optimal plant performance.

With current technological advancements in sensors and data analytics, it is possible to replace a significant portion of operations activities with sensors and a centralized decision making process. The outcome will enable appropriate organizations to address anomalies before their severity escalates. This end-state requires developing methods to analyze plant process and support systems data on a holistic level. It will also require identifying plant monitoring gaps and introducing new technologies or sensors to improve the operator's decision making process.

The project will research and develop methods to automate the methods of data collection to reduce the cost of manual operations processes in collaboration with Cooper Nuclear Station. The project will also collaborate with Luminant in researching and developing methods and technologies to gradually integrate data from different sources to enable a centralized monitoring approach and combine direct measurements from the plant with plant process data to develop deeper insight.

Project activities include: integrating data from various plant equipment sensors with plant process data for a holistic and continuous approach to operations monitoring, revealing anomalous conditions that cannot be inferred based on a single method of monitoring; and developing a library-based monitoring platform to enable rapid, flexible, and expandable integration of monitoring methods used by plants and vendors. The project will target high cost processes in order to ensure maximum return on investment. The scope will include migrating operations activities to an automated approach. Existing technology capabilities, data, and expertise will be leveraged to achieve reduction in O\&M costs on identified plant assets.

The research outcomes will be published in peer-reviewed conferences and journals and could result in generation of intellectual property that Battelle Energy Alliance (BEA)//INL could license.

In collaboration with nuclear utilities, vendors, and universities, conduct research in advanced OLM technologies to automate high cost preventive maintenance activities.

Schedule: FY 2019 to FY 2022

Remaining Project Milestones:

- (2019) Complete a technology roadmap for comprehensive NPP monitoring using advanced I\&C technology, enabling a transition to condition-based maintenance.

- (2019) Automate high cost manual monitoring, inspection and surveillance processes at a NPP.

- (2019) Develop a data driven method for monitoring plant operations performance that integrates process data with anomaly detection to reduce cost of operations and improve plant performance.

- (2019) Automate a new manual inspection and surveillance process at a NPP.

- (2020) Replace a surveillance equipment testing process by advanced monitoring. 
- (2020) Integrate direct measurements from multiple plant processes to monitor a complex plant system for anomalies.

- (2021) Automatically integrate the most common non-homogenous data from different plants using data patterns identification to create a centralized OLM platform.

- (2022) Develop the structure of a library-based equipment condition monitoring platform to enable rapid, flexible, and expandable integration of plants and vendors monitoring methods.

\subsubsection{Technology-Enabled Risk-Informed Maintenance Strategy}

Continuing to operate NPPs in an electricity market selling wholesale electricity for \$22/MWh becomes unsustainable with current O\&M costs accounting for at least $66 \%$ of the total operating cost; thereby pushing production costs higher than market price of electricity. As identified, one of the major contributors to the total operating costs today is the O\&M costs, which include labor-intense preventive maintenance $(\mathrm{PM})$ programs. PM programs involves manually-performed inspection, calibration, testing, and maintenance of plant assets at periodic frequency, and time-based replacement of assets, irrespective of equipment condition. This has resulted in a labor-centric business model to achieve high capacity factors. In order to be competitive, the industry must transition from this labor-centric business model to an optimal maintenance program. To enable this transition, a reliable method is needed based on available advanced technologies to support assessing the condition and risk of equipment failure. Fortunately, there are technologies (i.e., advanced sensors, data analytics, and risk assessment methodologies) that can enable transition from a labor-centric business model to a technology-centric business model. The technology-centric business model will result in significant reduction of PM activities and, thereby, drive O\&M costs down.

Use of a technology-centric maintenance program will lay the foundation for real-time condition assessment of plant assets; this will allow plants to implement condition-based maintenance to simultaneously enhance safety, reliability, and economics of operation. The project scope is to achieve optimization of maintenance frequency, which in turn is further enhanced to achieve reduction in maintenance on a subset of assets by incorporating intelligent monitoring/diagnostics/prognostics (using additional sensor modalities). This would allow plants to identify when an asset actually requires maintenance and when it does not.

Part of the research activity proposed in this work package addresses the challenges of crediting digital equipment self-diagnostics/OLM for performing technical and non-technical (e.g. BOP) Specification surveillance requirements in nuclear plants licensed to 10 CFR Part 50. While approved methods exist for extending technical specification surveillance intervals for analog equipment, there remain gaps in technology and guidance for crediting internal self-diagnostics and OLM characteristics of newer digital equipment. Addressing these gaps is likely to result in advances that reduce maintenance costs for LWRs.

Specifically, self-diagnostic/OLM capabilities of newer digital equipment being installed in nonsafety and safety applications are expected to detect failures and potentially provide early warning of potential failures, and notify plant operators to take appropriate action so that safety margins are maintained. There is a need to adapt and apply OLM and diagnostics for condition assessment of digital equipment and subsequent surveillance frequency extension. This requires development of a methodology for analysis of both the hardware and software equipment at a component and system level to ensure that all regulations are met, and safety function performance is not degraded. The scope of this project spans methodology development for extending Technical Specification surveillance frequency intervals for digital equipment to account for OLM capabilities; OLM and diagnostic technology development for selected components and systems; and the development of a partnership with one or more nuclear utilities for future pilot-scale deployment of the developed technology in an operating plant. 
Schedule: 2019-2021

Remaining Project Milestones:

- (2019) Conduct research to develop and demonstrate technical evidence on the completeness of plant data for identified high value assets.

- (2019) Develop a risk model to optimize equipment maintenance frequency and diagnostic models of equipment performance to enable transition to condition-based maintenance strategy at NPPs.

- (2019) Development of a methodology for extending technical specification surveillance intervals for digital equipment.

- (2020) Integrate plant asset condition information into the probabilistic risk model to make riskinformed decision and development of user interface and visualization requirements.

- (2020) Demonstrate a methodology for extending technical specification surveillance intervals for digital equipment.

- (2021) Integrate the project outcomes in a scalable tool to enable predictive maintenance implementation strategy and calibration monitoring and perform cost-benefit analysis on both the technology enabled methodologies.

\subsubsection{Advanced Online Monitoring Facility}

Sustainability for the U.S. LWR fleet is dependent on the preservation of plant assets far beyond the expected original life of 40 years. With most utilities pursing life extension to 60 years (with the possibility of 80 years), long-term plant asset management will have to be a prominent focus of the utility's technical staff.

Technologies are being rapidly developed that can provide early indication of component degradation in progress. Moving beyond empirical models of the degradation factors, physics -based models are now being developed that can mimic the effects on the overall component in response to degradation in one of the subcomponents. This provides the capability to move beyond mere monitoring of the condition to diagnosis of the degradation mechanism and prognosis of the RUL of the component and give the utility a window of opportunity to take remedial actions. These types of technologies are being developed under pilot projects described in Section 4.3.

This project integrates these new monitoring capabilities into a concept of fleet asset management based on a centralized OLM facility. The underlying information structure would be part of the digital plant architecture as described in Section 5.5.1.

The architecture would support the real-time acquisition of condition monitoring data from every type of source. This would include fixed sensors embedded in components such as in "smart pumps." It also would collect data streamed from mobile technologies used by field workers (see Section 5.1.1). This would include data from hand-held condition monitoring technologies such as thermal imaging, vibration monitors, and acoustic probes.

The architecture would organize the information in a manner that could be used for a variety of purposes. In addition to being available for the centralized asset management facility, the information would be available to other plant support function such as the plant engineering system health program, troubleshooting and root cause teams, original equipment manufacturers and technical consultants involved in component support, and the data historian and plant records archive.

This project will develop a prototype advanced OLM facility based on state-of-the-art information technologies and collaboration facilities, and will provide the following: 
- New visualization capabilities to create a better understanding a degrading components

- Video conferencing capability for direct collaboration with plant staff in a variety of settings (e.g., the control room, the OCC, engineering support groups)

- Access to industry databases on failure signatures and associated component data to assist in diagnosing component degradations

- Support of the concept of integrated operations to remotely support a number of operating plants as effectively as if it were onsite.

The prototype advanced OLM facility will initially be developed in the HSSL, where technology developments and human factors studies can be conducted in a test environment. Following that, a production facility would be developed at a host utility location for actual production testing. Based on this initial experience, a technical report will be written to provide recommendations for industry-wide implementation.

Schedule: FY 2020 to FY 2022

Remaining Project Milestones:

- (2020) Develop and demonstrate concepts for an advanced OLM facility in the HSSL that can collect and organize data from all types of monitoring systems and activities and can provide visualization of degradation where applicable.

- (2021) Develop and demonstrate concepts for real-time information integration and collaboration on degrading component issues with remote parties in the HSSL (e.g., control room, OCC, systems and component engineering staff, internal and external consultants, suppliers).

- (2022) Develop a digital architecture and publish a technical report for an advanced OLM facility, providing long-term asset management and providing real-time information directly to control room operators, troubleshooting and root cause teams, suppliers and technical consultants involved in component support, and engineering in support of the system health program.

\subsubsection{Virtual Plant Support Organization}

Due to the complexity of plant systems and the large number of components in NPPs, utilities maintain a large staff of highly trained operators, engineers, technicians, and other types of specialists to ensure safe and successful operations. Considerable ongoing investment in the form of training and development is made in this workforce to enable them to maintain the unique and aging technologies in the plants.

At present, the nuclear industry has arguably the most experienced workforce in its history. This is undoubtedly a significant factor in the operational success the industry has enjoyed over the last decade. However, this is an unsustainable path because, like the aging I\&C systems that plants must be replaced, the aging workforce is on the brink of a substantial retirement wave in which a significant portion of the workforce will have to be replaced in a relatively short amount of time.

Going forward, there are concerns whether the commercial nuclear industry will be able to attract the needed engineers and technicians given the looming shortage of technically trained workers in this country. In addition, the model of having career-long employees who develop deep expertise will likely be less successful in the future with a new generation of workers who will be more prone to change jobs.

A better model would include the ability to build a virtual plant organization that is seamlessly connected through advanced I\&C technologies. A virtual support organization is a combination of an NPP's own organization plus external organizations that have been delegated direct support roles in operating and maintaining the plant. The term "virtual" implies that the organization is interconnected through a digital architecture for data exchange, communications, and collaboration as opposed to having 
to be located onsite. This allows the NPP to tap into far greater resources and expertise than can be practically maintained at the NPP facility.

In general, this is an extension of the concept introduced with the advanced centralized OLM facility. It will allow specialty organizations, both within the utility and with outside companies, to assume full responsibilities of portions of the ongoing operations and support of the plants. Some examples of these types of operational and support roles include:

- An onsite, demineralized water production plant that could be owned and remotely operated by the original equipment manufacturer of the equipment, with minimum onsite support for hands-on maintenance.

- Condition monitoring that could be performed by remote experts in vibration analysis, oil sample analysis, and loose parts monitoring analysis rather than having to maintain this specialized expertise within the general plant engineering staff.

- I\&C system monitoring and diagnostics that could be performed by the manufacturers of the system, with a small onsite support staff to replace circuit boards once faults were isolated to a specific component.

- Radiation monitoring that could be performed remotely using data-linked monitors and video cameras to observe workers in the radiation control zones.

- Chemistry analysis that could be performed remotely using inline instruments that take either batch or continuous samples.

- System test results that could be reviewed and validated by remote engineering organizations that receive data directly from system performance tests.

- Portions of the plant support systems that could be monitored, or even operated remotely, by a centralized staff. This would exclude safety-related systems and those systems that are major transient initiators such as the main feedwater system. There could be a significant reduction in burden on the control room for having many of the auxiliary systems under centralized operations. Examples would include auxiliary steam systems, hydrogen purification skids, oil purification skids, chemistry systems, and radwaste systems.

A virtual support organization would be a significant step toward the concept of integrated operations for the LWR fleet. The workforce required to conduct the plant work activities could be appreciably reduced in number, resulting in a secondary proportional reduction in organizational support functions (i.e., number of supervisors, human resources specialists, trainers, etc.). This concept would move the NPP operating model away from a labor-centric model to a technology-centric model. This could greatly enhance LWR fleet cost competitiveness because technology is generally a declining cost factor while labor is always an increasing cost factor. By purchasing only the services a plant needs, rather than maintaining a full-time staff for all technical functions, considerable cost savings could be obtained.

The following are examples of specific benefits of a virtual organization:

- Specialty organizations could attract and maintain experts much more effectively than could individual operating companies. The experience base of a specialty organization would be much deeper in that they would see phenomena and problems across the entire industry and not just a few plants.

- The monitoring capabilities of a third party (or even a fleet-centralized service) would be more uniform over time because it would not depend on work schedules of one or two experts onsite.

- The NPP would be relieved of continual hiring, transferring, and training of replacement workers for these positions as inevitable attrition occurred. 
- In the case of having some plant auxiliary systems monitored or operated remotely by support organizations, there would be a net safety benefit in allowing the control room and onsite operations staff to concentrate more on the safety-significant portions of the plant.

This project will develop the underlying technologies enabling development of a virtual support organization. The information structure to do this will be built into the digital architecture for a highly automated plant (see Section 5.5.1). Human and organizational factors will be incorporated into a technical report for integrating external organizations directly into the line functions of the plant organization, as enabled by data sharing, communications (voice and video), and collaboration technologies that will compose a seamless work environment. These technologies will first be created and studied in the HSSL reconfigurable simulator, where it will be possible to evaluate the dynamics of a remote organization conducting a key plant support function. An open standard for data sharing technology will be developed for this architecture to promote a fair and competitive market for external services.

The project will identify which plant functions are priorities for outsourcing using the virtual plant support organization concept. The project will work with a host utility NPP to implement some trial instances of remote support. Evaluations of these initial examples will be the basis for a technical report on how to implement the virtual plant support organization on an expanded scale.

\section{Schedule: FY 2021 to FY 2024}

Remaining Project Milestones:

- (2021) For chemistry activities, conduct a study and publish a technical report on opportunities to provide remote services from centralized or third-party service providers, based on advanced realtime communication and collaboration technologies built on the digital architecture for a highly automated plant. Demonstrate representative remote activities with a host NPP.

- (2022) For maintenance activities, conduct a study and publish a technical report on opportunities to provide remote services from centralized or third-party service providers, based on advanced real-time communication and collaboration technologies built on the digital architecture for a highly automated plant. Demonstrate representative remote activities with a host NPP.

- (2023) For radiation protection activities, conduct a study and publish a technical report on opportunities to provide remote services from centralized or third-party service providers, based on advanced real-time communication and collaboration technologies built on the digital architecture for a highly automated plant. Demonstrate representative remote activities with a host NPP.

- (2024) Publish human and organizational factors studies and a technical report for a virtual plant support organization technology platform consisting of data sharing, communications (voice and video), and collaboration technologies that will compose a seamless work environment for a geographically dispersed NPP support organization.

\subsubsection{Management Decision Support Center}

Operational decision-making is a foundational element of safe nuclear operations. Processes for decision-making are formal and rigorous in all levels of the nuclear utility management structure. Nuclear managers are required to be technically competent and actively engaged in the issues facing their nuclear facilities, such that they can effectively participate and be held accountable in ongoing operational decisions. 
Plant functional managers typically serve in both standing and special-purpose decision review boards that are formally invoked for significant plant issues. One such example required by a nuclear utility's Quality Assurance Program is the onsite Plant Operational Review Committee, or a similarly titled group. The Plant Operational Review Committee is required by the facility license to have a broad range of technical expertise and competence in plant issues and is required to review a number of different types of plant issues and provide a recommendation to the plant manager on the advisability of proposed plant actions. There are similar groups that are appointed for other special purposes (such as to provide oversight of operational decision-making and risk management).

On a more informal basis, the plant management typically meets early every weekday morning to review current operational concerns and to ensure that all work plans are well-coordinated and meet risk management expectations. This is yet another forum for operational decision-making on the adequacy of the daily work plan and the response to emergent problems. A similar daily management meeting is held during outages to address issues arising from ongoing work.

Another category of management decision-making pertains to the emergency response organization. These are the decisions on how to classify, mitigate, and provide protective actions for nuclear emergency events. These deliberations occur in the dedicated emergency response facilities, namely the Technical Support Center, the Operations Support Center, and the Emergency Operations Facility; the latter of which is offsite and sometimes serves the entire fleet.

What these decision-making processes and forums have in common is the critical need for accurate, timely information on which to base operational decisions made by plant managers. There are many examples in the industry where a plant management team made decision errors, not due to a lack of competence among management staff, but simply because they did not have an accurate picture of what was actually happening at the time and what was at stake.

To improve understanding in these settings, technology will be introduced that provides a better visual picture of the situation (such as real-time video taken at the location of the problem). In other cases, where pictures of the problem are not practical (e.g., core power imbalances due to dropped rods), simulations and symbolic presentations of the issues will be developed.

The concept of a management decision support center would address these needs by employing advanced digital technologies to improve the quality of operational decision-making. It would be a dedicated facility where all regular and special management oversight meetings would be held. (The exception to this would be emergency response facilities, which have to be maintained in a state of readiness. The technologies of the management decision support center would be separately implemented in emergency response facilities.) The following are examples of the types of technologies that would be implemented:

- Multiple large-screen displays that can handle many different data sources at a time

- Video streaming capability directly onto any of the large displays, including video conferencing

- Access to all data and displays of the plant computer and safety parameter display system

- Real-time images of the main control room control boards, with real-time data refreshing

- Ability to run the plant simulator for the scenario of concern

- Real-time plant risk assessments and defense-in-depth measures

- Severe accident management guidelines and extensive damage mitigation guidelines

- Access to all plant process applications (e.g., technical specification logs, operator logs, schedules, work orders, and test results)

- Access to all plant documentation through an electronic document management system 
- Access to NPP field worker mobile technologies for streaming of activity related-information

- Access to outside data sources, such as weather, media, regulatory information, and external databases

- Decision-support and resource allocation software

- General presentation capabilities.

This concept could be applied at the fleet level where decisions involving multiple NPPs or processes between plant- and fleet-level management occur. Collaboration tools would allow information views to be pushed to other participating centers so that a shared context for discussions and decisions would be available.

Obviously, this project will build on many of the capabilities that are developed in other pilot projects, but will focus them on the unique aspects of nuclear management decision -making. The project will team with a host utility to identify the needed capabilities in such a facility. The digital architecture pilot project will address the information requirements of this facility. The facility will be prototyped in the HSSL to demonstrate and evaluate the various capabilities. Human factors studies will be a key part of the evaluation to ensure the information presentations are well-designed for comprehension and do not result in an information -overload situation. Protocols for managing the information resources during a management decision -making meeting will also be developed. Following the laboratory demonstration, a management decision support center will be implemented at the host utility NPP for trial usage. Field studies will assess any needed corrections to the concept or implementation. A technical report will be developed for industry-wide implementation.

Schedule: FY 2023 to FY 2025

Remaining Project Milestones:

- (2023) Develop and demonstrate concepts for a management decision support center that incorporates advanced communication, collaboration, and display technologies in the HSSL to provide enhanced situational awareness and contingency analysis.

- (2024) Develop and demonstrate concepts for advanced emergency response facilities that incorporate advanced communication, collaboration, and display technologies in the HSSL to provide enhanced situational awareness and real -time coordination with the control room, other emergency response facilities, field teams, the NRC, and other emergency response agencies.

- (2025) Publish human and organizational factors studies and a technical report for a management decision support center consisting of advanced digital display and decision -support technologies, thereby enhancing nuclear safety margin, asset protection, regulatory performance, and production success.

\subsection{Advanced Applications and Process Automation}

Despite over a decade of strong emphasis on human performance improvement, the LWR fleet continues to be impacted by human error, resulting in plant transients, nuclear safety challenges, and equipment damage. While consequential error rates are relatively low (typically measured in the range of $10^{-4}$ consequential errors on a base of $10 \mathrm{~K}$ hours worked), the sheer number of work hours accumulated by plant staff over time means that errors impacting plant safety and reliability still occur too frequently.

The traditional approach to improving plant worker human performance has been to focus on correcting worker behaviors. This has indeed produced substantial improvement since the time this emphasis began in the mid-1990s. Up to that time, there were frequent plant trips and transients due to human error (such as working on the wrong component or even the wrong operating unit). These types of errors have gradually been reduced until they are presently relatively rare. However, other types of errors 
continue to cause or complicate nuclear safety challenges. In the 2008 to 2010 timeframe, there were a series of incidents at various NPPs, many of which were considered to be among the industry's best performers. These incidents were documented in the INPO SOER 10-2, "Engaged, Thinking Organizations," [4] which assigned a significant portion of the causes to human error and lack of operator fundamental knowledge.

The focus on correct worker behaviors typically involves an analysis of the inappropriate worker actions and implementation of corrective actions in the form of additional training, procedure upgrades, job and memory aids (i.e., acronyms and neck strap cards), additional peer-checking, management job observations, and so forth. While some improvement is usually obtained from these corrective actions, there has been a cumulative negative effect in adding complexity to work activities that make work tasks slow and cumbersome. To the operators, the focus seems to be more about human error prevention tools (job aides) than the actual task or activity being conducted. Job satisfaction has eroded and the added complexity has become an enticement to take short-cuts with these additional requirements, further perpetuating the cycle of human error. Much frustration on the part of workers and their managers has resulted from the ever -increasing job expectations added to work activities with, in actuality, diminishing returns in terms of error -free performance. Some industry observers believe that a saturation point has been reached, where the added complexity is contributing to the rate of human error (due to divided attention) and that the industry has reached the practical limits of human reliability at the present error rates.

To further improve human performance for NPP field workers, a fundamental shift in approach is needed. Digital technology can transform tedious error -prone manual tasks in NPP field activities into technology based structured functions with error- prevention- features. This has the potential to eliminate human variability in performing routine actions such as identifying the correct components to be worked on. In short, the technology can perform tasks at much higher reliability rates, while maintaining desired worker roles of task direction, decision-making, and work quality oversight.

NPPs are perhaps the only remaining safety -critical operations that rely to a large degree on human skill to conduct routine and emergency activities. Adoption of digital technologies has transformed other high -risk industries (e.g., aviation, medical procedures, and high -precision manufacturing) to where tedious control functions are performed by automation while the operator remains in an oversight, directory role.

This situation is largely due to technology limitations during the 1970s and early 1980s when the currently operating NPPs were designed. While main processes pertaining to reactor operations are automated (e.g., core power level with automatic rod control), the vast majority of plant controls for configuration changes or placing equipment in and out of service are manual. This over-reliance on manual control on such a large scale challenges operators and results in human error rates that are unacceptable.

The concept of a highly automated plant is one where the most frequent and high-risk control activities are performed automatically under the direction of an operator. Because of higher reliability in well-designed automatic control systems, improvements will be realized in nuclear safety, operator efficiency, and production. The chief impediment to the widespread implementation of this concept is the cost of retrofitting new sensors, actuators, and automatic control technology to existing manual controls. The goal of this research will be to demonstrate that the resulting improvement in safety and operating efficiencies will offset the cost of making these upgrades. 


\subsubsection{Mobile Technologies for Nuclear Power Plant Field Workers}

Virtually all plant work activities are conducted under the control of rigorous work processes that convey the required job quality and technical requirements. Up until now, these work processes have generally relied on printed paper to present information to plant workers and to serve as the medium to direct execution and recording of the specific work activity tasks. However, paper (as a medium) has the obvious limitation of not being interactive with real -time information sources; it is inflexible in its usage, leaves room for interpretation, and is incapable of enforcing its printed requirements. Technologies that have replaced the use of paper processes in the office environment have not been as easily adapted to field worker requirements.

The primary difficulty in providing plant workers with technology to improve their performance has been the fact that sometimes the workers must move about the plant in relatively inhospitable environments for digital technology (e.g., temperature extremes, radiation, radio frequency interference, confined spaces). Also, there has been no practical way to connect these devices for real -time interactions to assist mobile workers.

Outside the nuclear industry, the use of mobile technologies to improve human performance is far more pervasive. A rapid transformation is in progress in the use of mobile technologies to revolutionize how humans conduct their routine personal and work -related activities. These technologies range from the applications in the latest smart phones to the hand-held business technologies used to receive and track mobile objects such as overnight packages, rental cars, and warehouse inventories. What these technologies have in common is that they correctly identify the intended work object, apply the correct process, guide the worker through the correct process steps, validate information, and post real -time work status to the corporate process systems - all from the job location.

These devices rely on wireless networks, digital processing devices, object identification capabilities (e.g., bar codes, radio frequency identification), voice command capability, and information processing software. In other words, many different technologies can be bundled in a single mobile device to address all aspects of a particular work activity. These technologies also have been "hardened," such that they are rugged and can perform reliably in challenging environments, including those found in an NPP.

However, it is not enough to simply provide field workers with mobile technologies. These technologies must be integrated into the plant work processes and must be able to access real -time plant information. Further, they must provide the ability for real -time interaction and collaboration with workers in other locations, in particular those who are coordinating overall plant operations, such as the NPP control room or OCC. The idea is to embed the field worker in the plant processes and plant systems with wearable technologies, such that the worker is an integral and connected part of the seamless digital environment supporting plant operations and related activities.

These integrated technologies must first be validated using human performance evaluations to ensure they are not introducing negative factors into the work setting. It is essential they be packaged and used in a manner that is intuitive, promotes situational awareness, and does not distract the worker from key job requirements or safety hazards in the area.

This research project will develop the basic mobile technology capabilities needed by an NPP field worker in performing typical plant work activities (Error! Reference source not found.). It will include general work process instructions, component identification capability, wireless communications to transmit and receive real-time information, audio, picture, and video streaming, and use of heads-up, hands-free displays for workers involved in hands -on work. It also will include human factors evaluations to ensure the technology does not introduce negative factors that are detrimental to the job outcomes or well-being of workers. 


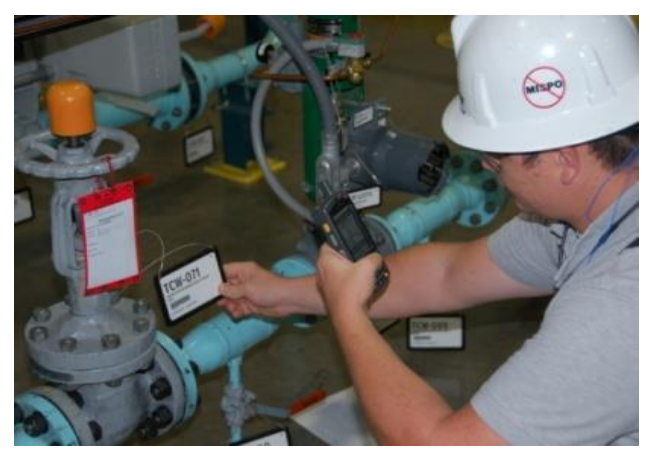

Figure 11. Operator at Catawba Nuclear Station using hand-held technology for component identification.

The initial application of this technology will address safety tagging of components and conducting valve line-up checklists. These two initial applications typify many other plant activities such that the technology can easily be expanded into these other uses. The project will also develop a prototype of a simplified CBP to test the suitability of the technology to handle interactive and shared content.

This pilot project is now complete with Duke Energy (Catawba Nuclear Station) having served as the host utility.

Schedule: FY 2011 to FY 2012

Remaining Project Milestones:

None

\subsubsection{Computer-Based Procedures for Nuclear Power Plant Field Workers}

The commercial nuclear industry conducts virtually all plant activities using standard or special procedures. This includes operational activities, abnormal or emergency actions, maintenance, testing, security measures, plant chemistry control, and radiation protection. The quality of the procedures, refined by operating experience over decades, has been an important contributing factor to the overall success of plant operational excellence and nuclear safety. Strict adherence to written procedures is a key tenet of operational standards.

Unlike many other safety -critical industries, procedures in the commercial nuclear industry are almost always paper-based. As such, these procedures remain prone to certain human errors and process deviations that continue to challenge the plants. Typical problems include:

- Applying the wrong procedure for the plant situation

- Making unauthorized or unintentional deviations from procedure steps

- Receiving unexpected results from procedure actions due to coincident plant conditions/configuration

- Introducing copy errors when transcribing plant data into the procedures

- Making computational errors in processing acquired data.

These types of problems can be largely prevented using CBPs (Error! Reference source not found.), which inherently enforce adherence expectations and perform data manipulations in a correct manner. Furthermore, in an integrated CBP environment using wireless technology, it is possible to track the timing of real -time actions of procedure steps to detect unintended interactions among procedures or with the desired plant configuration. The following important benefits are possible with such a system: 
- Integration with real -time plant data and system status

- Time monitoring for time-critical actions

- Detection of undesirable interactions

- State -based and mode-sensitive context

- Sequencing of steps and other procedures (workflows)

- Place-keeping

- Seamless transitions to other procedures

- Computational aids and validation of results

- Embedded job aids: reference material, training material, and operating experience reports

- Automatic information insertion and verification of plant response

- Remote concurrences and authorizations

- Soft controls - platform for the future "highly automated" plant

- $\quad$ Real-time task status

- Real-time risk assessment.

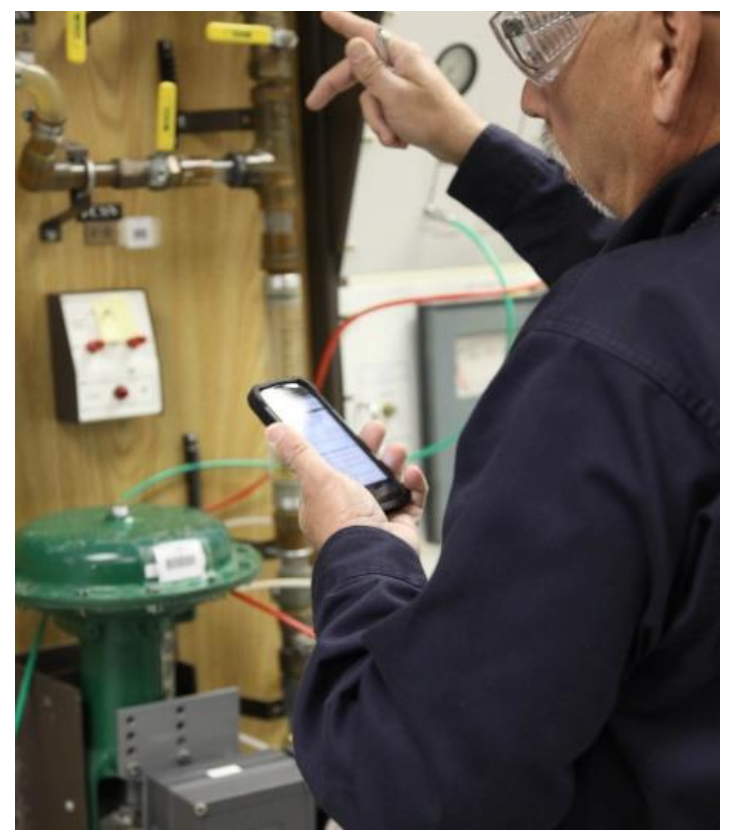

Figure 12. A field worker at Palo Verde Nuclear Generating Station uses the CBP to execute a task.

DOE has considerable expertise in CBPs, having produced papers and reference material for the NRC on this topic. Further, DOE's agreement with the Halden Reactor Project provides access to considerable research and products for CBPs, including direct experience in implementing such systems.

This pilot project will develop design guidance for CBPs for field workers (i.e., all organizations at the NPP that work outside the main control room [Error! Reference source not found.]). It will provide successive demonstrations of CBP capabilities as they are developed. To better illustrate the value of CBPs to NPP workers and senior management, the researchers conducted a series of field evaluation 
studies showing nuclear utilities using the CBP system to conduct selected tasks in the plant during a two month period.

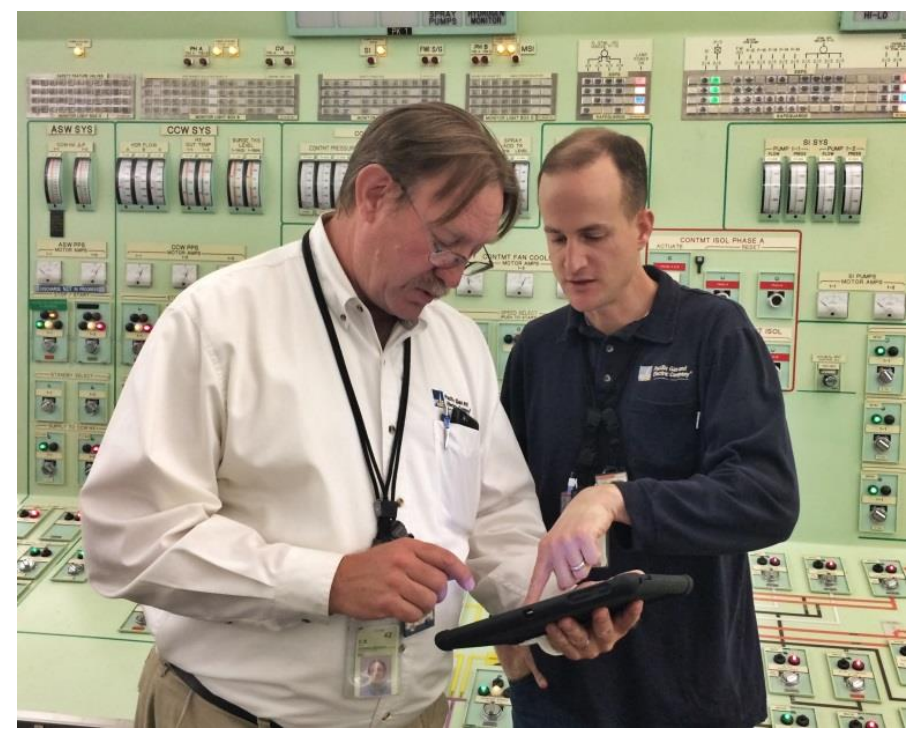

Figure 13. A control room operator and a field operator at Diablo Canyon Power Plant discuss a procedure using the CBP system on the hand-held device.

Putting the system in the hands of the field worker in the actual plant during normal operations makes the research more approachable and relatable to the industry. These are factors of great importance for the industry to consider moving forward with this type of advanced technology.

The research objectives are to develop and publish final design guidance for CBPs for field workers. The guidance will be presented both as a report and as an interactive tool. The researchers will also address the design and development of an authoring and editing tool for CBPs.

To date, the following utilities have hosted one or more studies:

- Arizona Public Service (Palo Verde Nuclear Generating Station)

- Duke Energy (Catawba Nuclear Station)

- Pacific Gas and Electric (Diablo Canyon Power Plant).

Schedule: FY 2012 to FY 2016

Remaining Project Milestones:

None

\subsubsection{Automation of the Work Process}

As NPPs roll in different types of mobile work management solutions, several high cost processes remain as part of the work process, and cannot be tackled by any mobile work management solution. Instead, these processes need to be automated with work process complimentary technologies. An ongoing study has identified multiple technologies that can save costs if augmented to the work process beyond electronic work packages, such as data mining, smart scheduling, and drones. Drones, for, example, were identified as a technology that has high cost saving impact, because they can be used to conduct periodic inspections and surveys such as fire loading (i.e. amount of transient combustibles), can be outfitted with tooling, sensors, and other materials in order to enter areas that are hazardous to humans to perform inspections or work, perform operator rounds and operator field actions, transport resources 
(such as materials, tools, equipment or documents) to and from a work site, survey radiation fields, enable supervisors, schedulers, and reviewers to remotely verify the work progress and completion, look for abnormalities and events such as conducting fire watch, compliment human activities to speed up delayed tasks, compensate for lack of certain human skills, and perform actions in human-restricted areas that would otherwise be done in outage only. This project will research, develop, and demonstrate technologies that address unique nuclear industry work process challenges.

This project will research and develop technologies that would replace human actions and have the highest cost saving of the work process by introducing new methods for sensors and data acquisition, activities execution, and process centralization, coupled with human factors research.

Schedule: FY 2014 to FY 2022

Remaining Project Milestones:

- (2019) Complete report that describes opportunities and benefits for the use of automated image processing technologies in operations and maintenance activities and demonstrate an example image processing technology in lab environment.

- (2019) Integrate drone compatible technology to support operations and maintenance activities at a NPP site.

- (2019) Conduct research that will identify or develop technologies needed to integrate radio frequency identification/wireless/image processing to fully automate valve lineups.

- (2020) Develop and demonstrate a drone compatible technology to support operations and maintenance activities at a NPP site.

- (2021) Develop methods for data mining of work packages of a NPP to create a new data source that enables integrating the work process with the plant.

- (2022) Develop a strategy to use machine learning for schedule optimization of a NPP.

\subsubsection{Advanced Outage Coordination}

NPP refueling outages are some of the most challenging periods of time in the ongoing operations of the facilities. There are usually more than 10,000 activities to be accomplished in a typical duration of 20 to 30 days. Enormous expenses are incurred for outage work, including supplemental workforce, which sometimes totals over 1,000 contractors. Schedule delays drive these costs up proportionately. In addition, the utilities incur additional costs for replacement power for the time NPPs are out of service. Nuclear safety is a particular challenge during outages due to the degraded configurations an NPP is sometimes in to accommodate work on the plant systems. In fact, a large percentage of the annual incremental core damage frequency of the plant's probabilistic risk assessment is incurred during outages. There is also a special regulatory risk because the plants are challenged to meet shutdown technical specifications and "maintenance -rule" risk mitigation measures. Finally, an outage is especially challenging from the standpoint of industrial safety in that the risk of plant workers getting hurt is highly elevated due to the types of activities that are conducted.

Managing nuclear outages in a safe and efficient manner is a very difficult task. In fact, the early history of refueling outages was one of significant cost and schedule overruns, as well as troubling nuclear safety challenges. This led utilities to develop formal outage organizations dedicated to planning and executing their refueling and forced outages. They also built OCCs that co--locate the activity managers for all of the major site organizations so that they can closely coordinate their activities. In addition, they maintain a number of other work execution centers that control critical elements of the work, such as safety tagging for system and component isolations, nuclear risk management coordinators, and similar functions needed to address other constraints on how the outage is conducted. 
As a result of these practices, today's outage performance is greatly improved from what it once was. Outage cost and durations are considerably lower than in the past. Nuclear safety is also greatly improved. However, there remain some significant opportunities and challenges for the industry, including:

- Further reducing the duration of refueling outages remains the largest opportunity to improve plant capacity factors and increase the economic value of the facilities.

- In spite of impressive gains in shutdown safety, there are still too many serious safety challenges (such as loss of residual heat removal and unintended additions of positive reactivity).

- Regulatory violations continue to occur due to subtle configuration control issues resulting from unintended interactions among concurrent work activities.

In spite of the impressive organizations and facilities that have been implemented to improve outage performance, outage management generally relies on the very basic technology of radios, telephones, and stand-alone computer applications. There is some growing usage of remote video for point applications and activity monitoring. Utilities have not made widespread usage of mobile technologies for controlling field work, collaboration technologies for coordinating issues across the broad organization, or advanced configuration management technologies for improving safety and regulatory performance.

There is no question that improved technology for outage management would provide a step change in a utility's ability to conduct outages in a safe and efficient manner. This research program is well positioned with its HSSL, human and organizational factors expertise, and knowledge of NPP outage practices to demonstrate and provide guidance for application of advanced digital technologies to achieve substantial economic value and nuclear safety enhancement through outage performance improvement.

The amount of information that must be processed by the OCC is staggering. OCC managers must obtain the status of thousands of ongoing work activities, project the expected progress of the activities, and then adjust near -term activities for gains or losses in the overall schedule. Accurate work status is difficult to obtain due to communication barriers with field work, particularly in hard -to -access areas of the plant. Also, work status sometimes reflects an overly optimistic outlook by those performing the work. The term "real -time truth" is sometimes used by outage managers to refer to this need for the true status of the work -in-progress.

Outage managers also deal with a continual stream of emergent issues caused by deviations in the expected progress of planned activities or new problems that arise (e.g., equipment failures, unexpected interactions between work activities, other unanticipated outage conditions). Outage managers have to quickly assess the impact of the new issues on the overall outage plan and schedule, consult with knowledgeable individuals on the nature of the problems and possible solution options, determine the solution that results in the least impact on the overall outage objectives, and communicate changes to plans and schedules to the affected activity managers.

These typical outage management activities rely on telephone calls, impromptu meetings, "white board" solution sessions, manual transcribing of agreed -upon changes into a number of work process systems (e.g., work orders, schedules, risk management, radiation work permits, safety tagging, and warehouse parts), and communication throughout the organization using outage status meetings, e-mail, and direct telephone contact. This process is repeated tens of times per shift for the duration of the outage.

This pilot project will assess the needs of outage management and identify technologies that will greatly improve communications, coordination, and collaboration activities needed to minimize the impact of challenges to the outage plan and schedule. It will focus on capabilities that facilitate natural human interaction, while ensuring a high degree of situational awareness and shared understanding. Further, the technologies will be integrated in a way that minimizes the effort to keep all work management systems synchronized with changing plans. 
The project will also develop dynamic interfaces for information coming from mobile field workers, plant control and information systems, and the fluid information developed in the OCC (and other control centers) as the greater organization develops solutions to emergent outage problems (Error! Reference source not found.). Human factors assessments of the use of technology will be conducted to validate that the benefits are actually obtained and new problems are not introduced by technology usage. Results of the project will be a demonstration of the integrated technologies and a technical report for industry-wide implementation.

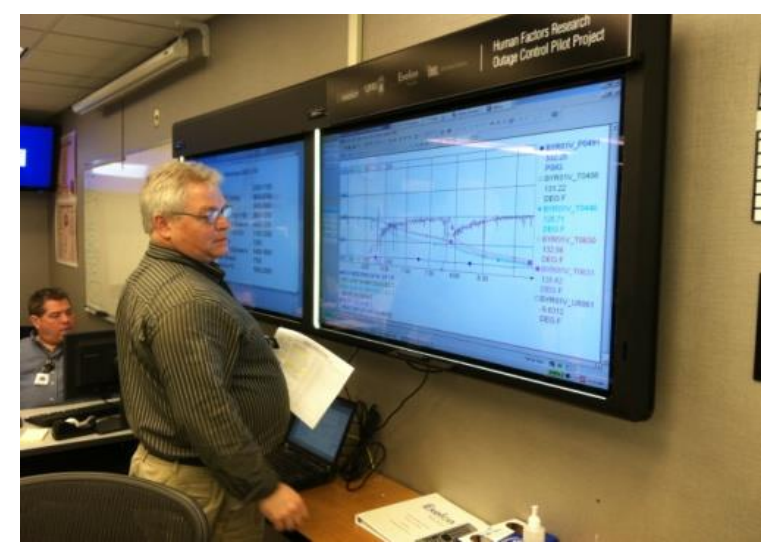

Figure 14. Remote collaboration technology in use at the spring 2011 Byron Nuclear Station refueling.

This pilot project currently is now complete with Exelon Nuclear (Byron Nuclear Station) having served as the host utility.

Schedule: FY 2010 to FY 2012

Remaining Project Milestones:

None

\subsubsection{Advanced Outage Control Center}

The OCC is the central command and control point for executing NPP outages. It is staffed 24 hours a day/7 days a week during outages and accommodates 10 to 15 managers and coordinators from the site and fleet organizations supporting the outage. These positions are typically grouped according to organization and informally interact with one another to coordinate their specific work activities and problem resolutions. Various types of meetings are held on a regular schedule each shift to communicate outage status, share information on upcoming activities and emergent issues, and verify with each organization that they are prepared to support the upcoming activities.

Many of the organizations represented in the OCC also maintain a functional support center at their own site locations to provide the specific services they conduct. For example, the radiation protection organization operates a center to develop and assign radiation work permits and authorize and brief workers who enter radiation control zones. Operations maintains centers to prepare safety tagouts, conduct risk assessments, and track plant configuration changes. There are similar functional support centers set up in other organizations such as chemistry and engineering. One of the key tasks of the OCC coordinators is to ensure these functional centers are aware of changing needs as determined in the OCC and are responding accordingly. The coordinators typically have to leave their positions in the OCC several times a shift to attend coordination meetings back in their functional support centers and are not available for coordination with other OCC positions during those times. 
In considering coordination activities, there is a significant need for advanced technologies to facilitate the information flow into, across, and out of the OCC. These include technologies to conduct interactive meetings with participants in other locations. These technologies will:

- Allow the entire OCC to share information as it develops in response to an emergent issue.

- Allow the OCC coordinators to meet electronically with their respective functional support centers without having to leave the OCC.

- Update all affected work management systems as decisions are made on how to resolve a problem.

- Provide the overall outage managers with the true status on the progress of work and the implementation status of outage plan changes from the OCC managers and coordinators.

These technologies will be integrated into an advanced OCC specifically designed to accommodate and maximize the value of the technologies, while preserving the features of the existing OCCs that facilitate human interaction (Error! Reference source not found.). Where appropriate, these features will be extended to the functional support centers to accommodate their interface with the OCC.

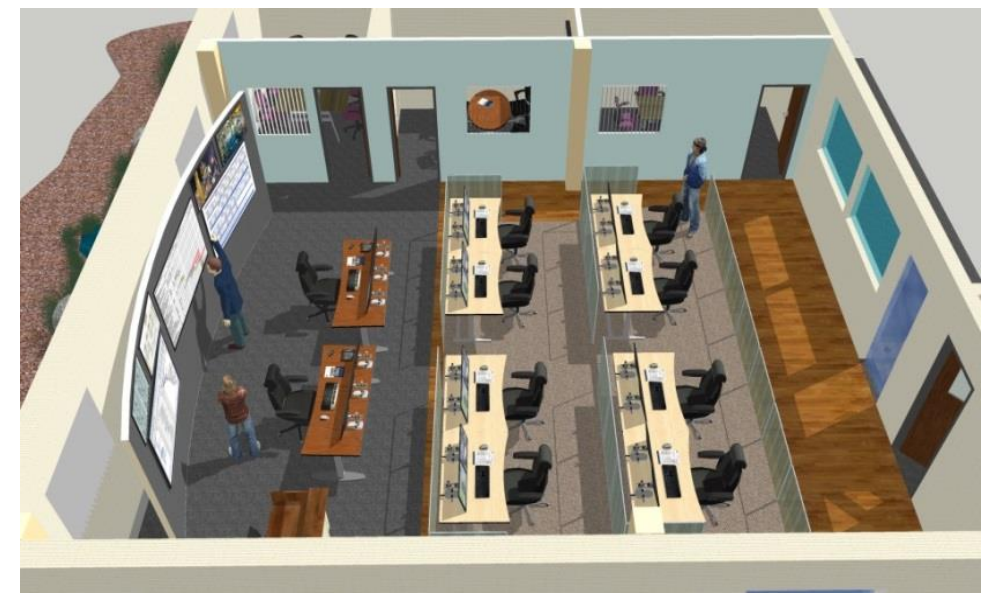

Figure 15. Advanced Outage Control Center concept design.

There is significant potential to take advantage of real-time status information that will be available by field workers using AWPs/EWPs. Technologies are being developed to collect status information effectively, display this information, and assist outage decision making. This work will coordinate with research from other LWRS pilot projects.

This pilot project will integrate these technologies into a prototype advanced OCC using HSSL. It will be set up to facilitate the display and processing of information and collaboration within the OCC or with parties remote to the OCC. This prototype facility will be used to simulate outage coordination functions so the technology and associated human factors can be evaluated. It will test interaction with all required sources of information needed by the OCC, including mobile technology operated by NPP field workers, plant control and information systems, other control and functional support centers, and information sources external to the plant. As a final product, a technical report will be developed for industry-wide implementation of the advanced OCC.

This pilot project began in FY 2013, with Arizona Public Service (Palo Verde Nuclear Generating Station) serving as the host utility (Figure 16Error! Reference source not found.). Currently, AOCC concepts have been implemented at plants in the Southern Nuclear fleet, Tennessee Valley Authority Fleet, Byron Nuclear Station, and South Texas Project. Several Duke Energy fleet plants are in the 
process of implementing new OCCs incorporating advanced design features. This pilot project is now complete.

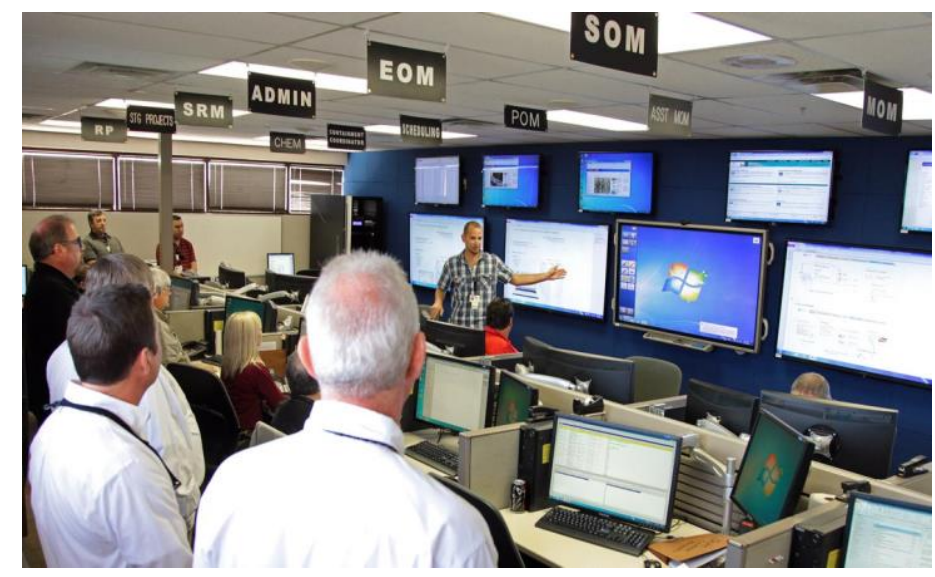

Figure 16. Advanced Outage Control Center at Palo Verde.

Schedule: FY 2013 to FY 2016

Remaining Project Milestones:

None

\subsubsection{Outage Risk Management Improvement}

Significant efforts are expended to manage the nuclear risk of an outage. The utilities conduct preoutage risk assessments, based on a very detailed review of the outage schedule, to identify where combinations of outage work and out-of-service equipment would result in degraded conditions with respect to nuclear safety or regulatory compliance. Probabilistic risk assessment studies are conducted to quantify the incremental core damage frequency as a result of the outage activities and system unavailability. These studies are usually presented to site and fleet management, the site plant operational review committee, and the NPP's independent Nuclear Safety Review Board for concurrence that the outage is planned safely and that reasonable measures have been taken to reduce the added risk of conducting the outage.

During the outage, the plant configuration is monitored continuously to ensure that it conforms to the approved safety plan. Deviations must be assessed and approved by management committees and, in some cases, the plant operational review committee. In virtually all outage meetings and job briefings, the current nuclear safety status of the plant is communicated, including information on the specific equipment that is being relied on to meet the requirements of the nuclear safety plan. In addition, Operations and the Outage organizations implement several layers of physical and administrative barriers to prevent unintended interaction with the systems and equipment credited for nuclear safety.

In spite of all of these efforts, nuclear safety challenges still occur too frequently in outages. While some of these are due to equipment failure credited for safety, the majority occur because of human error. These typically involve some form of interaction between work activities and plant configuration changes. Some of them are very subtle and are extremely challenging to detect in advance. Nevertheless, they are not acceptable and represent clear opportunities to improve nuclear safety during outages.

This pilot project will investigate methods to improve real -time plant risk management and configuration control during outages as a function of work activities and plant system alignments. It will develop a means for combining actual plant status information with intended component manipulations embedded in procedures and work packages that are underway. This information will, in turn, be compared to design information (e.g., piping and instrumentation diagrams and one--line diagrams) to 
identify the set of possible interactions. Finally, the information will consider the technical specifications (and other licensing basis requirements), probabilistic risk assessment information (e.g., accident precursors), and ongoing risk mitigation plans to report possible interactions of concern. The project will demonstrate the techniques and underlying technologies to perform this type of outage safety analysis. The project deliverables will include the new technologies and guidance for integrating them into outage preparation and execution activities.

Schedule: FY 2017 to FY 2019

Remaining Project Milestones:

- (2019) Research and develop technologies to automate assessing risk of planned work vs current plant conditions

\subsubsection{Augmented Reality for Nuclear Power Plant Field Workers}

NPP field workers are often in a plant environment where information critical to successful completion of their activities and even their well-being is not visually available, including the following:

- Temperature of surrounding components

- Whether a valve is open or closed

- Proximity to reactor trip sensitive-equipment

- Proximity to temporary hazard boundaries (e.g., radiography or overhead load paths).

- Plant data (pressure, flow, and set points) concerning nearby components

- Strength of radiation fields and location of hotspots

- Oxygen-deficient environments.

Therefore, plant workers must have this information provided in their work packages already or they have to rely on others to supply this information during the activity through the available communication channels. This is time -consuming and often results in an inadequate understanding of the actual field conditions.

Technologies are emerging that will connect the field worker to this information in a dynamic and context -based way. These technologies will allow the worker to "see" otherwise invisible information that will enable them to make informed decisions about their activities and their personal proximity to hazards. For instance, this might include smart safety glasses that can superimpose a transparent color -shaded representation of a radiation field directly into a worker's field of view. Similarly, plant data could be superimposed directly onto the components in the field of view, allowing the worker to "read" the data by merely looking at the components.

This capability would be made possible through the use of wireless communications to supply information from the plant computer and other sources, in combination with technologies that can determine the worker's location, orientation, and field of view. Further, the information provided would be context-based because the worker's purpose for being in that location would be known to the information system. In this way, only data relevant to that purpose would be automatically pushed to the worker. However, the worker could request any other desired information. In addition, it would be possible to remotely monitor personal physiological data, when necessary, such as workers in high-temperature work environments or during confined space entries with the potential for hazardous gases. 
These capabilities would create a whole new dimension in the concept of an "intelligent plant worker." They could be combined with the concept of automated work packages to produce extraordinary efficiencies in conducting plant activities and keeping the worker safe. There would be secondary benefits to knowing the location and surrounding environment of each worker. For example, this would greatly simplify accounting for personnel in emergency situations, such as containment evacuations and security events. It could enable remote monitoring of radiation dose and allow for optimized dispatch of field workers supporting concurrent work activities such as quality control inspectors. It could also enable the concept of "picture procedures" in which images of the actions required by a procedure step are superimposed on the equipment being manipulated via the worker's heads up-display.

This project will develop the needed technologies to create augmented realities for NPP field workers and will test these technologies in the HSSL and, ultimately, in a host utility NPP. Studies during testing will include both technical and human factors evaluations. The final product will be a technical report on how to implement these technologies in conjunction with the previously developed mobile technologies for NPP field workers. It also will provide guidance for integrating augmented reality technology with compatible automated work packages.

The Halden Reactor Project is already developing these types of technologies, including those that can determine the location and orientation of a field worker. The Plant Modernization pathway will work closely with Halden to take full advantage of the augmented reality technologies as they are developed.

Schedule: FY 2020 to FY 2022

Remaining Project Milestones:

- (2020) Develop and demonstrate augmented reality technologies for visualization of radiation fields for mobile plant workers.

- (2021) Develop and demonstrate augmented reality technologies for visualization of real -time plant parameters (e.g., pressures, flows, valve positions, and restricted boundaries) for mobile plant workers.

- (2022) Publish a technical report on augmented reality technologies developed for NPP field workers, enabling them to visualize abstract data and invisible phenomena, resulting in significantly improved situational awareness, access to context -based plant information, and generally improved effectiveness and efficiency in conducting field work activities.

\subsubsection{Automating Manually Performed Plant Activities}

NPPs have a higher ratio of staffing to unit of power output than any other form of electrical generation. For example, an NPP will typically have ten times the amount of staffing as a similar -sized fossil generation station. Labor is the largest component of an NPP's O\&M cost, typically accounting for $70 \%$ of the annual operating budget.

These high staffing requirements are due to the fact that NPPs have such a large number of systems and that most operations are manually performed. Work processes tend to be fairly complex due to nuclear quality and documentation requirements. Because of nuclear safety concerns, there are time consuming-human performance protocols for virtually all work activities. For example, most plant manipulations have to be verified by a second person and sometimes even a third person in high risk- situations.

As current I\&C systems in the plants today approach end-of-life and are faced with reliability and component aging issues, an opportunity presents itself to upgrade the systems in a manner that can reduce dependence on manual activity. Whereas this once would have been thought to be cost -prohibitive, new advances in technology now make this economically feasible. Some of these advances are as follows: 
- Low-cost, highly-reliable sensors and actuators (with low-maintenance requirements).

- Wireless technology, avoiding the need for long runs of expensive instrument cable

- Easy-to-maintain control technologies such as field programmable gate arrays, programmable logic controllers, and other digital control devices

- Power harvesting from ambient energy (e.g., light, heat, vibration).

To make this automation cost-effective, plant activities must be transformed so that the cost of automation is offset by reductions in plant staff required to conduct these activities. Otherwise, the technology upgrade costs would simply be added to the cost of the present plant structure of staffing and manual processes and no real efficiencies would be gained. Therefore, research is required to determine how to conduct these activities in a fundamentally different way, relying on automation rather than manual efforts to accomplish the end objectives.

Examples of these kinds of opportunities include:

- Replacement of stand-alone analog control loops with digital technology. A typical example would be a throttle valve control circuit, which would rely on an analog sensor/transmitter hard-wired to the control room, a controller with a set point or manual control, and an output circuit with a current loop connected to a pneumatic control loop connected to the valve's air operator. The objective would be to replace these analog technologies with digital equivalents, eliminating the frequent maintenance work required for these legacy technologies, while gaining improved accuracy and reliability of the digital technology.

- Elimination of manual gauges and displays that have to be locally read on a frequent basis by replacing them with wireless equivalents.

- Addition of low -cost, wireless component position indicators, thereby eliminating time -consuming and error -prone field walk-downs of valves, breakers, and dampers to verify they are in the correct position.

- In-line chemistry instruments, eliminating the effort to obtain field samples that have to be transported to an analysis laboratory for processing.

- Replacing local control panels with automated soft controls that can be operated from more convenient locations.

- Conversion of protective relays to integrated digital relay systems that would eliminate tedious manual testing of these individual devices and greatly reduce the effort to modify settings.

This project will analyze the NPP current staffing and cost model in a top -down manner to identify opportunities to significantly lower operating costs through selective automation of frequently performed manual activities. It will examine the technologies from a maturity perspective and a human factors perspective. It will make broad recommendations on gradually transforming the operating model of NPPs from one that is labor centric to one that is technology centric. In making this transformation, the underlying technologies that are deployed will enable a concept of integrated operations, which will support outsourcing of appropriate plant support functions.

Schedule: FY 2020 to FY 2024

Remaining Project Milestones:

- (2020) For NPP operations activities, analyze the staffing, tasks, and cost models to identify the opportunities for application of digital technologies to improve nuclear safety, efficiency, and human performance based on optimum human -technology function allocation. Demonstrate representative activities as transformed by technology with results published in a technical report. 
- (2021) For NPP chemistry activities, analyze the staffing, tasks, and cost models to identify the opportunities for application of digital technologies to improve nuclear safety, efficiency, and human performance based on optimum human -technology function allocation. Demonstrate representative activities as transformed by technology with results published in a technical report.

- (2022) For NPP maintenance activities, analyze the staffing, tasks, and cost models to identify the opportunities for application of digital technologies to improve nuclear safety, efficiency, and human performance based on optimum human -technology function allocation. Demonstrate representative activities as transformed by technology with results published in a technical report.

- (2023) For NPP radiation protection activities, analyze the staffing, tasks, and cost models to identify the opportunities for application of digital technologies to improve nuclear safety, efficiency, and human performance based on optimum human -technology function allocation. Demonstrate representative activities as transformed by technology with results published in a technical report.

- (2024) Develop and publish a transformed NPP operating model and organizational design derived from a top -down analysis of NPP operational and support activities, quantifying the efficiencies that can be realized through highly automated plant activities using advanced digital technologies.

\section{REFERENCES}

1. Department of Energy Light Water Reactor Sustainability Program - Integrated Program Plan, INL/EXT-11-23452, Revision 4, Idaho National Laboratory, 2016

2. National Research Council, Digital Instrumentation and Control Systems in Nuclear Power Plants - Safety and Reliability Issues, Washington, DC, 1997

3. Thomas, K., and B. Hallbert, 2012, Long-Term Instrumentation, Information, and Control Systems (II\&C) Modernization Future Vision and Strategy, INL/EXT-11-24154, Rev, 2m February 2013

4. Institute of Nuclear Power Operations, Significant Operating Experience Report (SOER) 10-2, Engaged, Thinking Organizations, Atlanta, GA, 2010

5. Boring, R. L., Agarwal, V., Joe, J.C., and Persensky, J.J., 2012, Digital Full-Scope Mockup of a Conventional Nuclear Power Plant Control Room, Phase 1: Installation of a Utility Simulator at the Idaho National Laboratory, INL/EXT-12-26367, Revision 0, June 2012

6. Wells, R., Anderson, R., Hoffman, R., Cyber Security Considerations in Support of the Light Water Reactor Sustainability Program, INL/LTD-12-27315 Revision 2, Idaho National Laboratory, 2013

7. Thomas, K., Thow, M., Kenny, T., Watkins, L., Cyber Security Evaluation of II\&C Technologies, INL/EXT-14-33609, Idaho National Laboratory, 2014

8. Light Water Reactor Sustainability Program Quality Assurance Program Document, INL/EXT10-19844, Idaho National Laboratory, 2010.

9. American Society of Mechanical Engineers (ASME), Quality Assurance Requirements for Nuclear Facility Applications NQA-1 - 2008 
10. Thomas, K., Lawrie, S., Hart, A., Vlahoplus, C., Digital Technology Business Case Methodology Guide, INL/EXT-14-33129, Idaho National Laboratory, 2014

11. Thomas, K., Lawrie, S., Niedermuller, J., Pilot Project Technology Business Case: Mobile Work Packages, INL/EXT-15-35327, Idaho National Laboratory, 2015

12. Thomas, K., Lawrie, S., Niedermuller, J., A Business Case for Advanced Outage Management, INL/EXT-16-38265, Idaho National Laboratory, 2016

13. Thomas, K., Lawrie, S., Niedermuller, J., A Business Case for Nuclear Plant Control Room Modernization, INL/EXT-16-39098, Idaho National Laboratory, 2016

14. Mahadevan, S., Agarwal, V., Neal, K., Kosson, D., Adams, D., Interim Report on Concrete Degradation Mechanisms and Online Monitoring Techniques, INL/EXT-14-33134, Idaho National Laboratory, 2014

15. Thomas, K., Oxstrand, J., Digital Architecture Requirements, INL/EXT-15-34696, Idaho National Laboratory, 2015

16. Oxstrand, J., Thomas, K., Fitzgerald, K., Digital Architecture - Results from a Gap Analysis, INL/EXT-15-36662, Idaho National Laboratory, 2015

17. Oxstrand, J., Al Rashdan, A., Bly, A., Rice, B., Fitzgerald, K., Wilson, K., Digital Architecture Planning Model, INL/EXT-16-38220, Idaho National Laboratory, 2016

18. Nuclear Regulatory Commission, Human Factors Engineering Program Review Model, NUREG0711, Revision 3, Washington, DC, 2012

19. Thomas, K., Boring, R., Lew, R., Ulrich, T., Vilim, R., A Computerized Operator Support System Prototype, INL/EXT-13-29751, Idaho National Laboratory, 2013

20. Department of Energy, DOE-NE Light Water Reactor Sustainability Program and EPRI Long Term Operations Program - Joint Research and Development Plan, INL/EXT-12-24562A Revision 1, Idaho National Laboratory, 2012 


\section{Appendix A. Historical Reports}

\begin{tabular}{|c|c|c|}
\hline Project & Report Name & Report Number \\
\hline $\begin{array}{l}\text { Advanced Outage } \\
\text { Control Center }\end{array}$ & $\begin{array}{l}\text { Development of Methodologies for Technology Deployment for } \\
\text { Advanced Outage Control Centers that Improve Outage } \\
\text { Coordination, Problem Resolution and Outage Risk Management }\end{array}$ & INL/EXT-13-29934 \\
\hline $\begin{array}{l}\text { Advanced Outage } \\
\text { Control Center }\end{array}$ & $\begin{array}{l}\text { Guidelines for Implementation of an Advanced Outage Control } \\
\text { Center to Improve Outage Coordination, Problem Resolution, and } \\
\text { Outage Risk Management }\end{array}$ & INL/EXT-14-33182 \\
\hline $\begin{array}{l}\text { Advanced Outage } \\
\text { Control Center }\end{array}$ & $\begin{array}{l}\text { Status Report on the Development of Micro Scheduling- Software } \\
\text { for the Advanced Outage Control Center Project }\end{array}$ & INL/EXT-14-33036 \\
\hline $\begin{array}{l}\text { Advanced Outage } \\
\text { Control Center }\end{array}$ & $\begin{array}{l}\text { Benchmark Report on Key Outage Attributes: An Analysis of } \\
\text { Outage Improvement Opportunities and Priorities }\end{array}$ & INL/EXT-14-32848 \\
\hline $\begin{array}{l}\text { Advanced Outage } \\
\text { Control Center }\end{array}$ & $\begin{array}{l}\text { Development of Improved Graphical Displays for an Advanced } \\
\text { Outage Control Center, Employing Human Factors Principles for } \\
\text { Outage Schedule Management }\end{array}$ & INL/EXT-15-36489 \\
\hline $\begin{array}{l}\text { Advanced Outage } \\
\text { Control Center }\end{array}$ & $\begin{array}{l}\text { Development of an Overview Display to Allow Advanced Outage } \\
\text { Control Center Management to Quickly Evaluate Outage Status }\end{array}$ & INL/EXT-16-39622 \\
\hline $\begin{array}{l}\text { Advanced Outage } \\
\text { Coordination }\end{array}$ & $\begin{array}{l}\text { Advanced Outage and Control Center: Strategies for Nuclear Plant } \\
\text { Outage Work Status Capabilities }\end{array}$ & INL/EXT-12-26197 \\
\hline $\begin{array}{l}\text { Advanced Outage } \\
\text { Coordination }\end{array}$ & Resolving Emergent Issues during Nuclear Plant Outages) & INL/EXT-12-26807 \\
\hline $\begin{array}{l}\text { Automated Work } \\
\text { Packages }\end{array}$ & $\begin{array}{l}\text { Describe the technologies that have the greatest impact for reducing } \\
\text { work package operation and maintenance costs in the light water } \\
\text { reactors fleet }\end{array}$ & INL/EXT-18-51457 \\
\hline $\begin{array}{l}\text { Automated Work } \\
\text { Packages }\end{array}$ & $\begin{array}{l}\text { Describe a strategy and plan to support a cooperative research } \\
\text { project with industrial partners that delivers a risk-informed } \\
\text { maintenance strategy which will reduces maintenance costs }\end{array}$ & INL/LTD-18-51448 \\
\hline $\begin{array}{l}\text { Automation of the Work } \\
\text { Process }\end{array}$ & $\begin{array}{l}\text { Automated Work Packages: An Initial Set of Human Factors and } \\
\text { Instrumentation and Control Requirements }\end{array}$ & INL/EXT-14-33172 \\
\hline $\begin{array}{l}\text { Automation of the Work } \\
\text { Process }\end{array}$ & $\begin{array}{l}\text { Automated Work Package Prototype: Initial Design, Development, } \\
\text { and Evaluation }\end{array}$ & INL/EXT-15-35825 \\
\hline $\begin{array}{l}\text { Automation of the Work } \\
\text { Process }\end{array}$ & $\begin{array}{l}\text { Automated Work Package: Conceptual Design and Data } \\
\text { Architecture }\end{array}$ & INL/EXT-16-38809 \\
\hline $\begin{array}{l}\text { Automation of the Work } \\
\text { Process }\end{array}$ & $\begin{array}{l}\text { Automated Work Package: Radio Frequency Identification, } \\
\text { Bluetooth Beacons, and Video Applications in the Nuclear Power } \\
\text { Industry }\end{array}$ & INL/EXT-17-43264 \\
\hline $\begin{array}{l}\text { Computer-Based } \\
\text { Procedures for Nuclear } \\
\text { Power Plant Field } \\
\text { Workers }\end{array}$ & $\begin{array}{l}\text { Computer Based- Procedures for Field Workers in Nuclear Power } \\
\text { Plants: Development of a Model of Procedure Usage and } \\
\text { Identification of Requirements }\end{array}$ & INL/EXT-12-25671 \\
\hline
\end{tabular}




\begin{tabular}{|c|c|c|}
\hline Project & Report Name & Report Number \\
\hline $\begin{array}{l}\text { Computer-Based } \\
\text { Procedures for Nuclear } \\
\text { Power Plant Field } \\
\text { Workers }\end{array}$ & Evaluation of Computer Based- Procedure System Prototype & INL/EXT-12-27155 \\
\hline $\begin{array}{l}\text { Computer-Based } \\
\text { Procedures for Nuclear } \\
\text { Power Plant Field } \\
\text { Workers }\end{array}$ & $\begin{array}{l}\text { Evaluation of Revised Computer -Based Procedure System } \\
\text { Prototype) }\end{array}$ & INL/EXT-13-28226 \\
\hline $\begin{array}{l}\text { Computer-Based } \\
\text { Procedures for Nuclear } \\
\text { Power Plant Field } \\
\text { Workers }\end{array}$ & $\begin{array}{l}\text { Computer Based- Procedures for Field Workers: Results from } \\
\text { Three Evaluation Studies }\end{array}$ & INL/EXT-13-30183 \\
\hline $\begin{array}{l}\text { Computer-Based } \\
\text { Procedures for Nuclear } \\
\text { Power Plant Field } \\
\text { Workers }\end{array}$ & $\begin{array}{l}\text { Computer Based- Procedures for Field Activities: Results from } \\
\text { Three Evaluations at Nuclear Power Plants }\end{array}$ & INL/EXT-14-33212 \\
\hline $\begin{array}{l}\text { Computer-Based } \\
\text { Procedures for Nuclear } \\
\text { Power Plant Field } \\
\text { Workers }\end{array}$ & Computer -Based Procedures for Field Worker - Identified Benefits & INL/EXT-14-33011 \\
\hline $\begin{array}{l}\text { Computer-Based } \\
\text { Procedures for Nuclear } \\
\text { Power Plant Field } \\
\text { Workers }\end{array}$ & $\begin{array}{l}\text { Computer Based- Procedures for Field Workers-Result and } \\
\text { Insights from Three Usability and Interface Design Evaluations }\end{array}$ & INL/EXT-15-36615 \\
\hline $\begin{array}{l}\text { Computer-Based } \\
\text { Procedures for Nuclear } \\
\text { Power Plant Field } \\
\text { Workers }\end{array}$ & $\begin{array}{l}\text { Computer-Based Procedures for Field Workers - FY16 Research } \\
\text { Activities }\end{array}$ & INL/EXT-16-39984 \\
\hline $\begin{array}{l}\text { Computer-Based } \\
\text { Procedures for Nuclear } \\
\text { Power Plant Field } \\
\text { Workers }\end{array}$ & $\begin{array}{l}\text { Design Guidance for Computer-Based Procedures for Field } \\
\text { Workers }\end{array}$ & INL/EXT-16-39808 \\
\hline $\begin{array}{l}\text { Computer-Based } \\
\text { Procedures for Nuclear } \\
\text { Power Plant Field } \\
\text { Workers }\end{array}$ & $\begin{array}{l}\text { Seamless Digital Environment - Plan for Data Analytics Use Case } \\
\text { Study }\end{array}$ & INL/EXT-16-39985 \\
\hline $\begin{array}{l}\text { Control Room } \\
\text { Modernization }\end{array}$ & $\begin{array}{l}\text { Alarm Design Workshop for Control Room Upgrades: Summary } \\
\text { and Presentations }\end{array}$ & INL/MIS-11-22907 \\
\hline $\begin{array}{l}\text { Control Room } \\
\text { Modernization }\end{array}$ & $\begin{array}{l}\text { Deployment of a Full-Scope Commercial Nuclear Power Plant } \\
\text { Control Room Simulator at the Idaho National Laboratory }\end{array}$ & INL/EXT-11-23421 \\
\hline $\begin{array}{l}\text { Control Room } \\
\text { Modernization }\end{array}$ & $\begin{array}{l}\text { Digital Full-Scope Mockup of a Conventional Nuclear Power Plant } \\
\text { Control Room, Phase 1: Installation of a Utility Simulator at the } \\
\text { Idaho National Laboratory }\end{array}$ & INL/EXT-12-26367 \\
\hline $\begin{array}{l}\text { Control Room } \\
\text { Modernization }\end{array}$ & $\begin{array}{l}\text { Applying Human Factors Evaluation and Design Guidance to a } \\
\text { Nuclear Power Plant Digital Control System }\end{array}$ & INL/EXT-12-26787 \\
\hline
\end{tabular}




\begin{tabular}{|c|c|c|}
\hline Project & Report Name & Report Number \\
\hline $\begin{array}{l}\text { Control Room } \\
\text { Modernization }\end{array}$ & $\begin{array}{l}\text { Digital Full-Scope Simulation of a Conventional Nuclear Power } \\
\text { Plant Control Room, Phase 2: Installation of a Reconfigurable } \\
\text { Simulator to Support Nuclear Plant Sustainability }\end{array}$ & INL/EXT-13-28432 \\
\hline $\begin{array}{l}\text { Control Room } \\
\text { Modernization }\end{array}$ & $\begin{array}{l}\text { A Reference Plan for Control Room Modernization: Planning and } \\
\text { Analysis Phase }\end{array}$ & INL/EXT-13-30109 \\
\hline $\begin{array}{l}\text { Control Room } \\
\text { Modernization }\end{array}$ & $\begin{array}{l}\text { Installation of Halden Reactor Project Digital Interface Prototypes } \\
\text { in the Human Systems Simulation Laboratory }\end{array}$ & INL/EXT-13-29039 \\
\hline $\begin{array}{l}\text { Control Room } \\
\text { Modernization }\end{array}$ & $\begin{array}{l}\text { Operator Performance Metrics for Control Room Modernization: A } \\
\text { Practical Guide for Early Design Evaluation }\end{array}$ & INL/EXT-14-31511 \\
\hline $\begin{array}{l}\text { Control Room } \\
\text { Modernization }\end{array}$ & $\begin{array}{l}\text { Strategy for Migration of Traditional to Hybrid Control Boards in a } \\
\text { Nuclear Power Plant }\end{array}$ & INL/EXT-14-32534 \\
\hline $\begin{array}{l}\text { Control Room } \\
\text { Modernization }\end{array}$ & $\begin{array}{l}\text { Human Factors Engineering Design Phase Report for Control } \\
\text { Room Modernization }\end{array}$ & INL/EXT-14-33221 \\
\hline $\begin{array}{l}\text { Control Room } \\
\text { Modernization }\end{array}$ & $\begin{array}{l}\text { Baseline Human Factors and Ergonomics in Support of Control } \\
\text { Room Modernization at Nuclear Power Plants }\end{array}$ & INL/EXT-14-33223 \\
\hline $\begin{array}{l}\text { Control Room } \\
\text { Modernization }\end{array}$ & $\begin{array}{l}\text { A Distributed Control System Prototyping Environment to Support } \\
\text { Control Room Modernization }\end{array}$ & INL/EXT-14-33957 \\
\hline $\begin{array}{l}\text { Control Room } \\
\text { Modernization }\end{array}$ & $\begin{array}{l}\text { Revision 1, Operator Performance Metrics for Control Room } \\
\text { Modernization: A Practical Guide for Early Design Evaluation }\end{array}$ & INL/EXT-14-31511, \\
\hline $\begin{array}{l}\text { Control Room } \\
\text { Modernization }\end{array}$ & HSI Prototypes for Human Systems Simulation Laboratory & INL/EXT-15-36839 \\
\hline $\begin{array}{l}\text { Control Room } \\
\text { Modernization }\end{array}$ & Verification and Validation of Digitally Upgraded Control Rooms & INL/EXT-15-36704 \\
\hline $\begin{array}{l}\text { Control Room } \\
\text { Modernization }\end{array}$ & $\begin{array}{l}\text { Migration of Older to New Digital Control Systems in Nuclear } \\
\text { Power Plant Main Control Rooms }\end{array}$ & INL/EXT-16-38576 \\
\hline $\begin{array}{l}\text { Control Room } \\
\text { Modernization }\end{array}$ & Control Room Modernization End-State Design Philosophy & INL/EXT-18-44739 \\
\hline $\begin{array}{l}\text { Control Room } \\
\text { Modernization }\end{array}$ & $\begin{array}{l}\text { The Influence of Individual Human-System Interface Display } \\
\text { Features on Visual Information Processing during Naturalistic } \\
\text { Process Control Tasks }\end{array}$ & INL/JOU-18-45483 \\
\hline $\begin{array}{l}\text { Control Room } \\
\text { Modernization }\end{array}$ & $\begin{array}{l}\text { Submit a journal article documenting the research activities that } \\
\text { serve as a technical basis for control room design. }\end{array}$ & INL/EXT-18-45755 \\
\hline $\begin{array}{l}\text { Control Room } \\
\text { Modernization }\end{array}$ & $\begin{array}{l}\text { Development and evaluation of the conceptual design for a liquid } \\
\text { radiological waste system in an advanced hybrid control room. }\end{array}$ & INL/EXT-18-51107 \\
\hline $\begin{array}{l}\text { Control Room } \\
\text { Modernization }\end{array}$ & $\begin{array}{l}\text { Document the implementation of the end state concept for turbine } \\
\text { control and feedwater systems }\end{array}$ & INL/LTD-18-51582 \\
\hline Cyber Security & $\begin{array}{l}\text { Cyber Security Considerations in Support of the Light Water } \\
\text { Reactor Sustainability Program, Revision } 2\end{array}$ & INL/LTD-12-27315 \\
\hline Cyber Security & Cyber Security Evaluation of II\&C Technologies & INL/EXT-14-33609 \\
\hline $\begin{array}{l}\text { Data Driven Condition } \\
\text { Monitoring }\end{array}$ & $\begin{array}{l}\text { Process to move a plant from manual and analog to automatic and } \\
\text { digital data acquisition which will be critical to enable data driven } \\
\text { condition monitoring }\end{array}$ & INL/EXT-18-51456 \\
\hline
\end{tabular}




\begin{tabular}{|c|c|c|}
\hline Project & Report Name & Report Number \\
\hline $\begin{array}{l}\text { Digital Architecture for } \\
\text { an Automated Plant }\end{array}$ & Digital Architecture Project Plan & INL/EXT-14-33177 \\
\hline $\begin{array}{l}\text { Digital Architecture for } \\
\text { an Automated Plant }\end{array}$ & Digital Architecture Requirements & INL/EXT-15-34696 \\
\hline $\begin{array}{l}\text { Digital Architecture for } \\
\text { an Automated Plant }\end{array}$ & Digital Architecture - Results from a Gap Analysis & INL/EXT-15-36662 \\
\hline $\begin{array}{l}\text { Digital Architecture for } \\
\text { an Automated Plant }\end{array}$ & Digital Architecture Planning Model & INL/EXT-16-38220 \\
\hline $\begin{array}{l}\text { Digital Architecture for } \\
\text { an Automated Plant }\end{array}$ & Seamless Digital Environment - Data Analytics Case Study & INL/EXT-17-4291, \\
\hline $\begin{array}{l}\text { Digital Information and } \\
\text { Control }\end{array}$ & Strategy for Implementation of Safety-Related Digital I\&C Systems & INL/EXT-18-45683 \\
\hline $\begin{array}{l}\text { Digital Instrumentation } \\
\text { and Control } \\
\text { Qualification }\end{array}$ & $\begin{array}{l}\text { Definition of the Methods, Tools, and Computing Resources for } \\
\text { Instrumentation and Control Device Testability }\end{array}$ & INL/EXT-18-51521 \\
\hline $\begin{array}{l}\text { Digital Technology } \\
\text { Business Case } \\
\text { Methodology }\end{array}$ & Digital Technology Business Case Methodology & INL/EXT-14-33129 \\
\hline $\begin{array}{l}\text { Digital Technology } \\
\text { Business Case } \\
\text { Methodology }\end{array}$ & Pilot Project Technology Business Case: Mobile Work Packages & INL/EXT-15-35327 \\
\hline $\begin{array}{l}\text { Digital Technology } \\
\text { Business Case } \\
\text { Methodology }\end{array}$ & A Business Case for Advanced Outage Management & INL/EXT-16-38265 \\
\hline $\begin{array}{l}\text { Digital Technology } \\
\text { Business Case } \\
\text { Methodology }\end{array}$ & A Business Case for Nuclear Plant Control Room Modernization & INL/EXT-16-39098 \\
\hline $\begin{array}{l}\text { Fleet Based Control } \\
\text { Room Modernization }\end{array}$ & $\begin{array}{l}\text { Human Factors Engineering Evaluations of Planned Digital } \\
\text { Instrumentation and Control System Upgrades at the Braidwood } \\
\text { Nuclear Generating Station }\end{array}$ & INL_LTD-18-44295 \\
\hline $\begin{array}{l}\text { Fleet Based Control } \\
\text { Room Modernization }\end{array}$ & $\begin{array}{l}\text { A Human Factors Operator-in-the-Loop Evaluation of the Digital } \\
\text { Control System Upgrades for the Braidwood and Byron Nuclear } \\
\text { Generating Stations }\end{array}$ & INL_LTD-18-44617 \\
\hline $\begin{array}{l}\text { Fleet Based Control } \\
\text { Room Modernization }\end{array}$ & $\begin{array}{l}\text { Connecting LWRS Human Factors Engineering R\&D to NUREG- } \\
0711 \text { Elements and Modification Activities in Nuclear Generating } \\
\text { Plants }\end{array}$ & INL/EXT-18-45149 \\
\hline $\begin{array}{l}\text { Fleet Based Control } \\
\text { Room Modernization }\end{array}$ & $\begin{array}{l}\text { Lessons Learned from Performing a Human Factors Engineering } \\
\text { Validation of an Upgraded Digital Control System in a Nuclear } \\
\text { Power Plant Control Room }\end{array}$ & INL/LTD-18-51380 \\
\hline $\begin{array}{l}\text { Fleet Based Control } \\
\text { Room Modernization }\end{array}$ & $\begin{array}{l}\text { Planning and Analyses Performed to Install Halden's Advanced } \\
\text { Control Room Concept in the Human Systems Simulation } \\
\text { Laboratory }\end{array}$ & INL/EXT-18-45966 \\
\hline
\end{tabular}




\begin{tabular}{|c|c|c|}
\hline Project & Report Name & Report Number \\
\hline $\begin{array}{l}\text { Fleet Based Control } \\
\text { Room Modernization }\end{array}$ & $\begin{array}{l}\text { Developing a Human Factors Engineering Program Plan and End } \\
\text { State Vision to Support Full Nuclear Power Plant Modernization }\end{array}$ & INL/EXT-18-51212 \\
\hline $\begin{array}{l}\text { Fleet Based Control } \\
\text { Room Modernization }\end{array}$ & $\begin{array}{l}\text { Summarize the human factors R\&D performed in collaboration } \\
\text { with Exelon }\end{array}$ & INL/EXT-18-51365 \\
\hline $\begin{array}{l}\text { Fleet Based Control } \\
\text { Room Modernization }\end{array}$ & $\begin{array}{l}\text { Summarize the human factors studies conducted in support of the } \\
\text { Control Room Modernization project. }\end{array}$ & INL/EXT-18-51365 \\
\hline $\begin{array}{l}\text { Fleet Based Control } \\
\text { Room Modernization }\end{array}$ & $\begin{array}{l}\text { Document the development of a preliminary strategy for full } \\
\text { nuclear plant modernization based upon digital technology } \\
\text { deployment timelines to reduce costs and improve efficiencies }\end{array}$ & INL/EXT-18-51366 \\
\hline $\begin{array}{l}\text { Full Nuclear Plant } \\
\text { Modernization }\end{array}$ & $\begin{array}{l}\text { Preliminary Human Factors Evaluation of Control System } \\
\text { Upgrades for the Byron and Braidwood Nuclear Power Stations }\end{array}$ & INL/EXT-16-40705 \\
\hline $\begin{array}{l}\text { Full Nuclear Plant } \\
\text { Modernization }\end{array}$ & $\begin{array}{l}\text { Human Factors Engineering Aspects of Modifications in Control } \\
\text { Room Modernization }\end{array}$ & INL/EXT-17-42190 \\
\hline $\begin{array}{l}\text { Full Nuclear Plant } \\
\text { Modernization }\end{array}$ & $\begin{array}{l}\text { Development of an Initial Business Case Framework for Fleet- } \\
\text { Based Control Room Modernization }\end{array}$ & INL/EXT-17-42604 \\
\hline $\begin{array}{l}\text { Full Nuclear Plant } \\
\text { Modernization }\end{array}$ & $\begin{array}{l}\text { Results from a Preliminary Dynamic Operator Workshop on } \\
\text { Control Room Modernization Activities for Braidwood Unit } 1\end{array}$ & INL/LTD-17-43205 \\
\hline Halden & $\begin{array}{l}\text { Development of Task Based Displays for the Fleet-Based Control } \\
\text { Room Modernization Design Project }\end{array}$ & INL/LTD-18-44296 \\
\hline Halden & $\begin{array}{l}\text { Summarize operator-in-the-loop studies conducted in support of the } \\
\text { Fleet-Based Control Room Modernization project }\end{array}$ & INL/EXT-18-51360 \\
\hline $\begin{array}{l}\text { Industrial and } \\
\text { Regulatory Engagement }\end{array}$ & Industrial and Regulatory Engagement Activities & INL/EXT-18-51462 \\
\hline $\begin{array}{l}\text { Mobile Technologies for } \\
\text { Nuclear Power Plant } \\
\text { Field Workers }\end{array}$ & $\begin{array}{l}\text { Advanced Instrumentation, Information and Control (II\&C) } \\
\text { Research and Development Facility Buildout and Project Execution } \\
\text { of LWRS II\&C Pilot Project } 3\end{array}$ & INL/MIS-12-25139 \\
\hline $\begin{array}{l}\text { Mobile Technologies for } \\
\text { Nuclear Power Plant } \\
\text { Field Workers }\end{array}$ & $\begin{array}{l}\text { Guidance for Deployment of Mobile Technologies for Nuclear } \\
\text { Power Plant Field Workers }\end{array}$ & INL/EXT-12-27094 \\
\hline $\begin{array}{l}\text { Online Monitoring of } \\
\text { Active Components }\end{array}$ & $\begin{array}{l}\text { Online Monitoring Technical Basis and Analysis Framework for } \\
\text { Large Power Transformers; Interim Report for FY } 2012\end{array}$ & INL/EXT-12-27181 \\
\hline $\begin{array}{l}\text { Online Monitoring of } \\
\text { Active Components }\end{array}$ & $\begin{array}{l}\text { Online Monitoring Technical Basis and Analysis Framework for } \\
\text { Emergency Diesel Generators-Interim Report for FY } 2013\end{array}$ & INL/EXT-12-27754 \\
\hline $\begin{array}{l}\text { Online Monitoring of } \\
\text { Active Components }\end{array}$ & $\begin{array}{l}\text { Demonstration of Online Monitoring for Generator Step -up } \\
\text { Transformers and Emergency Diesel Generators }\end{array}$ & INL/EXT-13-30155 \\
\hline $\begin{array}{l}\text { Online Monitoring of } \\
\text { Active Components }\end{array}$ & $\begin{array}{l}\text { Diagnostic and Prognostic Models for Generator Step-Up } \\
\text { Transformers }\end{array}$ & INL/EXT-14-33124 \\
\hline $\begin{array}{l}\text { Online Monitoring of } \\
\text { Active Components }\end{array}$ & Online Monitoring of Induction Motors & INL/EXT-15-36681 \\
\hline
\end{tabular}




\begin{tabular}{|c|c|c|}
\hline Project & Report Name & Report Number \\
\hline $\begin{array}{l}\text { Online Monitoring of } \\
\text { Concrete Structures in } \\
\text { Nuclear Power Plants }\end{array}$ & $\begin{array}{l}\text { Interim Report on Concrete Degradation Mechanisms and Online } \\
\text { Monitoring Techniques }\end{array}$ & INL/EXT-14-33134 \\
\hline $\begin{array}{l}\text { Online Monitoring of } \\
\text { Concrete Structures in } \\
\text { Nuclear Power Plants }\end{array}$ & $\begin{array}{l}\text { A Simple Demonstration of Concrete Structural Health Monitoring } \\
\text { Framework; }\end{array}$ & INL/EXT-15-34729 \\
\hline $\begin{array}{l}\text { Online Monitoring of } \\
\text { Concrete Structures in } \\
\text { Nuclear Power Plants }\end{array}$ & $\begin{array}{l}\text { Monitoring, Modeling, and Diagnosis of Alkali-Silica- Reaction in } \\
\text { Small Concrete Samples }\end{array}$ & INL/EXT-15-36683 \\
\hline $\begin{array}{l}\text { Online Monitoring of } \\
\text { Concrete Structures in } \\
\text { Nuclear Power Plants }\end{array}$ & $\begin{array}{l}\text { Revision 0, Framework for Structural Online Health Monitoring of } \\
\text { Aging and Degradation of Secondary Systems due to some Aspects } \\
\text { of Erosion }\end{array}$ & INL/EXT-16-39903 \\
\hline $\begin{array}{l}\text { Online Monitoring of } \\
\text { Concrete Structures in } \\
\text { Nuclear Power Plants }\end{array}$ & $\begin{array}{l}\text { Joint Research Plan on Structural Health Monitoring with the } \\
\text { Electric Power Research Institute }\end{array}$ & INL/INT-16-38821 \\
\hline $\begin{array}{l}\text { Online Monitoring of } \\
\text { Concrete Structures in } \\
\text { Nuclear Power Plants }\end{array}$ & $\begin{array}{l}\text { Rev 1, Interrogation of Alkali-Silica Reaction Degraded Concrete } \\
\text { Samples using Acoustic and Thermal Techniques to Support } \\
\text { Development of a Structural Health Monitoring Framework }\end{array}$ & INL/EXT-17-41852 \\
\hline $\begin{array}{l}\text { Online Monitoring of } \\
\text { Concrete Structures in } \\
\text { Nuclear Power Plants }\end{array}$ & $\begin{array}{l}\text { Enhancement of the Structural Health Monitoring Framework by } \\
\text { Optimizing Vibro Acoustic Modulation Technique to Localize } \\
\text { Alkali Silica Reaction Degradation In Medium Sized Concrete } \\
\text { Samples }\end{array}$ & INL/EXT-18-45212 \\
\hline $\begin{array}{l}\text { Online Monitoring of } \\
\text { Concrete Structures in } \\
\text { Nuclear Power Plants }\end{array}$ & $\begin{array}{l}\text { Uncertainty quantification methodologies developed to support the } \\
\text { concrete structural health monitoring framework }\end{array}$ & INL/EXT-18-51460 \\
\hline $\begin{array}{l}\text { Online Monitoring of } \\
\text { Concrete Structures in } \\
\text { Nuclear Power Plants }\end{array}$ & Document the progress of casting of reinforced concrete beam & INL/EXT-18-51461 \\
\hline $\begin{array}{l}\text { Online Monitoring of } \\
\text { Second Phase Structures } \\
\text { in Nuclear Power Plants }\end{array}$ & Flow Assisted- Corrosion in Nuclear Power Plants & INL/EXT-15-36611 \\
\hline $\begin{array}{l}\text { Online Monitoring of } \\
\text { Second Phase Structures } \\
\text { in Nuclear Power Plants }\end{array}$ & $\begin{array}{l}\text { Revision 0, Framework for Structural Online Health Monitoring of } \\
\text { Aging and Degradation of Secondary Systems due to some Aspects } \\
\text { of Erosion }\end{array}$ & INL/EXT-16-39903 \\
\hline $\begin{array}{l}\text { Online Monitoring of } \\
\text { Second Phase Structures } \\
\text { in Nuclear Power Plants }\end{array}$ & $\begin{array}{l}\text { Joint Research Plan on Structural Health Monitoring with the } \\
\text { Electric Power Research Institute }\end{array}$ & INL/INT-16-38821 \\
\hline $\begin{array}{l}\text { Online Monitoring of } \\
\text { Second Phase Structures } \\
\text { in Nuclear Power Plants }\end{array}$ & $\begin{array}{l}\text { Potential to Extend the Range of Established Online Monitoring } \\
\text { Technologies, Such as Guided Waves in Nuclear Power Plant } \\
\text { Systems }\end{array}$ & INL/EXT-17-43242 \\
\hline
\end{tabular}




\begin{tabular}{|c|c|c|}
\hline Project & Report Name & Report Number \\
\hline $\begin{array}{l}\text { Online Monitoring of } \\
\text { Second Phase Structures } \\
\text { in Nuclear Power Plants }\end{array}$ & $\begin{array}{l}\text { Describe performance of advanced signal processing and pattern } \\
\text { recognition algorithms using raw data from ultrasonic guided } \\
\text { waves transducers and provide recommendations on capabilities of } \\
\text { advanced data analytics }\end{array}$ & INL/EXT-18-51429 \\
\hline $\begin{array}{l}\text { Outage Risk } \\
\text { Management } \\
\text { Improvement }\end{array}$ & $\begin{array}{l}\text { Technologies for Detecting Interactions between Current Plant } \\
\text { Configuration States and Component Manipulations Directed by In- } \\
\text { Use Procedures }\end{array}$ & INL/EXT-17-43234 \\
\hline $\begin{array}{l}\text { Outage Risk } \\
\text { Management } \\
\text { Improvement }\end{array}$ & $\begin{array}{l}\text { Prototype system for detecting interactions between status } \\
\text { (configuration) states and concurrent component manipulations } \\
\text { directed by in-use procedures including data integration and } \\
\text { industry feedback }\end{array}$ & INL/EXT-18-51474 \\
\hline Project Management & Technical Program Plan for the Plant Modernization Pathway & $\begin{array}{l}\text { INL/EXT-13-28055 } \\
\text { Rev. } 8\end{array}$ \\
\hline Quality Insurance & $\begin{array}{l}\text { Light Water Reactor Sustainability Program Quality Assurance } \\
\text { Program Document. }\end{array}$ & INL/EXT-10-19844 \\
\hline $\begin{array}{l}\text { Risk-Informed } \\
\text { Methodologies }\end{array}$ & $\begin{array}{l}\text { Describe the design basis for a resilient plant based on margin } \\
\text { recovery and the application of new technologies to reduce the } \\
\text { safety significance of design basis events }\end{array}$ & INL/EXT-18-51531 \\
\hline
\end{tabular}

